\title{
Seguimento de crianças nascidas com baixo peso num Município da Grande São Paulo
}

\author{
ROSANGELA FILIPINI
}

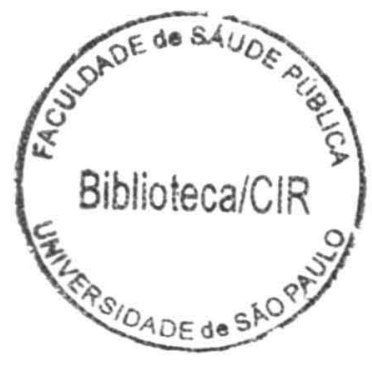

Tese apresentada ao Programa de Pós-Graduação em Saúde Pública da Faculdade de Saúde Pública da Universidade de São Paulo para obtenção do título de Doutor em Saúde Pública.

Área de concentração- Saúde Materno Infantil.

Orientador: Prof. Dr. ARNALDO AUGUSTO FRANCO DE SIQUEIRA

São Paulo

2005 
Autorizo, exclusivamente para fins acadêmicos e científicos, a reprodução total ou parcial desta tese, por processos fotocopiadores.

Assinatura:

Data:

$46280 / 2005$ doc 


\section{Agradecimentos}

* Agradeço ao professor Arnaldo Augusto Franco de Siqueira, meu orientador. Foram quase 10 anos nesta escola em que, além de seus ensinamentos, sempre tive seu apoio e incentivo. Obrigada mestre!

* À Secretaria da Saúde de Mauá, pelo acolhimento e oportunidade ao realizar esta pesquisa, especialmente ao Sérgio Hércules que foi o principal interlocutor com as UBSs e Secretaria da Saúde.

* À Lurdinha e equipe da Atenção Básica de Saúde do Município de Mauá, especialmente seus coordenadores das UBS e os agentes comunitários de saúde, sem a ajuda de vocês este trabalho não seria possível.

* À Profa. Dra. Maria Belén, minha grande amiga, te agradeço pela sua disponibilidade, ensinamentos e carinho na avaliação do meu trabalho.

* Ao Prof. Dráuzio Viegas, é uma honra tê-lo em minha defesa de tese!

* À Diretoria da Faculdade de Medicina do $A B C$, Prof. Dr. Luis H. Camargo Paschoal e Prof. Dr.Ferrucio, agradeço pela compreensão e reconhecimento por meu trabalho.

* À Aline que me acompanhou em todo o trabalho de coleta dos dados, por sua disponibilidade: à Isabel que também colaborou neste momento da pesquisa e a Sandrinha, por sua atenção ao ajudar-me com as referências bibliográficas.

* Aos queridos secretários, Iara e Leandro, do Departamento Materno Infantil desta Faculdade. Já sinto saudades... E às meninas da pós-graduação, pela delicadeza que sempre me atenderam. 
* Aos professores, Profa. Dra. Márcia FurKin, obrigada pelas valiosas sugestões, tanto na qualificação quanto na finalização desta tese e ao Prof. Dr.Alberto O. A. Reis que compõe por suas considerações e por compor a minha banca de defesa.

* A todos os meus amigos, são muitos que me apoiaram e incentivaram, , Ana Paula, Ana, Gladis, Loide, Elizete, Maura e demais amigos e colegas de meu trabalho.

* À minha família maravilhosa que me apoiou nos momentos mais difíceis! Minhas queridas irmãs, Babinha, Di, Claudinha que, inclusive, opinaram e contribuíram com o trabalho, e Cecília, minha irmã de coração.

Meus sobrinhos queridos, Julia, Henrique, Daniel e Helena, também Carolina e Leo, por compreenderem a ausência da tia e os meus outros afilhadinhos, Victor $e$ Giovana.

Ao Cláudio, que contribuiu para a realização deste trabalho.

Aos meus cunhados, Irani, Fran e Sérgio. Aos tios, Andréia, Cleuza, Dijanira, Nelson...E as vovós.

E finalmente, aos meus queridos pais, Santo e Lourdes, pelo grande amor que têm por mim. 


\section{RESUMO}

Filipini, R. Seguimento de crianças nascidas de baixo num município da Grande São Paulo. São Paulo, 2005. [Tese de Doutorado - Faculdade de Saúde Pública- USP].

Objetivo: Verificar a evolução do crescimento e desenvolvimento neuropsicomotor de crianças nascidas de baixo peso (BPN) em Mauá.

Metodologia: Trata-se de um estudo de coorte retrospectiva, com uma amostra não probabilística de 86 crianças com BPN, ambos os sexos, nascidas e residentes em Mauá, em 2001 e seguidas até 2004. Obtiveram-se dados secundários por meio da Declaração de Nascidos Vivos e primários com entrevistas, antropometria, Teste de Denver II e avaliação de apego materno. Aplicou-se o modelo de regressão binária, para associação entre as variáveis e estimar o Risco Relativo (RR) o nível de significância foi de $5 \%$.

Resultados e discussão: Da amostra, $46(53,5 \%)$ foram do sexo feminino e 40 (46,5\%) masculino. Nasceram $31(37,8 \%)$ pré-termos sendo que $11(35,5 \%)$ com menos de $2.000 \mathrm{~g}$ e nenhum de extremo baixo peso. Determinantes biológicos do bebê e mãe e a escolaridade tiveram associação com o BPN (Idade Gestacional com $\mathrm{p}<0,0001$; complicações neonatais, $\mathrm{p}<0,001$; complicações gestacionais, $\mathrm{p}<0,008$ e escolaridade materna, $\mathrm{p}<0,01)$. Na fase neonatal e pós verificou-se $50(58,1 \%)$ hospitalizações pelo menos uma vez entre 3 a 4 anos e ao final deste período $5(5,8 \%)$ tinham déficits nutricionais ( escore $\mathrm{Z}<-2$ ) para o $\mathrm{P} / \mathrm{E}, 11(12,8 \%)$ para $\mathrm{P} / \mathrm{I}$ e $4(4,7 \%)$ para $\mathrm{E} / \mathrm{I}$ e para o desenvolvimento neuropsicomotor 49 (57\%) com Denver II não normal. Houve pouca influência das variáveis por ocasião do nascimento ao crescimento e desenvolvimento. Apresentaram uma chance de risco ao $\mathrm{P} / \mathrm{I}$ a ausência de companheiro materna $(\mathrm{R} R=2,9)$ e poucas consultas de pré-natal para o $\mathrm{E} / \mathrm{I}(\mathrm{RR}=10)$. O número de filhos apresentou chance de risco $(R R=1,7)$ ao desenvolvimento. Outras variáveis, escolaridade materna e complicações neonatais apresentaram risco, sem significância. A hospitalização apresentou chances de risco $(\mathrm{R} R=1,6)$ para o desenvolvimento e o número de filhos continuou apresentando chances de risco no período pós-neonatal $(R R=1,5)$, assim como 
a escolaridade $(R R=1,6)$ e renda familiar $(R R=2,2)$. $O$ apego materno inseguro apresentou $\mathrm{RR}=3,3$ ao desenvolvimento e após a análise multivariada, somente ela permaneceu no modelo.

Conclusões: A baixa prevalência dos expostos pode ter influenciado nos dados que apresentaram risco, mas não significantes estatisticamente. Tendo em vista que o grupo não foi de alto risco, o maior impacto ao crescimento e desenvolvimento foram os fatores associados às condições atuais da criança e relacionadas aos cuidados maternos, apesar da hospitalização ter exercido uma influência significativa. Neste sentido, o baixo peso ao nascer permanece como fator de risco à qualidade de vida da criança.

Descritores: Baixo peso ao nascer, follow-up, apego materno, cuidado. 


\begin{abstract}
Filipini, R. Seguimento de crianças nascidas de baixo peso num município da Grande São Paulo (Follow-up of low birth weight children in a city of the Great São Paulo area). São Paulo, 2005. [PhD Dissertation - School of Public Health USP].
\end{abstract}

Objective: To verify the evolution of neuropsychomotor growth and development of low birth weight (LBW) children in the city of Mauá.

Methods: It is a retrospective cohort study with a non-probabilistic sample of 86 LBW children, of both sexes, born and residing in Mauá in 2001 and followed up until 2004. Secondary data were obtained through Birth Certificates, and primary data were collected by means of interviews, anthropometry, the Denver II Test and evaluation of maternal attachment. The binary regression model was applied. In order to associate variables and estimate the Relative Risk (RR), the level of significance was $5 \%$.

Results and discussion: In the sample, 46 (53.5\%) were females and $40(46.5 \%)$ were males. 31 preterm babies $(37.8 \%)$ were born. Of this total, $11(35.5 \%)$ weighed less than $2,000 \mathrm{~g}$ but none presented extremely low birth weight. Biological determinants of the baby and mother and level of education were associated with LBW (Gestational Age with $p<0.0001$; neonatal complications, $p<0.001$; gestational complications, $p<0.008$; and the mother's level of education, $p<0.01$ ). In the neonatal and post-neonatal phases, 50 hospitalizations $(58.1 \%)$ were verified at least once in children from 3 to 4 years of age and at the end of this period, 5 $(5.8 \%)$ had nutritional deficits $(Z$ score <-2) for weight/height, $11(12.8 \%)$ for weight/age and $4(4.7 \%)$ for height/age. Concerning neuropsychomotor development, $49(57 \%)$ presented a non-normal Denver II. There was little influence of the variables on the occasion of birth on growth and development. Absence of mother's partner $(R R=2.9)$ presented a chance of risk for weight/age, 
and few prenatal appointments, for height/age $(R R=10)$. Number of children presented a chance of risk for development $(R R=1.7)$. Other variables, such as mother's level of education and neonatal complications, presented a non-significant risk. Hospitalization presented risk chances $(R R=1.6)$ for development and number of children continued to present risk chances in the post-neonatal period $(R R=1.5)$, as well as level of education $(R R=1.6)$ and family income $(R R=2,2)$. Insecure maternal attachment presented a Relative Risk of $\mathbf{3 . 3}$ for development and after the multivariate analysis, it was the only variable that remained in the model.

Conclusions: The low prevalence of the exposed children may have influenced the data that presented risk but were not statistically significant. Taking into account that the group was not a high-risk one, the variables that presented the greatest impact on growth and development were the factors associated with the child's current conditions and related to maternal care, although hospitalization had a significant influence. In this sense, low birth weight remains as a risk factor for the child's quality of life.

Descriptors: Low birth weight, follow-up, maternal attachment, care. 


\section{ÍNDICE DE TABELAS}

Tabela A. Coeficientes de Mortalidade Infantil e Perinatal, 1990 - 2003

Tabela B. Nascidos vivos segundo sexo e taxas de natalidade do município de Mauá

$1989-2003$

Tabela C. Nascidos vivos com baixo peso em 2001 -DIR II- frequiência por município e residência

Tabela D. População de crianças com baixo peso ao nascer em 2001 e as sobreviventes até 2004, no município de Mauá-SP, 2004

Tabela E. Amostra da população de crianças nascidas em 2001 na cidade de Mauá, com baixo peso ao nascer por Unidades Básicas de Saúde por Regiões, 2.004

Tabela F. Distribuição de crianças nascidas em 2001 com baixo peso ao nascer. Mauá, 2004

Tabela 1. Média, valores mínimo, máximo e desvios- padrão das idades das mãe, número de filhos vivos e mortos de crianças com baixo peso ao nascer em 2001, Mauá, 2004

Tabela 2. Distribuição do número de consultas de pré-natal de mães de crianças com baixo peso ao nascer em 2001, Mauá, 2004

Tabela 3. Distribuição de variáveis sócio-culturais maternas por ocasião do parto de crianças com baixo peso ao nascer em 2001, Mauá, 2004

Tabela 4. Idade Média, mínimo, máximo e desvios- padrão e sexo de crianças com baixo peso ao nascer em 2001, Mauá, 2004

Tabela 5. Distribuição do sexo e características da gestação e parto de crianças com baixo peso ao nascer em 2001, Mauá, 2004

Tabela 6-Média, valores mínimo, máximo e desvios- padrão do peso ao nascer de crianças com baixo peso ao nascer em 2001, Mauá, 2004 
Tabela 7. Associação entre o peso ao nascer e variáveis por ocasião do parto de crianças com baixo peso ao nascer em 2001, Mauá, 2004

Tabela 8. Distribuição de variáveis retrospectivas gestacionais maternas segundo relato da mãe de crianças com baixo peso ao nascer em 2001, Mauá, 2004

Tabela 9. Média, valores mínimo, máximo e desvios-padrão de renda familiar de crianças com baixo peso ao nascer em 2001, Mauá, 2004

Tabela 10. Distribuição de variáveis sócio-culturais maternas atuais de crianças com baixo peso ao nascer em 2001, Mauá, 2004

Tabela 11. Distribuição de complicações neonatais de crianças com baixo peso ao nascer em 2001, Mauá, 2004

Tabela 12. Distribuição de variáveis pós-neonatais de crianças com baixo peso ao nascer em 2001, Mauá, 2004

Tabela 13. Distribuição da prática de aleitamento materno de crianças com baixo peso ao nascer em 2001, Mauá, 2004

Tabela 14. Média, valores mínimo, máximo e desvio- padrão do tempo de aleitamento, e tempo de aleitamento misto de crianças com baixo peso ao nascer em 2001, Mauá, 2004

p.92

Tabela 15. Distribuição dos escores $Z$ dos índices nutricionais de crianças com baixo peso ao nascer em 2001, Mauá, 2004

Tabela 16. Mínimo, máximo e desvios-padrão dos escores $Z$ dos índices nutricionais de crianças com baixo peso ao nascer em 2001, Mauá, 2004

Tabela 17. Média, valores mínimo, máximo e desvios-padrão do comportamento de apego seguro de crianças com baixo peso ao nascer em 2001, Mauá, 2004

Tabela 18. Distribuição contínua dos comportamentos de apego seguro de crianças com baixo peso ao nascer em 2001, Mauá, 2004 
Tabela 19. Associação e risco relativo de peso/idade segundo o sexo e situação conjugal por ocasião do parto de crianças com baixo peso ao nascer em 2001, Mauá, 2004

p.104

Tabela 20. Associação e risco relativo de estatura/idade segundo consulta de pré-natal e situação conjugal atual de crianças com baixo peso ao nascer em 2001, Maú, 2004.

p.105

Tabela 21. Valor de p e qui-quadrado das associações entre os índices nutricionais e variáveis do período perinatal de crianças com baixo peso ao nascer em 2001, Mauá, 2004

p.106

Tabela 22. Valor de p e qui-quadrado das associações entre os índices nutricionais e variáveis sociais e da gestação maternas de crianças com baixo peso ao nascer em 2001, Mauá, 2004

p.106

Tabela23. Valor de p e qui-quadrado das associações entre os índices nutricionais e aleitamento materno de crianças com baixo peso ao nascer em 2001, Mauá, 2004.

Tabela 24. Valor de p e qui-quadrado das associações entre os índices nutricionais e variáveis da vida atual da criança daquelas com baixo peso ao nascer em 2001, Mauá, 2004

Tabela 25. Valor de p e qui-quadrado das associações entre os índices nutricionais e variáveis maternas da vida atual da criança com baixo peso ao nascer em 2001, Mauá, 2004

$$
\text { p.108 }
$$

Tabela 26. Distribuição do Teste de Denver II de crianças com baixo peso ao nascer em 2001, Mauá, 2004

p. 112

Tabela 27. Distribuição do Teste de Denver II por setores de crianças com baixo peso ao nascer em 2001, Mauá, 2004

Tabela 28. Distribuição dos tipos de comportamento no Teste de Denver II de crianças com baixo peso ao nascer 2001, Mauá, 2004

p.113 
Tabela 29. Associação entre o Teste de Denver II e comportamento no teste de crianças com baixo peso ao nascer 2001, Mauá, 2004

Tabela 30. Associação e risco relativo entre o Teste de Denver II e variáveis biológicas e por ocasião do parto de crianças com baixo peso ao nascer 2001, Mauá, 2004 p.116

Tabela 31. Associação entre oTeste de DenverII e peso ao nascer segundo médias, mínimo, máximo, desvio padrão e valor p de crianças com baixo peso ao nascer 2001, Mauá, 2004

Tabela 32. Associação e risco relativo entre oTeste de DenverII e classificação e peso ao nascer de crianças com baixo peso ao nascer 2001, Mauá, 2004

Tabela 33. Associação e risco relativo de crianças nascidas entre o doTeste de DenverII e aleitamento materno de crianças com baixo peso ao nascer 2001, Mauá, 2004 p.118

Tabela 34. Associação e risco relativo entre o Teste de DenverII e a classificação e índices nutricionais de crianças com baixo peso ao nascer 2001, Mauá, 2004

Tabela 35. Associação e risco relativo entre o teste de DenverII e variáveis de seguimento de vida de crianças com baixo peso ao nascer 2001, Mauá, 2004

Tabela 36. Associação e risco relativo entre o teste de DenverII e variáveis sócioculturais maternas por ocasião do parto de crianças com baixo peso ao nascer 2001, Mauá, 2004

Tabela 37. Associação e risco relativo entre o teste de DenverII e variáveis gestacionais de crianças com baixo peso ao nascer 2001, Mauá, 2004

Tabela 38. Associação e risco relativo entre o teste de Denver II características atuais da mãe e família de crianças com baixo peso ao nascer 2001, Mauá, 2004 p.126

Tabela 39. Associação entre oTeste de DenverII e comportamento de apego seguro segundo médias, mínimo, máximo, desvio padrão e valor p de crianças com baixo peso ao nascer 2001, Mauá, 2004

Tabela 40. Associação e risco relativo entre o Teste de Denver II com o comportamento de apego seguro de crianças com baixo peso ao nascer 2001, Mauá, 2004 
Tabela 41. Análise multivariada de apego materno com déficit de desenvolvimento pelo Teste deDenverII de crianças com baixo peso ao nascer 2001, Mauá, $2004 \quad$ p.129 


\section{ÍNDICE DE FIGURAS}

Figura 1. Desenho do Tipo de estudo

p.30

Figura 2. Mapa do município de Mauá, localizado na Grande São Paulo, com suas principais vias de acesso. 2005 p.34

Figura 3. Nascidos vivos com Baixo Peso . Mauá p.39

Figura 4. Distribuição da amostra de crianças nascidas em 2001 com baixo peso em todo o território do município de Mauá, SP, 2004 p.51

FIGURA 5. Fluxograma para definição da amostra p.52 


\section{LISTA DE ABREVIATURAS}

BPN- Baixo peso ao nascer.

IG- Idade gestacional

DNV- Declaração de nascidos vivos

PIG- Pequeno para idade gestacional

RCIU- Retardo de crescimento intra-uterino

RPM- Rotura prematura de membranas

RN- Recém-nascido

SIM- Sistema informação de mortalidade

SINASC- Sistema de informação de nascidos vivos 


\section{SUMÁRIO}

1 INTRODUÇÃO $\quad$ p.01

2 CONSIDERAÇÕES SOBRE A TEORIA DO APEGO p.16

\section{OBJETIVOS}

$\begin{array}{ll}3.1 \text { Geral } & \text { p.28 }\end{array}$

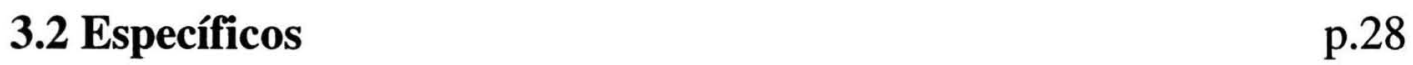

4 METODOLOGIA

$\begin{array}{ll}4.1 & \text { Tipo de estudo p.29 }\end{array}$

4.20bjeto do estudo p.31

4.3Universo da pesquisa p.31

4.3.1. População de estudo p.31

4.3.2. Caracterização do Município de Mauá p.31

4.3.3 Critérios de escolha da amostra p.40

4.4. Procedimentos da coleta de dados

4.4.1. Entrevista $\quad$ p.40

4.4.2. Teste de Triagem de desenvolvimento de Denver II p.53

4.4.3. Antropometria p.57

4.4.4. Avaliação do Comportamento de Apego Seguro p.58

4.5Descrição ds variáveis $\quad$ p.66

5 ANÁLISE DOS DADOS p.71

6 CONSIDERAÇÕES ÉTICAS p.72 


\section{RESULTADOS}

7.1Análise da coorte segundo dados secundários obtidos da DNV

7.1.1 Características maternas p.73

7.1.2 Características do bebê p.76

7.2 Análise da coorte segundo dados da entrevista

7.2.1 Características maternas p.81

7.2.2 Características da criança p.81

7.3 Análise do crescimento físico p.103

7.4 Análise do desenvolvimento neuropsicomotor p.109

7.5 Regressão múltipla p. 130

8 DISCUSSÃO p.130

9 CONSIDERAÇÕES FINAIS

10 REFERÊNCIAS BIBLIOGRÁFICAS

\section{ANEXOS}

A. 1. Curva de crescimento intra-uterino de Battaglia e Lubchenco

p. 170

A.2. Modelo da lista de endereços para localização da criança de BPN

p.171

A.3. Planejamento da coleta

p.172

A.4. Planejamento da coleta2

p. 173

A.5. Carta de convocação da mãe

p.174

A.6. Relatos de caso

p. 175

A.7. Termo de Consentimento Livre e Esclarecido

p.178

A.8. formulário da coleta de dados

p.179

A.9. Lista das variáveis da declaração de nascidos vivos e suas descrições

p. 182

A.10. Teste de triagem do desenvolvimento de Denver II

p.184 
$\begin{array}{ll}\text { A.11. Classificação do AQS- adaptado } & \text { p.185 }\end{array}$

$\begin{array}{lr}\text { A.12. Lista de itens da Classificação do AQS } & \text { p.187 }\end{array}$

$\begin{array}{lr}\text { A.13. Modelo de Regressão } & \text { p.190 }\end{array}$

A.14. Parecer do Comitê de Ética em Pesquisa da FSP-USP p.195

$\begin{array}{lr}\text { A.15. Tabela F } & \text { p.196 }\end{array}$ 


\section{INTRODUÇÃO}

O conceito de recém-nascido de baixo peso é vincado pelo peso que ele tem ao nascimento. A partir desse parâmetro se estabelece uma série de medidas e atitudes exercidas, tanto pela equipe de saúde, quanto pela família do bebê. $\mathrm{O}$ receio da "não normalidade" perpassa pelo pensamento daqueles que o assiste.

Nesse sentido, RAMOS (2003) evidencia a complexidade do conceito de recémnascido normal. Afirma que se a consideração de normalidade estiver associada à presença de doença, este conceito é subjetivo, tendo em vista que dependerá da percepção de quem o avaliará e o quanto se tem de conhecimento de seus atributos. Enfatiza que nem sempre um recém-nascido "normal" é aquele de termo.

Isto seja talvez um dos motivos propulsores para que as ações de saúde venham sendo reavaliadas para, não somente, garantir sua sobrevivência, mas, sobretudo, assegurar a qualidade de vida destes bebês de baixo peso.

Neste aspecto, a diminuição nas taxas de mortalidade entre os bebês nascidos com baixo peso tem provocado reflexões acerca das estratégias tecnológicas e assistenciais adotadas para garantir a viabilidade entre aqueles que nasceram muito pequenos.

A suspeita de que talvez se tenha extrapolado o limite da viabilidade é quase certa e, portanto, tornou-se necessário inverter este processo e dar outro rumo às ações de saúde direcionadas a estes recém-nascidos, tal como estabelecer medidas preventivas 
no período gestacional evitando o nascimento de bebês de muito baixo peso (TANAKA 1989; LEONE 2003 ).

Uma razão vem dos resultados obtidos quando se avaliam as condições dos bebês sobreviventes. LEONE (2003) afirma que mesmo com todos os recursos disponíveis, desde os tecnológicos até programas de seguimento, não se consegue reverter quadros de seqüelas neurológicas entre os bebês que nasceram com extremo baixo peso e, portanto, eles ficam em situação desfavorável frente aos bebês nascidos normais.

O estudo de ALMEIDA (1995) realizado em Santo André destacou que o baixo peso ao nascer (BPN) e gestação pré-termo formaram os grandes fatores de risco para a mortalidade neonatal nesta cidade paulista. Afirma que as mudanças nas taxas podem ser atribuídas aos avanços tecnológicos na assistência à mãe e bebê e ao monitoramento do desenvolvimento do neonato. Isto possibilitou sua viabilidade, inclusive dos recémnascidos com extremo BPN (inferior a $1.000 \mathrm{~g}$ ) e, sendo assim, recomenda dimensionar mais adequadamente a assistência ao pré-natal e ao parto.

Por conseguinte, a preocupação com os bebês de BPN mantém sua relevância dado que inúmeros trabalhos, nas últimas décadas, até os mais recentes, afirmam que estas crianças permanecem com mais chances de morrer e adoecer após o nascimento (LUBCHENCO 1970; SIQUEIRA 1981; LAURENTI et al 1984; SOUZA et al 1988; HORTA et al 1996; BELSEY 1993; VICTORA et al 1994, 1996; ALMEIDA e MELLO JORGE 1998; BARBIERI et al 2000; WHO, 2000 ).

O Sub-Committee on Nutrition ( WHO 2000) divulgou que a cada ano nascem 17 milhões de crianças com baixo peso em países em desenvolvimento, contudo, afirma 
que elas nascem com comprometimento neurológico, cognitivo e, mais tardiamente, com riscos de doenças cardíacas, hipertensão e diabetes.

Assevera a maior chance de morrer, descrevendo que morrem quatro vezes mais durante os primeiros 28 dias de vida que aqueles com peso maior que $2.500 \mathrm{~g} \mathrm{e} 10$ vezes mais que os bebês com mais de $3.000 \mathrm{~g}$. Cita a população de Bangladesh como exemplo de que metade das mortes de bebês por pneumonia e diarréia poderia ter sido evitada se o baixo peso fosse eliminado (WHO 2000).

A princípio, a mortalidade se apresenta como um importante indicador para a compreensão dos fatores determinantes do BPN. A par disso, as taxas de sobrevida no Brasil, melhoraram significativamente com a redução das taxas de mortalidade infantil, registradas no censo demográfico do Instituto Brasileiro de Geografia e Estatística (IBGE 2001) com 29,6 mortes para mil nascidos vivos em 2000.

Alguns dados regionais, como a região do $\mathrm{ABC}$ paulista, mostram esta tendência ao declínio da mortalidade infantil que pode ser verificado numa série histórica desde 1970, quando o coeficiente de mortalidade infantil era de 101,2 caindo 30 anos depois para 15,6 (FUNDAÇÃO SEADE 2004).

É de consenso que nestas taxas há um percentual importante de causas perinatais tal como em São Paulo, em 1999, que da taxa de mortalidade infantil em torno de 22,06 por mil nascidos vivos, 57,7\% foram de causas perinatais (FIOCRUZ 1999), mas, felizmente, estas taxas também vêm se reduzindo. O Estado de São Paulo apresenta uma taxa de mortalidade perinatal atual em torno de 20 por mil que tem variado entre os anos 
de 1999 a 2002 em 22,06; 21,36; 20,10 e 19,23 respectivamente (DATASUS 2005) e que apesar do declínio se mantém acima do que se observa em outros países.

HAWKINS (1993) analisou a mortalidade perinatal nos países desenvolvidos nos últimos 50 anos e concluiu que o decréscimo foi drástico e exponencial de 1920 a 1980. $\mathrm{Na}$ Grã-Bretanha, por exemplo, a taxa de 60 por mil nascidos vivos em 1930, diminuiu para 10 por mil em 1980 e permanece atualmente com taxas em torno de cinco a seis por mil nascidos vivos, verificando-se a mesma tendência, desde o final da década de 20 , em vários países desenvolvidos da Europa.

Importante se destacar que as características de seus indicadores têm comportamentos distintos.

Cita-se, como exemplo, o estudo de morbidade e mortalidade perinatal de LAURENTI et al (1984), entre os anos de 81 a 82, quando, descrevendo a evolução da mortalidade em três décadas (40 a 50 e no ano de 82 ) observaram o expressivo declínio nas taxas de mortalidade perinatal, contudo, o resultado da sua pesquisa obteve uma taxa maior. A explicação foi pelo fato das maternidades estudadas serem referência a gestantes de risco.

Uma pesquisa recente corroborou a necessidade de associar os fatores à análise dos dados obtidos. SILVA et al (2003) associando baixo peso ao nascer e mortalidade infantil estimaram algumas taxas em duas coortes no Brasil, cujos resultados mostraram taxas menores em região considerada mais vulnerável. Assim, concluíram que o resultado discrepante esteja associado à melhor qualidade na assistência perinatal e, por isso, os bebês menores sobreviveram mais. Sugerem, portanto, que a taxa de baixo peso 
ao nascer não deve ser sistematicamente considerada como indicador de desenvolvimento social.

Os estudos sobre a coorte da cidade de Pelotas (VICTORA et al 1994; HORTA et al 1996; BARROS 1996a; MENEZES et al 1998) ganharam importância porque serviram de referência na saúde perinatal. E nestas pesquisas identificaram aumento da incidência dos bebês BPN e que mantiveram uma taxa limiar destes pesos durante o período de seguimento, de $9 \%$ em 1982 para 9,8\% em 1993. Os fatores associados à manutenção das taxas foram melhorias nas condições sócio-econômicas da mãe e maior cobertura do pré-natal. E por outro lado, seus dados mostraram que os recém-nascidos de famílias de baixa renda tiveram mais chances de nascerem de baixo peso.

BARBIERI et al (2000) igualmente analisaram duas coortes de recém-nascidos, nas décadas de 70 e 90, em Ribeirão Preto/SP, onde encontraram dados semelhantes aos trabalhos anteriormente citados. Ou seja, aumento da incidência de bebês de BPN, 7,8\% para $10 \%$ e com predomínio de baixos pesos, sobretudo, em famílias menos estruturadas, mães sem companheiros, fumantes, baixa escolaridade e com poucas consultas de pré- natal.

Do mesmo modo, SOUZA et al (1988) confirmam que o nascimento de bebês BPN se acentua, especialmente entre populações menos favorecidas e que têm mais dificuldades de acesso aos serviços de saúde. No estudo realizado com uma população representativa de Florianópolis/SC, das taxas obtidas de BPN, esta aumentou quando restritas às famílias pobres. Outros trabalhos encontraram dados semelhantes (ALMEIDA e MELLO JORGE 1998). 
SAIGAL (1993) concorda que há evidências de que os cuidados neonatais têm contribuído para uma efetiva queda da mortalidade, primeiramente, os bebês entre $1.000 \mathrm{~g}$ e $1.500 \mathrm{~g}$ e, nos últimos 15 anos, os menores de $1.000 \mathrm{~g}$, considerados extremo baixo peso, também sofreram queda. Considera, ainda, esse o fenômeno conseqüente a fatores sócio-demográficos e às sofisticadas práticas de terapia intensiva, resultando na sobrevida dos extremos baixo peso sujeitos a sofrer variações podendo, inclusive, morrer no primeiro ano de vida.

Em pesquisas sobre óbitos perinatais evitáveis, ROSA e HORTALE (2000), do mesmo modo, destacam a qualidade na assistência como fator essencial para a sobrevida dos bebês.

A despeito das considerações iniciais e destas últimas, torna-se indiscutível a questão de cuidar dos sobreviventes. E cuidar demanda conhecimento em todos os níveis de atenção à saúde. RAMOS et al (2003a) alegam que para se avaliar um recém-nascido é necessário conhecer duas variáveis: o peso ao nascer e a idade gestacional, sendo de consenso as classificações do recém-nascido. $\mathrm{O}$ termo prematuro é atribuído àquele que nasceu com menos de 37 semanas de idade gestacional, que é o conceito recomendado pela Organização Mundial de Saúde (OMS) desde 1961. E os bebês de baixo peso ao nascer são os que nascem com menos de 2.500 gramas, independentes de sua idade gestacional.

RAMOS et al (2003a) destacam a importância em distinguir o prematuro que cresceu adequadamente no útero daquele que sofreu retardo do crescimento intra-uterino (RCIU), isto porque terão evoluções diferentes. Se houver disponibilidade dos valores 
do peso e idade gestacional a curva de crescimento intra-uterino (anexo 1 ) é a mais indicada para classificar o bebê dentre as nove categorias de peso por idade gestacional.

RAMOS et al ( 2003a) afirmam que a classificação foi proposta por Battaglia e Lubchenco, em 1967, mas inicialmente usada por Lubchenco et al em 1963 (p.322)

A propósito, LUBCHENCO (1970) salientou a necessidade desta classificação isolada dos tipos de bebês de baixo peso ao nascer (BPN) devido às dificuldades em se distinguir entre o normal e anormal do peso por idade quando não existir alguma referência. Por isto, ela e Battaglia criaram uma curva de crescimento e idade gestacional (anexo 1) que possibilitou a caracterização dos pequenos para a idade gestacional (PIG), bem como, o estudo da influência do RCIU sobre a mortalidade neonatal (LUBCHENCO et al 1963; LUBCHENCO 1970).

Pelo critério de BATTAGLIA E LUBCHENCO (LUBCHENCO et al 1963; LUBCHENCO 1970), o recém-nascido PIG é aquele que o seu peso de nascimento se situa abaixo do percentil 10 para sua idade gestacional, com base na curva de crescimento intra-uterino ( SIQUEIRA 1981; HORTA 1996; ALMEIDA e MELLO JORGE 1998; WHO 2000; RAMOS ET AL 2003b).

Existem outros critérios, em desvios-padrão ou com percentis menores, com o limite no percentil 5. Contudo, o critério de Battaglia e Lubchenco é o mais freqüentemente usado (RAMOS et al 2003b).

ALMEIDA E MELLO JORGE (1998) referiram que a proporção de recémnascidos PIG em Santo André foi reduzida e sendo atribuído o fato à boa condição 
sócio-econômica da população do estudo. Entretanto, destacaram que os PIG apresentaram um risco de morte maior que os não PIG e afirmaram, portanto, que o retardo do crescimento intra-uterino (RCIU) se constituiu um fator de risco para a mortalidade perinatal.

SIQUEIRA (1981) referiu que somente com Lubchenco e colaboradores se estabeleceram padrões de peso para idade gestacional e com isto dois tipos de recémnascidos com baixo-peso. Um seria o "verdadeiro prematuro" e que teve um ritmo normal de crescimento e o outro seria o neonato que teve o retardo no ritmo de crescimento intra-uterino, Denominando-os "desnutridos" ou "desnutridos intrauterinos".

A avaliação da idade gestacional (IG) é igualmente importante. FARR e MITCHELL (1969) consideraram o seu cálculo uma maneira de diferenciar bebês imaturos e propuseram determiná-la por meio dos caracteres físicos externos do bebê, tais como a cor e textura da pele, opacidade, lanugem, forma da orelha, genitália.

Para CAPURRO et al (1978) o diagnóstico da IG no período neonatal é de fundamental importância para a prevenção, cuidados e tratamento do neonato. Partindo do método de Dubowitz propuseram dois métodos mais simples, de parâmetros neurológicos e somáticos o que possibilitou seu uso imediato após o nascimento.

NAUFEL (1998), num estudo crítico da literatura sobre o baixo peso ao nascer (BPN), afirma que o diagnóstico da IG está bem estabelecido e sugere o uso deste método, conhecido como "método de Capurro". 
A propósito, estas duas variáveis estão entre os determinantes do BPN. MONTEIRO et al (2000) classificaram os determinantes do baixo peso ao nascer e consideram a duração da gestação e a velocidade do crescimento intra-uterino com determinantes proximais do peso ao nascer. $\mathrm{E}$ estes, dependentes dos determinantes intermediários que são os atributos maternos, a saber, os estado nutricional da gestante, estatura baixa, doenças, tabagismo e fontes de estresse na gravidez, pré-natal, idade da gestante e paridade. E finalmente, os intermediários com dependentes dos determinantes , distais como as condições socioeconômicas, renda e escolaridade da gestante.

Neste aspecto, se explica o fato de vários autores considerarem os atributos maternos como determinantes para o BPN em países em desenvolvimento (SIQUEIRA 1981; KRAMER 1990; FANAROFF 1993; ALMEIDA e MELLO JORGE 1998; BARROS 1996a, 1996b; WHO 2000).

O papel destes determinantes ao baixo peso vem sendo objeto de estudo de vários trabalhos e conforme os resultados uns se sobrepõem aos outros. Contudo, fica evidente que o valor de importância dependerá do contexto em que eles estiverem inseridos.Tal como o trabalho de ALMEIDA e MELO JORGE (1998) que identificaram fatores de risco ao retardo do crescimento intra-uterino como: mães com mais de 35 anos e menores de 20, primíparas e multíparas, fatores sociais, baixa renda e escolaridade.

Outros fatores maternos vêm apresentando evidências de risco ao BPN. A exemplo, a infecção do trato genital ou a vaginite bacteriana que pode levar ao parto prematuro por conseqüência da rotura prematura de membranas. 
Sendo assim, as infecções gênito-urinárias têm recebido certo destaque como grande fator de risco para a prematuridade. Alguns autores verificaram forte relação entre eles e por isso, possivelmente, sejam elas uma das grandes causas da rotura prematura de membranas (FRAIRE 1977; SANTOS 1986; SILVA 1995; ALEXANDER et al 2000; OVALLE 2000).

Com relação aos fatores comportamentais, NEWMAN (2001) comenta que entre as mulheres inseridas no mercado de trabalho e grávidas, $80 \%$ delas permanecem no emprego no $3^{\circ}$ trimestre de gravidez e quase metade durante o nono mês. Por sua vez, a fadiga ocupacional promoverá um potencial de impacto na gestação e parto.

Esse autor destaca, ainda que, destas mulheres, as que sofrem complicações são aquelas que têm mais dificuldades sócio-econômicas e educacionais. Identificou 14,4\% de partos prematuros e destes $4,5 \%$ com rotura prematura de membranas que, por sua vez, estava relacionada à fadiga ocupacional e vaginite bacteriana. A propósito, identificou nas associações que entre as nulíparas trabalhando em ambiente de estresse a vaginite foi significantemente mais alta.

Um outro determinante importante trata-se das condições sócioeconômicas e pertencentes aos determinantes distais do BPN. MONTEIRO (2000) afirma que a renda e a escolaridade são as variáveis mais importantes do ponto de vista de risco ao baixo peso.

É evidente que as medidas de atenção à saúde devem vir munidas de uma estratégia adequada e, neste aspecto, o enfoque de risco vem se apresentando como uma estratégia para a organização e garantia de qualidade dos serviços de saúde. A 
identificação dos fatores de risco, que se dá antes do aparecimento do evento ou dano, se apresenta como um fator fundamental para a realização desta estratégia de atenção à saúde (CÉSAR 1990, 1998).

HAWKINS (1993) recomenda que as mães devem realizar o pré-natal em grupos específicos, de acordo com o seu estado geral, e descreve uma série de intervenções, desde um cuidado extremamente especial com a dieta até aconselhamento genético às mulheres com idade acima de 35 anos.

Outrossim, SIQUEIRA (1991) considera o nascimento um dos momentos de maior risco para o ser humano, justamente pelas inúmeras transformações a que se submete. Desde a mudança de ambiente, do meio líquido para um meio gasoso, até a adaptação a todas as suas necessidades fisiológicas e provavelmente emocionais. Assim, parece claro que, ao nascimento, os bebês de baixo peso ao nascer encontrarão um ambiente desfavorável que limite sua sobrevivência.

Por sua vez, o Sistema de Informação de Mortalidade (SIM/ MS) relaciona as afecções que acometem os recém-nascidos neste período de vida e que levam ao óbito. Em primeiro lugar as doenças respiratórias e a doença pulmonar da membrana hialina seguidos da prematuridade e BPN; infecção específica no período perinatal (exceto tétano); hipóxia e asfixia, além de outras afecções mal definidas (FIOCRUZ 1999).

Como se observa, os riscos de doenças são inúmeros e o BPN se insere entre eles. BOSSI (1993) relaciona outros problemas, secundários, mas que podem trazer eventos adversos ao bebê, como a hipotermia, apnéia, aspiração, infecção, hipoglicemia, hiperbilirrubinemia, como também patologias gastrointestinais. Afirma, ainda, que os 
bebês de baixo peso são mais os vulneráveis e que têm grandes chances de apresentar problemas futuros.

No parecer da WHO (2000), estes bebês nascidos com baixo peso têm mais risco em desenvolver diarréia aguda e contrair pneumonia ou infecções respiratórias agudas quase duas vezes mais que os normais e mais do que três vezes se o seu peso for menor que $2.000 \mathrm{~g}$.

O seguimento destes bebês (follow-up) vem sendo recomendado e sua estratégia de ação tem sido descrita e aprovada. O programa, em síntese, consiste no atendimento multidisciplinar que vai desde o nascimento, com rotinas, critérios para alta e seguido de uma série de avaliações e acompanhamento na vida familiar (BOSSI 1993; LOPES 1999; SAIGAL 1993; RUGOLO 2003).

Vários autores destacam os comprometimentos que estes bebês podem apresentar, sendo que alguns desencadeados pela falha na assistência, desde o período perinatal.

BELSEY (1993) destaca que a própria falha na prevenção do baixo peso implicará na possibilidade de haver um comprometimento do crescimento físico e que, por sua vez, pode prejudicar suas habilidades mentais e o futuro desempenho escolar.

Esta falha do peso se explica pelo fato que o ganho de peso do feto é progressivo até o final da gestação e o ganho maior ocorre por volta de 30 semanas. BERTAGNON (1991) conclui que, portanto, nas últimas semanas em que ele pode ganhar mais peso o desnutrido intra-útero se distanciará mais dos normais. 
SAIGAL (1993) afirma que os baixo peso ao nascer crescem mais lentamente em peso e estatura e esta tendência se acentua em menores de $1.000 \mathrm{~g}$. Identificou que, por volta dos oito anos de idade, comparando as crianças a termo e os de extremo baixo peso, estes últimos são significativamente mais baixos e mais magros e tem menor circunferência cefálica.

A WHO (2000) considera os bebês que tiveram retardo de crescimento intrauterino com pior prognóstico para o crescimento. E apontam conseqüências sociais em razão de que destas crianças com BPN, provavelmente, terão menor força e menos massa muscular resultando em baixa produtividade a si e à sociedade em decorrência do decréscimo em sua capacidade de trabalho.

Um serviço de seguimento de bebês de baixo peso do Rio de Janeiro identificou maior impacto no desenvolvimento entre aqueles que tiveram retardo do crescimento intra-uterino e alterações do desenvolvimento cognitivo associado aos fatores sócioeconômicos (PORTO 1999). Neste mesmo Serviço, distúrbios de origem neuromotora, de conduta e comportamento foram notados e associados aos aspectos tanto de ordem cognitiva quanto afetiva (MORSCH 1999).

Vários autores concordam que desde os vínculos iniciais, especialmente o apego mãe-bebê levarão a um bom desenvolvimento cognitivo (BRUM e SCHERMANN 2004; RAMIRES 2003; VAN IJZENDOORN et al 2004).

SAIGAL (1993) fez referências que na década de 70 e 80 a prevalência de prejuízos neuro-sensórios esteve entre $17 \%$ e $24 \%$ para bebês menores de mil gramas. Dentre estes, a prevalência de cegueira e problemas visuais têm sido consideradas 
significantes, variando de 6 a 10\%. Descreve que alguns trabalhos encontraram $24 \%$ de crianças com extremo baixo peso ao nascer usando óculos aos oito anos comparadas com $5 \%$ de crianças a termo, como também problemas auditivos em $13 \%$ naqueles e $3 \%$ nos termos.

Em pesquisas mais recentes, SAIGAL (1993) descreve outras anormalidades neuropsicomotoras notadas em bebês prematuros nos primeiros 18 meses de vida. Tal como habilidades cognitivas identificadas em pesquisas de caso-controle, no qual o QI (quociente de inteligência) estiveram mais baixos quando comparados aos controles. E quanto ao comportamento, outro estudo observou crianças com baixo peso ao nascer com mais problemas na escola, com atitudes de passividade, distraídas, com dificuldades sociais ou hiperativas.

Quanto às conseqüências tardias, há indícios de que possam resultar em adultos mais susceptíveis a problemas cardíacos e coronarianos, doenças renais e diabetes e além disto, mantendo-se num ambiente nutricional inadequado, permitirão o desenvolvimento de distúrbios crônicos digestivos (SAIGAL 1993).

Como todos os fatores de risco mencionados como determinantes ao baixo peso ao nascer e suas conseqüências puderam retratar a vulnerabilidade destes bebês, assim, desse modo, obrigatório se faz acompanhá-los e identificar os fatores protetores capazes de apresentar uma visão de melhor prognóstico.

O aleitamento materno é, reconhecidamente, um destes fatores protetores, pelo papel nutritivo que representa, além de possibilitar a criação de vínculo mãe e bebê (NÓBREGA 2000). BOWLBY (2002), em sua teoria do apego, afirma que não é o 
alimento em si, neste caso o leite, que proporciona o apego materno, mas, a sucção que é reconhecida, por ele, como sendo um dos instrumentos de proximidade entre a mãe e o recém-nascido. Por esta razão, o apego materno talvez seja um outro determinante que se compõe aos outros para produzir efeitos protetores à saúde da criança e, assim, para ser investigado é fundamental conhecer aspectos conceituais desta teoria na qual será abordada no tópico seguinte.

Saber como os bebês de BPN estão crescendo e se desenvolvendo e identificar os fatores de risco e de proteção que influenciaram no decorrer de suas vidas permitirá estabelecer medidas de ações de saúde articuladas, eficazes e humanizadas. Com esta finalidade este trabalho se propôs investigar uma amostra de crianças que nasceram com esta característica no município de Mauá, localizado no Grande ABC Paulista, contribuindo com a organização e desenvolvimento do serviço de saúde da região. 


\section{CONSIDERAÇÕES SOBRE A TEORIA DO APEGO}

VAN IJZENDOORN et al (2004) afirma que as relações afetivas, particularmente entre pais e filhos, têm se mostrado essenciais para garantir um adequado desenvolvimento e qualidade de vida e consideram a teoria do apego uma fonte de hipóteses para pesquisa sobre o desenvolvimento emocional de crianças pequenas.

Apego que de acordo com PENDRY (1998) pode ser caracterizado como um forte vínculo emocional que se desenvolve entre a criança e seu cuidador, provendo a criança de segurança emocional. E descreve que foi John Bowlby, psiquiatra e psicanalista inglês, quem primeiro aplicou a idéia de vínculo bebê-cuidador inspirado nos estudos de Lorenz em 1952.

Lorenz, segundo PENDRY (1998), acreditava que o bebê humano, como muitas espécies de bebês animais, é provido de uma série de comportamentos embutidos que o ajudam a manter proximidade com os pais para protegê-los dos perigos e a segurança de que seriam alimentados, no entanto, vale lembrar que Bowlby, de acordo com NEWCOMBE 1996 e PENDRY 1998 considere que a alimentação não é a base do apego e nem resultado de satisfazer a necessidade infantil de alimentos.

BOWLBY (2002) acredita que o relacionamento da criança com os pais iniciase com uma série de sinais inatos que chamam o adulto para o lado do bebê. E que, com o passar do tempo, um verdadeiro vínculo de afeição se desenvolve com capacidades emocionais e cognitivas tão boas quanto forem os cuidados responsivos, consistentes e 
sensíveis dos pais. Como também, um vínculo resistente possibilitará à criança usar esta figura de apego como uma base segura através do tempo e distância (PENDRY 1998; ZIMBEROFF e HARTMAN 2002). WATERS E DEANE (1985) afirmam que os padrões de apego podem sofrer modificações em resposta a significantes padrões no cuidado.

BOWLBY (2002) reconhece a privação materna como uma variável dominante para distúrbios na infância e que a perda da assistência nos primeiros meses de vida é de suma importância a ponto de afirmar que "a avidez da criança pelo amor e a presença da mãe é tão grande quanto a fome de alimento"( p. XII). Ele e sua equipe concluíram que a perda da figura materna pode gerar conseqüências patológicas não só na infância como também na vida adulta, se não receber acolhimento, amor daqueles que dela se responsabilize (BOWLBY 2002).

O trabalho de Bowlby realizou observações em outras espécies que não a humana e justificou tal método valorizando a Etologia ${ }^{*}$, no sentido que esta ciência oferece possibilidades em adquirir novos conceitos que possam ser provados. Afirmou que "o homem não detém o monopólio dos conflitos nem do comportamento patológico"(p.8) e se possuímos com espécies inferiores semelhanças fisiológicas e anatômicas que atendam nossas necessidades básicas podemos, também, compartilhar alguns tipos de comportamento (BOWLBY 2002).

\footnotetext{
${ }^{*}$ Etologia-Tratado dos costumes, uso e caracteres humanos. Estudo comparado do comportamento dos animais. Estudo dos hábitos dos animais e da sua acomodação às condições do ambiente. Ferreira, AB H. Dicionário da Língua Portuguesa.2 .ed., RJ:Ed Nova Front, 1996.p.733.
} 
Bowlby concorda com Freud ao considerar que nos primeiros cinco ou seis anos de vida todo indivíduo tende a ser vulnerável e que o seu "ego" é frágil, imaturo e incapaz de resistência. Há consenso em que a separação da mãe pode se tornar traumática e gerar processos defensivos especialmente se ela for deslocada para um lugar e com pessoas estranhas neste período vulnerável da infância.(BOWLBY 2002).

BOWLBY (2002) refere que até 1958 existiam quatro fortes teorias sobre a origem e natureza do vínculo. A primeira e mais aceita se reporta ao fato da mãe atender as necessidades fisiológicas da criança, e, por isso fonte de sua satisfação, é reconhecida como a teoria do amor interesseiro que ele chamou de Teoria do Impulso Secundário, derivado da Teoria da Aprendizagem. Mostra, contudo, certa perda da credibilidade dessa teoria por meio de vários experimentos que Bowlby cita, por exemplo: o dos bebês macacos em contato com mães "confortáveis", construídas de pano, sem alimento e mães de arame com alimento. Os bebês macacos passavam a maior parte do tempo com as mães confortáveis e para se alimentarem se esticavam para mamar no seio da mãe de arame, mas agarrados à mãe de pano.

BOWLBY (2002), no entanto, afirma que o bebê humano desde o nascimento responde e se acalma com sinais, toques e falas, não necessariamente, precisando do alimento. E responde rapidamente aos estímulos sociais tal como o prazer que a criança expressa ao estar com outra da própria idade. Nesse sentido, alerta que se a criança apegou-se a esta figura ela pode, portanto, apegar-se a uma outra que não precise lhe fornecer alimentos. Outra evidência do apego foi a mensuração da reação da outra figura 
frente à criança e como interage com ela e afirma que a própria evolução motora responde melhor, quanto maior for o incentivo da figura objeto do apego.

Descreve as seguintes, segunda, terceira e quarta teorias que são, respectivamente, Teoria da Sucção do Objeto Primário, em que o bebê associa o seio com um ser humano; Teoria da Adesão ao Objeto Primário que diz respeito à necessidade da criança ter contato com outro objeto, pois, segundo o autor, "nos bebês existe uma propensão inata para o contato físico intenso com o ser humano" (p.220).

E, finalmente, a Teoria do Anseio Primário de Retorno ao Ventre que o próprio nome define a teoria.

Com base nestes estudos Bowlby sugeriu uma nova hipótese baseada na teoria do comportamento instintivo, no qual propôs que "o vínculo da criança com sua mãe é um produto da atividade de um certo número de sistemas comportamentais que têm a proximidade com a mãe como resultado previsível" (BOWLBY 2002, p. 221).

Ele descreve alguns destes sistemas, essenciais, que fornecem a base para o desenvolvimento do comportamento do apego, alguns como:

"sistemas primitivos mediadores do choro, sucção, agarramento e orientação do recém-nascido. A estes serão adicionados, apenas algumas semanas depois, o sorriso e a balbuciação e, alguns meses mais tarde, o engatinhar e o andar."(BOWLBY 2002,p.330).

Assim, das quatro teorias as que se aproximaram de sua hipótese foram as de sucção ao objeto primário e de adesão ao objeto primário. Tendo em vista que sua hipótese postula que comportamentos ligados ao apego convertem-se numa meta-fixada, 
tais como, os quatro padrões de comportamento, sugar, seguir, chorar e sorrir, que, entre os nove e dezoito meses, estão incorporados ao sistema, refinados e corrigidos para a meta. Portanto, não se tratam somente de respostas instintivas, mas de comportamentos de ligação.Isto quer dizer que, provavelmente, por volta dos dois anos de idade já é possível ser observado o comportamento do apego porque a ontogênese ${ }^{*}$ destes sistemas está quase toda ativada ( BOWLBY 2002).

Ele destaca a necessidade de estímulos para favorecer o desenvolvimento destes sistemas comportamentais como os "estímulos auditivos provenientes da voz humana, os estímulos visuais provenientes do rosto humano e os estímulos táteis e cinestésicos oriundos dos braços e corpo humano"(p.330 e, caso presentes, aparece certa discriminação no comportamento.

BOWLBY (2002) dividiu o desenvolvimento do apego em fases.

\section{Fase 1}

Inicia-se ao nascimento, verificado pela capacidade de discriminação de figuras, denominada de orientação e sinais com discriminação limitada de figura (p.330), dura do nascimento até oito ou cerca de doze semanas de idade, ou mais, se em condições desfavoráveis. Segundo o autor, a capacidade de discriminação limita-se aos estímulos olfativos e auditivos. Seu comportamento com relação às pessoas ao seu redor se dá por meio de "movimentos oculares de acompanhamento, estender o braço e agarrar, sorrir e balbuciar" (BOWLBY 2002, p.330). Afirma que após este período as respostas sociais tornam-se mais intensas.

\footnotetext{
* Ontogenia- Desenvolvimento do indivíduo desde a fecundação até a maturidade para a reprodução. ...FERREIRA, ABH. Novo dicionário da língua portuguesa. .2 .ed., RJ:Ed Nova Front, 1996.p.1225.
} 
A par disso, BRUM e SCHERMANN (2004) corroboram tais conclusões quando fazem considerações profundas sobre os vínculos iniciais e desenvolvimento infantil e tecem comentários sobre a enorme capacidade do bebê em interagir tal como um bebê de seis dias reconhecer sua mãe pelo olfato.

\section{Fase 2}

Esta fase foi denominada Orientação $e$ sinais dirigidos para uma figura discriminada ( ou mais de uma) (BOWLBY 2002, p.331). Em linhas gerais, o autor descreve a criança mantendo-se amistosa, como na fase anterior, mas de forma mais acentuada com a figura materna. Para ele, as respostas diferenciais para os estímulos auditivos e visuais ocorrem mais facilmente após quatro semanas e as visuais não antes de dez. Esta fase dura cerca de seis meses ou mais e BRUM e SCHERMANN (2004) descrevem opiniões que estas respostas aparecem em tempo menor.

\section{Fase 3}

Corresponde à manutenção da proximidade com uma figura discriminada por meio de locomoção ou de sinais (BOWLBY 2002, p.331), no qual o bebê aumenta sua capacidade de discriminação com as pessoas e as respostas ampliam-se, especialmente com a mãe. Segue-a quando ela se afasta, alegra-se ao seu regresso usando-a como base para suas explorações. Começa, portanto, a declinar a indiscriminação com pessoas e passa a selecionar alguma, são as "figuras subsidiárias do apego"(p.331), desse modo, estranhos são tratados com crescente cautela. Destaca que alguns sistemas mediadores do comportamento de apego bebê/mãe tornam-se organizados, assim fica evidente o apego do bebê à figura materna. 
Esta fase se inicia entre os seis e sete meses. Em bebês com ausência da figura materna a fase pode ser retardada até após um ano e continua durante os dois e parte dos três anos de idade.

\section{Fase 4}

Esta última é denominada de Formação de uma parceria corrigida para a meta. Trata-se da habilidade da criança em perceber que a mãe tem seus próprios desejos e necessidades, separados dos dela e aprender a lidar com isto. É a capacidade da criança em compreender o que a mãe deseja ou quer. BOWLBY (2002) afirmou que esta transformação tem mais chance de ocorrer por volta dos quatro a cinco anos de idade, sendo que aos três é possível apenas para uma minoria deles e declarou:

$$
\begin{aligned}
& \text { “(....) desse ponto em diante, a visão que a criança tem do mundo } \\
& \text { torna-se potencialmente mais flexível (....) Pode-se afirmar que a } \\
& \text { criança passa a adquirir um discernimento intuitivo sobre os } \\
& \text { sentimentos e motivos da mãe. Uma vez atingido este ponto, estão } \\
& \text { lançadas as bases para desenvolver um relacionamento mútuo muito } \\
& \text { mais complexo, ao qual dou o nome de parceria.”(BOWLBY 2002, } \\
& \text { p.332) }
\end{aligned}
$$

Afirmou que, evidentemente, trata-se de uma nova fase e presente em algumas crianças na metade do terceiro ano de vida. Não obstante, enfatizou que é arbitrário afirmar em qual fase a criança se tornou apegada, pois se torna necessário avaliar todo o processo deste desenvolvimento comportamental para concluir tal coisa. Nesse sentido, para ele o comportamento de apego pode ser compreendido como a "busca e a manutenção da proximidade de um outro indivíduo" (p.240). Asseverou que a existência do 
comportamento de apego precisa ser comprovada como, por exemplo, observar se o bebê vai chorar quando a mãe sair do quarto ou se vai chorar e tentar seguí-la.

Quando procurou comparar o desenvolvimento de outras espécies de animais com o homem, descrito como o comportamento do apego e seu lugar na natureza, destacou que outras espécies podem movimentar-se livremente em pouquíssimo tempo. A relação mãe-filhote é bastante próxima e ao afastamento de um deles logo há a procura da proximidade, principalmente do filhote. Nestas relações existe, portanto, o reconhecimento individual e um comportamento altamente diferenciado, pais e filhos diferenciam suas espécies.

Nas suas observações em primatas concluiu que a mãe se mantém como figura fundamental nos primeiros meses de vida garantindo a proximidade de suas crias e, assim, proteção. Destaca, ainda, que mesmo entre os animais, o apego a pais adotivos é comum. Descrevendo o curso do comportamento de apego no homem concluiu que o comportamento de apego leva mais tempo para aparecer, por nascer muito imaturo e seu desenvolvimento ser mais lento (BOWLBY 2002).

Assim, destacou a diferença entre "dependência" e apego, como o caso do bebê que está extremamente dependente da mãe nas primeiras semanas de vida, mas ainda não está apegado e reafirma que até os seis meses não se evidencia o apego. E, por conseguinte mostrou que por volta dos três anos a criança aceita mais a ausência da mãe e é mais capaz de estar em lugar estranho, mas com pessoas conhecidas, sugerindo que nesta idade ultrapassou-se algum limiar de maturação (BOWLBY 2002). 
Trabalhos semelhantes foram realizados para identificar o desenvolvimento do comportamento do apego, sob a visão de Schaffer e Emerson, citados por BOWLBY (2002), as manifestações ocorrem antes mesmo dos 4 meses ou às vezes somente após os 12 meses. BRUM e SCHERMANN (2004) destacam que pesquisas de Brazelton, Scherman et al, Schaffer, Wendland-Carro et al, Klaus e Kennel, Claussen e Crittenden revelaram a enorme capacidade do bebê em interagir, desde os primeiros minutos de vida, inclusive discriminando mediante estímulos. Referem que os trabalhos de Ainsworth comprovaram comportamento de apego entre bebês e mostraram que aos seis meses ele já está presente, mais forte e consolidado.

Nos estudos desta autora ficou evidente que o desenvolvimento do comportamento de apego pode ocorrer de maneiras diferentes e por isso surgiu a necessidade de distinguí-los. Algumas condições foram descritas como favoráveis ao bom desenvolvimento do apego a uma figura e, novamente, a sensibilidade e interação da mãe com o bebê. AINSWORTH (2004) relacionou possíveis razões, tal como a fome, fadiga, doença, infelicidade, como também uma criança "alarmada", como fatores desencadeantes ao desenvolvimento dos tipos de comportamento de apego. Por exemplo, o aumento do choro ou o choro e busca a alguém familiar são formas de manifestação destes tipos de comportamento.

Foi observado que um padrão de interação adquirido entre os pares no primeiro ano de vida, persiste até dois ou três anos mais nos trabalhos de Appell e David citados por BOWLBY (2002), tal como o padrão exploratório do bebê em relação à figura materna, o qual corroborou suas observações. 
Mary Ainsworth pode ser considerada a co-fundadora da teoria do apego, pois contribuiu com os conceitos de que o cuidador é como uma base segura na qual a criança pequena explora o ambiente (ZIMBEROFF e HARTMAN 2002). A este respeito, BOWLBY (2002) determina que para qualquer tipo de comportamento juvenil que resulte em proximidade pode ser considerado como "comportamento de apego", e chama a reciprocidade do comportamento dos pais aos filhos de "comportamento de cuidar".

Em seu estudo longitudinal, AINSWORTH (2004), em Baltimore, observou o comportamento de apego da criança durante os primeiros doze meses de vida e avaliou diferenças na organização desses comportamentos através de sessões, em laboratório, usando brinquedos com e sem a mãe. Realizou uma seqüência de estudos que culminou numa classificação, o SSP ( Strange Situation Procedure), de bebês seguramente apegados ou inseguramente apegados, em pólos opostos na classificação. Com efeito, baseado no conceito de Bowlby no qual a segurança é um sentimento que pode ser experimentado no contexto do apego. Posteriormente, surgiram outros três padrões de classificação: seguramente apegado à mãe, a maior parte da amostra da população de seu estudo, ansiosamente apegados à mãe e esquivos, ansiosamente apegados à mãe $e$ resistentes (VAUGHUN e HELLER 1998; BOWLBY 2002; HONIG 2202; ZIMBEROFF e HARTMAN 2002; WATERS 2004; VAN IJZENDOORN et al 2004; BRUM E SCHERMANN 2004). 
Em última análise, estas classificações permitiram estabelecer distinção entre os tipos de comportamento e deste modo, facilitadores na identificação de supostos problemas de comportamento.

Posto isso, artigos recentes assinalam a importância do apego materno com o desenvolvimento infantil, tais como, BRUM e SCHERMANN (2004) ao destacarem que um apego seguro levará a um bom prognóstico dos desenvolvimentos afetivo, social e cognitivo em crianças. Também Ramires (2003) supõe ser possível estabelecer uma articulação entre o desenvolvimento cognitivo e afetivo com a teoria do apego e que são indissociáveis do processo do desenvolvimento infantil.

Nesse sentido, Bowlby referiu que o modo como a mãe cuidará do bebê pode ser percebida até antes do nascimento, mencionou vários estudos que corroboram esta afirmação e, portanto, supõe que bebês com mães mais responsivas se desenvolverão diferentemente daqueles em que as mães têm menos responsividade.

Finalmente, BOWLBY(2002) asseverou a importância da mãe e sua participação no comportamento da criança, afirmando que "assim como as características iniciais de um bebê podem influenciar o modo como a mãe cuida dele, também as características iniciais da mãe podem influenciar o modo como o bebê lhe responde"(p.425).

Outrossim, reafirma que, com base em numerosas provas, a mãe tem um papel extremamente importante na determinação do comportamento de apego que a criança desenvolverá. Para finalizar, BOWLBY (2002), no último capítulo do primeiro volume de sua trilogia, procura esclarecer a diferença que existe entre apego e comportamento de apego. De sua exposição compreende-se que qualquer criança apegada se refere 
àquela que tem à disposição, em buscar o contato ou proximidade a alguém de seu interesse, seja para o que for, concluindo, desse modo, fazendo parte da característica de qualquer criança e, portanto, não se modifica. Por outro lado, o comportamento de apego é qualquer modo de comportamento que a criança adota para obter ou manter a proximidade a alguém e, nesse sentido, (....) “depende em, alto grau, das condições que prevalecerem no momento.” (p.462). Em suma, supõe-se que esta capacidade da criança só será alcançada conforme a sensibilidade com que as tratarem. 


\section{OBJETIVOS}

\subsection{GERAL}

Verificar a evolução do crescimento e desenvolvimento neuropsicomotor de crianças nascidas com menos de $2.500 \mathrm{~g}$ na cidade de Mauá.

\subsection{ESPECÍFICOS}

- Caracterizar os recém-nascidos de baixo peso ao nascer segundo variáveis prédeterminadas com relação às fases gestacional, parto, período neonatal precoce, pósneonatal e variáveis do crescimento e desenvolvimento.

- Identificar relações de risco ou proteção entre as variáveis de desfecho, que são o crescimento e o desenvolvimento neuro-psicomotor e as variáveis independentes.

- Caracterizar o papel de adequação da relação do apego mãe-criança nessa associação com o crescimento e desenvolvimento. 


\section{METODOLOGIA}

\subsection{TIPO DE ESTUDO}

Trata-se de um estudo de coorte retrospectivo.

A escolha do estudo se justifica, pois se caracteriza como uma investigação que segue o curso normal dos acontecimentos, da causa, ou da exposição, em direção ao efeito. Também permite avaliar a relação causal entre os dois eventos (PEREIRA 2001).

FORATTINI (1996), afirma que "no estudo retrospectivo de coorte, o procedimento baseia-se na focalização de grupo de pessoas, a qual se sabe terem sido expostas ao fator objeto da pesquisa, em algum tempo passado, e seguido por determinado período" (p. 103).

O grupo escolhido desta pesquisa apresenta características exigidas para este tipo de estudo. Primeiro, é possível realizar a investigação exposição-doença, segundo, a cronologia dos acontecimentos está facilmente determinada, inicialmente ocorrendo a exposição, depois o desfecho clínico.

Com base nestas considerações, um desenho deste estudo pode ser estabelecido conforme se vê na Figura 1 . 


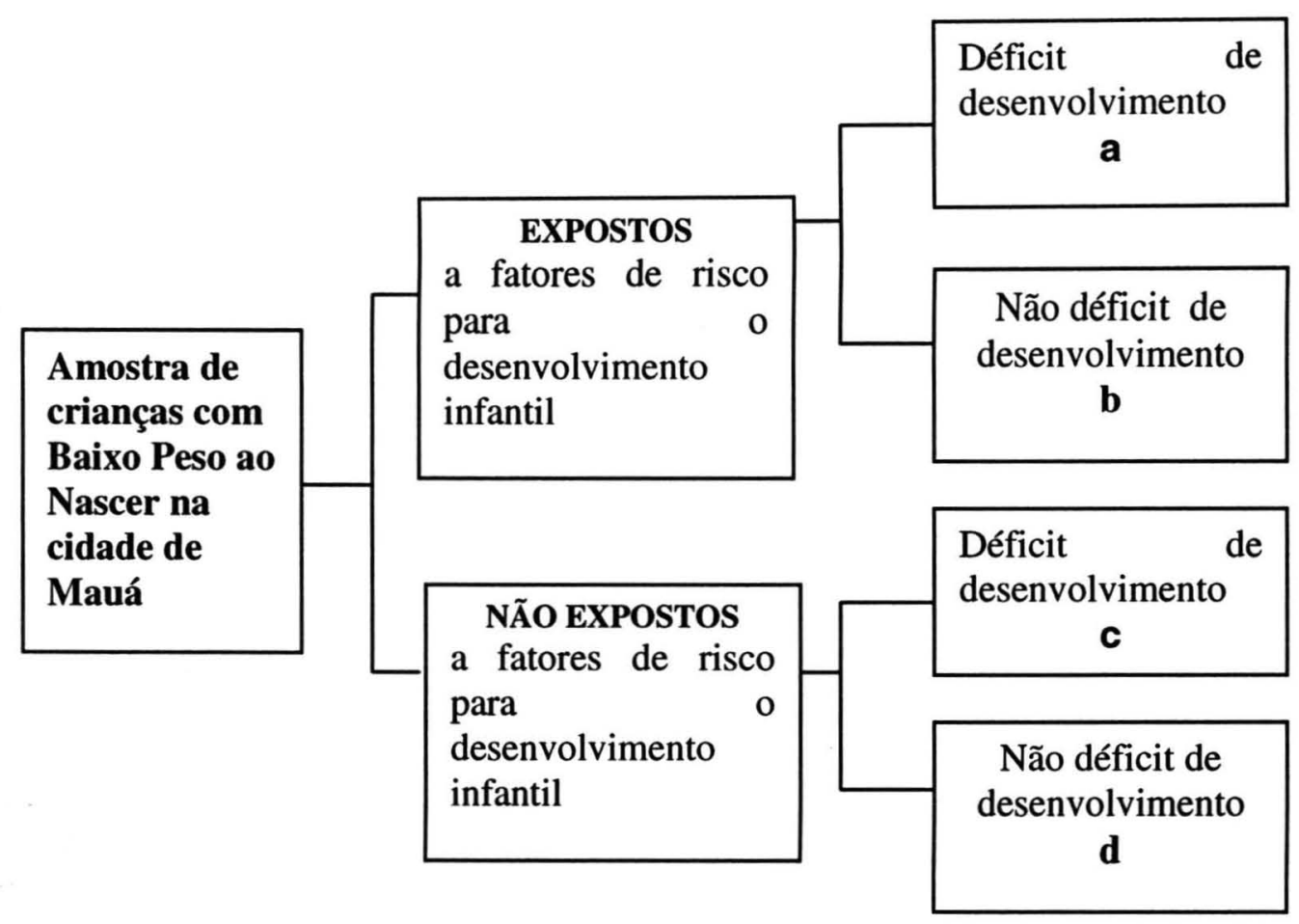

Figura 1 . DESENHO DO TIPO DE ESTUDO 


\subsection{OBJETO DE ESTUDO}

Evolução do crescimento e desenvolvimento de crianças nascidas com peso inferior a $2.500 \mathrm{~g}$.

\section{3 UNIVERSO DA PESQUISA}

\subsubsection{POPUlaÇÃo DE ESTUdO}

O grupo corresponde à amostra de 86 crianças da população total de nascidas e residentes no município de Mauá em 2001, com baixo peso ao nascer (menor de $2.500 \mathrm{~g}$ ) e ambos os sexos, do nascimento até os três ou quatro anos de idade.

\subsubsection{CARACTERIZAÇÃo do MUNicíPIO de MAUÁ}

A população em 2002 correspondia a um total de 377.780 habitantes.

\section{HISTÓRIA}

A cidade de Mauá surgiu em 1553, por meio da criação do primeiro povoado da Região do Grande ABC, a Vila de Santo André da Borda do Campo. Em 1560, esta Vila foi transferida para São Paulo de Piratininga devido aos ataques indígenas e foram necessários 300 anos para deixarem de pertencer à cidade de São Paulo, através da Lei 
provincial 38 (em 1889). Estes municípios só conseguiram sua emancipação a partir dos $\operatorname{anos} 40$.

Foi no início do século XVIII que se encontraram documentos que falam do território de Mauá, chamada como “Caçaguerra”, significando "Cercados Velhos”. Com o início das ferrovias, em 1860, ela começou a se destacar. A formação do município está ligada ao pequeno núcleo desenvolvido em torno da Capela de Nossa Senhora do Pilar (1799-1800). A Vila do Pilar passou a ser denominada Pilar, depois por Mauá, em 1926, em homenagem a Irineu Evangelista de Souza, o Barão de Mauá, que participou das obras da ferrovia ( MAUÁ 2004).

Seu desenvolvimento econômico inicial foi através do extrativismo de lenha, carvão e pedreiras, e também olarias. De 1923 a 1944 desenvolveu-se industrialmente com fábricas de cerâmica e porcelana, como as porcelanas Schmidt. O município passou a ser chamado de "Cidade da Porcelana".

Outra atividade importante está ligada à indústria petroquímica, com o Polo Petroquímico localizado em Capuava desde a década de 50.

O município desmembrou-se de Santo André pela Lei 2.456 de 30 de dezembro de 1953, em que se emancipou político-administrativamente ( HÉRCULES 2003; MAUÁ 2004).

\section{CARACTERÍSTICAS GEO- FÍSICAS}

Possui uma área urbana de $62,22 \mathrm{~km}^{2}$, sem área rural, mas com uma área de proteção de mananciais de $12,44 \mathrm{~km}^{2}$, conforme se observa na Figura 2. 
Quanto à Hidrografia, caracteriza-se por inúmeras nascentes e corpos d'água, mas a ocupação do território se deu de forma desordenada e sem atitudes reguladores do poder público. Assim, grande parte se encontra contaminada por esgotos domésticos ou efluentes industriais e ou irregularidade na disposição dos resíduos sólidos. Portanto, o aproveitamento adequado para lazer e paisagem está comprometido. O rio Tamanduateí nasce em Mauá, no Parque Municipal da Gruta de Santa Luzia. Infelizmente o rio está poluído, bem como outros afluentes; há deficiência da coleta de lixo em bairros, tais como Oratório, em que a disposição de lixo ocorre nos córregos. Esta somatória de problemas vem contribuindo para o aumento da poluição e comprometendo a saúde pública. Os corpos d'água da Área de Proteção e Recuperação dos Mananciais ainda conseguem manter suas características naturais, pelas restrições quanto à ocupação, mas a contaminação por esgotos domésticos vem ocorrendo (MAUÁ 2004).

A principal característica do Relevo é a elevada amplitude existente junto aos limites com São Paulo na porção centro-norte. Os trechos de maiores declividades são observados a partir do bairro Parque Bandeirante, na vertente oposta à Vila São João.

No final da década de 50 houve a implantação de loteamentos em Mauá, em áreas esparsas, porções menos íngremes do relevo, com exceção de duas áreas, as glebas A e B do Jardim Zaíra (norte do município) e a região de Vila Aparecida. Mas, na década de 60 , a expansão horizontal vem ocorrendo nas áreas mais íngremes, com predomínio de terraços, patamares de morros, morros e crestas, representando $80 \%$ da área total do Município. 


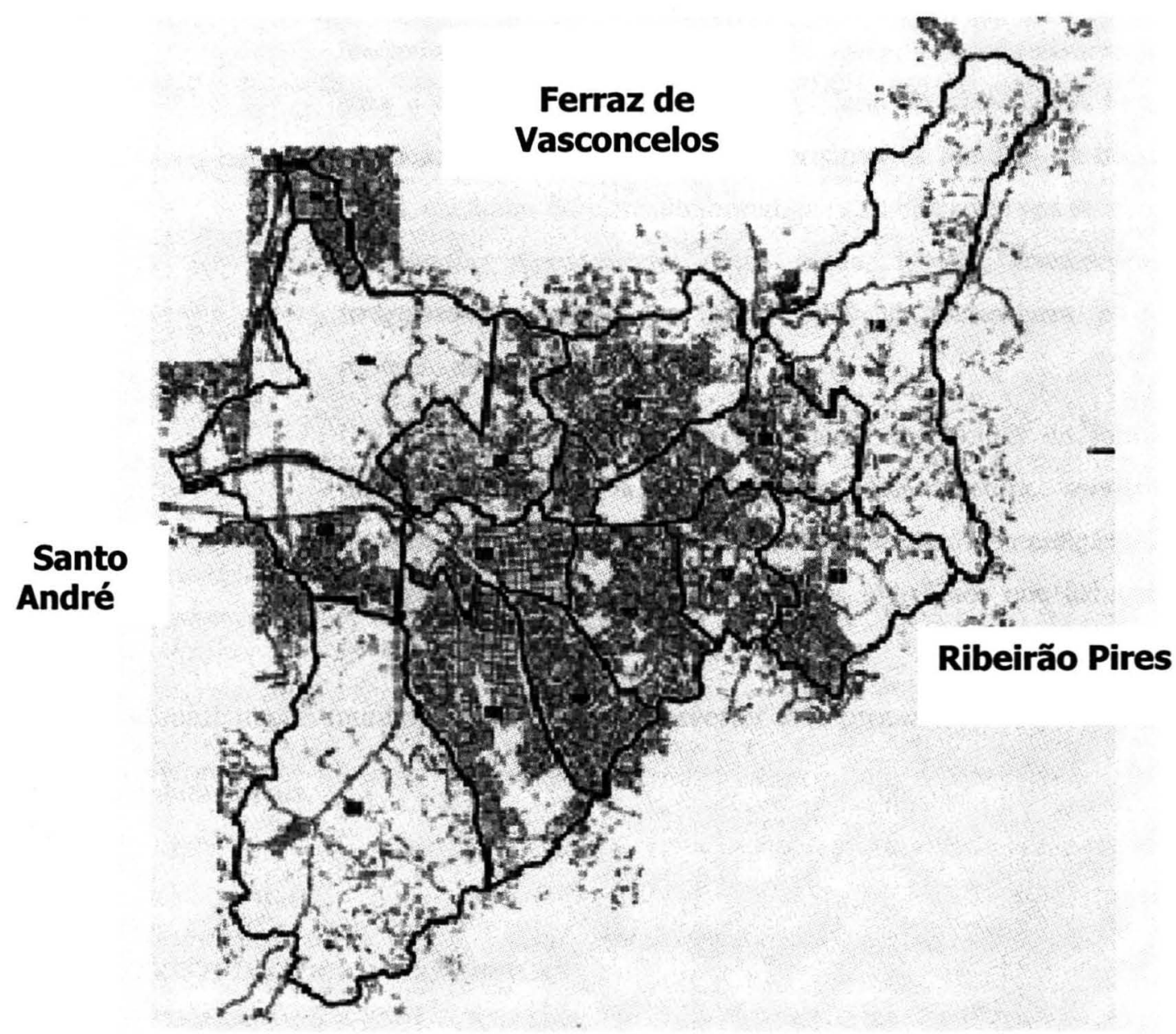

Figura 2. Mapa do município de Mauá, localizado na Grande São Paulo, com suas principais vias de acesso. 2005.

Fonte: http:// www.maua.sp.gov.br/perfil .[ acesso em 2005jan 15], 2005. 
A questão habitacional de Mauá ocorreu conforme descrito anteriormente, de forma desordenada e acelerada, mais na década de 70 , com o grande crescimento demográfico.

A falta de uma legislação urbanística, que fizesse com que a propriedade cumprisse o seu papel social, articulado aos mecanismos do mercado imobiliário, contribuiu significativamente para a expansão e construção da periferia da cidade. As áreas periféricas se apresentam como alternativa às famílias de baixa renda, excluídas do mercado formal, para viabilizarem seu sucesso à moradia; reproduzindo, desse modo, favelas, loteamentos irregulares/clandestinos em áreas públicas, particulares e de proteção de mananciais.

Os núcleos habitacionais são geralmente abastecidos de forma insuficiente, quanto à instalação de infra-estrutura, serviços urbanos e equipamentos públicos, ocasionando a interdição da riqueza social e cultural da cidade aos indivíduos que habitam nesses núcleos (MAUÀ 2005).

A administração municipal vem tentando reverter este processo com programas e projetos habitacionais.

\section{CARACTERísticas Sócio- ECONÔMICAS}

Segundo pesquisas sócio-econômicas realizadas em Mauá em 1998, a população possui uma renda per capita baixa, com 1,39 salário mínimo. As mesmas fontes apontaram que $67,16 \%$ têm um rendimento mensal de até três salários mínimos. A maioria dos trabalhadores, $48,82 \%$, possui ocupação em Mauá e o restante praticamente nas regiões do $\mathrm{ABC}$. 


\section{SAÚde de MAUÁ}

$\mathrm{O}$ processo de municipalização se iniciou na década de 80 . Atualmente a rede municipalizada de saúde é composta por:

- "Rede de Unidades Básicas de Saúde: 20 unidades, das quais 06 (seis) dotadas do Programa de Saúde da Família (PSF) e 14 do Programa do Agente Comunitário (PACs);

- Laboratório (instalado no Hospital Nardini);

- Centro de Reabilitação Dr. Jayme de Souza (Instalado na USF Central);

- Ambulatório de Saúde Mental (UBS Central e equipes de saúde mental na UBS Flórida e USF Jd. Zaira I);

- Ambulatório DST/Aids - COAS Centro de Orientação e Apoio Sorológico Beija Flor (Instalado na USF Central);

- Centro de Controle de Zoonoses - CCZ

- Hospital geral Nardini

- Santa Casa Municipal” (MAUÁ 2005).

\section{Aspectos epidemiológicos}

A variação do índice de mortalidade infantil de Mauá, no período de 1996 a 2003 foi de 27,94 para 17,15 . Com a mesma tendência quanto ao coeficiente de mortalidade perinatal, conforme se verifica no Tabela $A$ e a seguir o Tabela $B$ que mostra que a taxa de natalidade vem diminuindo e a Figura 3 que representam o número de nascidos vivos 
com baixo peso entre o ano de 1997 até 2003 na qual se observa uma diminuição de nascidos neste grupo.

Tabela A . Coeficientes de Mortalidade Infantil e Perinatal. Mauá,1990 - 2003

\begin{tabular}{|c|c|c|c|c|c|c|}
\hline \multicolumn{7}{|c|}{ Coeficiente de Mortalidade Infantil (1) } \\
\hline \multirow{2}{*}{ Ano } & \multicolumn{3}{|c|}{ Neonatal } & \multirow{2}{*}{ Pós-neonatal } & Total & Perinatal (1) \\
\cline { 2 - 7 } & Precoce & Tardia & Total & & & \\
\hline 1990 & 17,96 & 4,91 & 22,87 & 11,08 & 33,95 & 28,59 \\
\hline 1991 & 19,16 & 2,44 & 21,60 & 10,37 & 31,97 & 27,70 \\
\hline 1992 & 20,09 & 4,99 & 25,08 & 9,71 & 34,78 & 26,13 \\
\hline 1993 & 16,10 & 3,89 & 19,99 & 9,93 & 29,92 & 25,39 \\
\hline 1994 & 16,69 & 2,87 & 19,56 & 6,91 & 26,47 & 26,97 \\
\hline 1995 & 12,79 & 3,26 & 16,05 & 8,35 & 24,40 & 23,74 \\
\hline 1996 & 15,16 & 4,61 & 19,77 & 8,17 & 27,94 & 23,90 \\
\hline 1997 & 11,40 & 2,35 & 13,75 & 5,95 & 19,70 & 21,82 \\
\hline 1998 & 13,63 & 2,43 & 16,06 & 6,70 & 22,76 & 24,23 \\
\hline 1999 & 11,21 & 3,58 & 14,79 & 4,97 & 19,76 & 22,62 \\
\hline 2000 & 11,08 & 2,90 & 13,98 & 4,78 & 18,76 & 21,67 \\
\hline 2001 & 10,12 & 3,85 & 13,97 & 5,56 & 19,52 & 22,10 \\
\hline 2002 & 8,49 & 3,57 & 12,06 & 4,32 & 16,38 & 20,31 \\
\hline 2003 & 9,03 & 2,56 & 11,58 & 5,57 & 17,15 & $(2)$ \\
\hline Fonte: Fundação Seade. (1) por mil nascidos vivos. $(2)$ Dados não disponíveis. \\
\hline
\end{tabular}

Fonte: http:// www.maua.sp.gov.br/perfil .[ 2005jan 15], 2005a. 
Tabela B . Nascidos vivos segundo sexo e taxas de natalidade do município de Mauá $1989-2003$

\begin{tabular}{lcccc}
\hline \multicolumn{5}{c}{ Sexo } \\
\hline Ano & Masculino (1) & Feminino (1) & Total (1) (2) & Taxa (3) (4) \\
\hline 1989 & 3.759 & 3.570 & 7.329 & 26,65 \\
\hline 1990 & 3.601 & 3.527 & 7.128 & 25,10 \\
\hline 1991 & 4.267 & 3.929 & 8.196 & 27,96 \\
\hline 1992 & 3.754 & 3.661 & 7.415 & 24,65 \\
\hline 1993 & 3.834 & 3.619 & 7.453 & 24,18 \\
\hline 1994 & 3.880 & 3.788 & 7.668 & 24,29 \\
\hline 1995 & 3.870 & 3.793 & 7.663 & 23,71 \\
\hline 1996 & 3.821 & 3.766 & 7.587 & 22,95 \\
\hline 1997 & 4.095 & 3.976 & 8.071 & 23,86 \\
\hline 1998 & 4.370 & 4.286 & 8.656 & 24,99 \\
\hline 1999 & 4.473 & 4.179 & 8.652 & 24,39 \\
\hline 2000 & 4.019 & 3.923 & 7.942 & 21,90 \\
\hline 2001 & 3.541 & 3.476 & 7.017 & 18,99 \\
\hline 2002 & 3.411 & 3.306 & 6.717 & 17,84 \\
\hline 2003 & 3.430 & 3.217 & 6.647 & $(5)$ \\
\hline
\end{tabular}

Fonte: Fundação SEADE. (1) Para cômputo dos nascimentos, o instituto considera o local de residência habitual da mãe. (2) A diferença entre a soma dos nascidos vivos por sexo e os totais registrados deve-se aos nascidos vivos de sexo ignorado. (3) por mil habitantes. (4) As taxas de 1992 a 1999 foram alteradas em função de alterações verificadas em consulta ao site da Fundação SEADE, em 31/10/03. (5) Dados não disponíveis.

Fonte: http:// www.maua.sp.gov.br/perfil .[ 2005jan 15], 2005. 


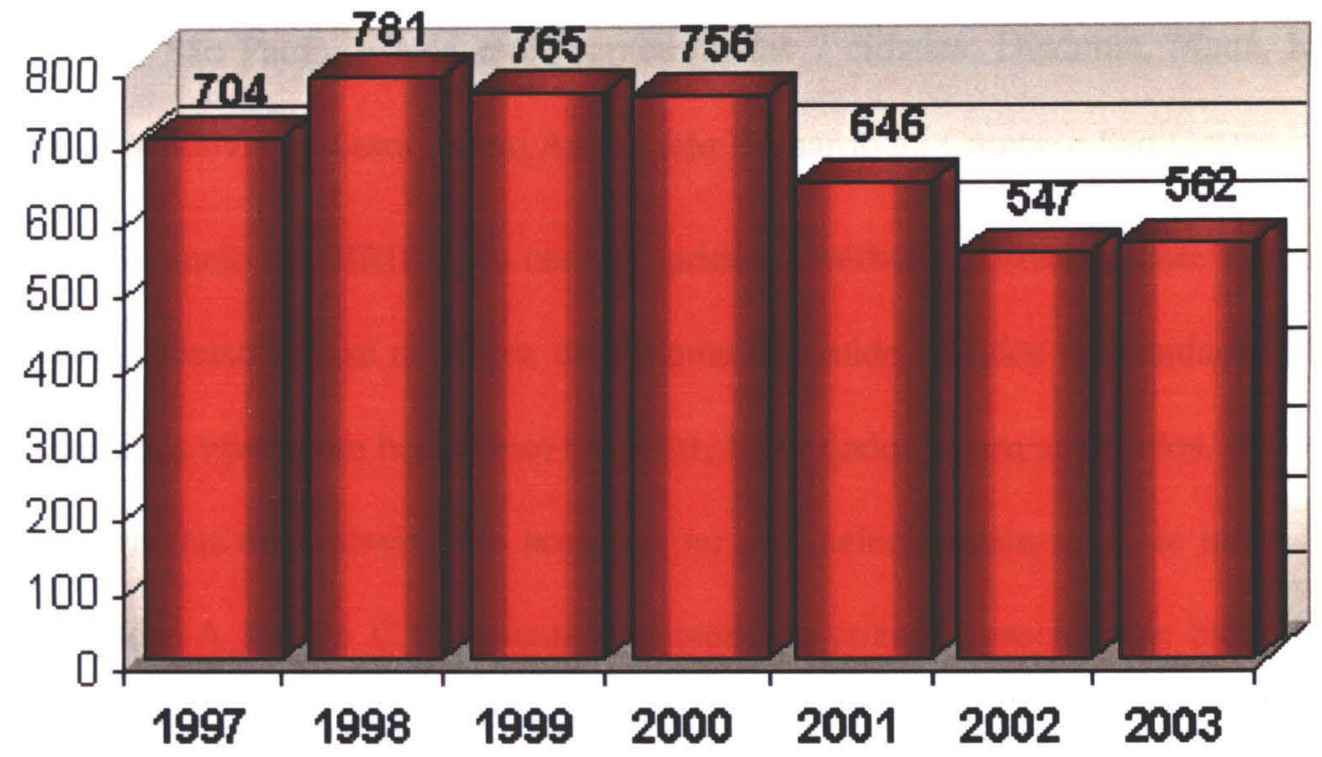

Figura 3 . Nascidos vivos com Baixo Peso . Mauá

Fonte: http:// www.maua.sp.gov.br/perfil .[ 2005jan 15], 2005. 


\subsubsection{ESCOLHA DA AMOSTRA}

\section{.Critérios da escolha}

A região do Grande $\mathrm{ABC}$ faz parte da Direção Regional de Saúde 2 (DIRII) do Estado de São Paulo, e nela estão representadas 7 cidades: Diadema, Mauá, Ribeirão Pires, Rio Grande da Serra, Santo André, São Bernardo do Campo e São Caetano do Sul.

Por meio da DIRII, após contato, primeiro verbal e posteriormente formalizado, obteve-se acesso à base de dados do Sistema de Saúde, obtidos da Fundação SEADE, dos nascidos vivos com baixo peso em 2001. Estes dados foram analisados, observandose as variáveis disponíveis para acesso e, no qual selecionaram-se as de interesse para este estudo. A Tabela $C$ representa o número de crianças nascidas de baixo peso ao nascer nos municípios do $\mathrm{ABC}$. Nota-se o predomínio de crianças nascidas com baixo peso em quatro cidades, Diadema, Mauá, Santo André e São Bernardo do Campo.

Tabela C- Nascidos vivos com baixo peso em 2001- Freqüência por município e residência-DIRII-SP

\begin{tabular}{ccccc}
\hline Munic Resid- SP & $\begin{array}{c}\text { 0g a 999g } \\
\text { (Extr. BP) }\end{array}$ & $\begin{array}{c}\text { 1000g a 1490g } \\
\text { (MBP) }\end{array}$ & $\begin{array}{c}\text { 1500g a 2499g } \\
\text { (BPN) }\end{array}$ & Total \\
\hline Diadema & 135 & 66 & 690 & 891 \\
Mauá & 40 & 57 & 565 & 662 \\
Ribeirão Pires & 21 & 12 & 137 & 170 \\
Rio Gr. da Serra & 3 & 5 & 61 & 69 \\
Santo André & 83 & 85 & 770 & 938 \\
São B. do Campo & 127 & 97 & 967 & 1191 \\
São Caet. do Sul & 43 & 13 & 141 & 197 \\
\hline Total & 425 & 335 & 3331 & 4118
\end{tabular}

Fonte: Sistema de Nascidos Vivos - SEADE- DIRII/SP, 2004. 
Após a análise destes dados, realizaram-se algumas reuniões com representantes dos gestores de saúde destes municípios, com o intuito de viabilizar a pesquisa numa destas cidades.

Tendo em vista que o método para a coleta dos dados necessitaria da contribuição das equipes de saúde das redes básicas, definiu-se o município de Mauá como a área da pesquisa, pois ele conta com um Serviço na Atenção Básica de Saúde de PACs (Programa de Agentes Comunitários de Saúde) e PSF (Programa de Saúde da Família) bem estruturados.

O projeto foi encaminhado e autorizado pelo Secretário da Saúde do Município de Mauá e pelo Comitê de Ética em Pesquisa em Seres Humanos da Faculdade de Saúde Pública da Universidade de São Paulo, seguindo as exigências formais para tal procedimento.

Por meio da Secretaria de Saúde de Mauá se obteve o banco de dados dos Sistemas de Saúde, SIM (Sistemas de Informações sobre Mortalidade) e SINASC (Sistema de Informações sobre Nascidos Vivos), do total de nascidos vivos de Baixo Peso do município.

Estes sistemas são de base nacional, gerenciados pela Secretaria de Vigilância em Saúde e obtidos dos formulários das Declarações de Nascidos Vivos. O SIM informa o número de mortes de crianças menores de um ano, com a coleta constante de informações das declarações de óbitos (DO), já o SINASC tem como principal instrumento de informação a declaração de nascido vivo (DN), que após o preenchimento das vias, ao nascimento, a primeira é encaminhada à Secretaria 
Municipal de Saúde. Tanto os dados do SIM e SINASC seguem o mesmo fluxo, da Secretaria Municipal de Saúde para a Secretaria Estadual de Saúde e finalmente para o DASIS (Departamento de Análise de Situação de Saúde) da Secretaria de Vigilância em Saúde ( MS 2004).

A confiabilidade destas informações permitiu que se verificasse a situação dos Nascidos Vivos de Baixo Peso em Mauá que, em 2001, foi de 604 recém-nascidos. O total de óbitos de crianças menores de cinco anos, no período de 2001 a junho de 2004, também foi obtido. Estes dados, em DBF (base de dados em DeBase) foram convertidos em Versão para o Software Epi-Info, versão 6.0 e analisados, com os resultados descritos na Tabela $D$.

Tabela D. População de crianças com baixo peso ao nascer em 2001 e as sobreviventes até 2004, no município de Mauá-SP, 2004.

\begin{tabular}{|c|c|c|c|c|c|c|}
\hline \multirow[t]{2}{*}{$\begin{array}{c}\text { Peso ao } \\
\text { nascer }\end{array}$} & \multicolumn{2}{|c|}{2001} & 2002 & 2003 & $\begin{array}{l}1^{\circ} \text { sem. } \\
2004\end{array}$ & $\begin{array}{c}\text { Total de } \\
\text { sobreviventes }\end{array}$ \\
\hline & $\begin{array}{c}\text { Nascidos } \\
\text { vivos }\end{array}$ & \multicolumn{4}{|c|}{ óbitos } & \\
\hline$<1000 \mathrm{~g}$ & 20 & 17 & 0 & 0 & 0 & 03 \\
\hline $1000 \mathrm{~g} \mathrm{a}$ & 42 & 16 & 0 & 01 & 0 & 25 \\
\hline $1499 \mathrm{~g}$ & & & & & & \\
\hline $1500 \mathrm{~g} \mathrm{a}$ & 542 & 32 & 03 & 0 & 0 & 507 \\
\hline $2499 \mathrm{~g}$ & & & & & & \\
\hline Total & 604 & 65 & 03 & 01 & 0 & 535 \\
\hline
\end{tabular}

Fonte: SIM/ SINASC - Secretaria Municipal de Saúde de Mauá, SP, 2004. 
Nota-se que os dados da totalidade de Nascidos Vivos (NV) diferenciam-se daquelas fornecidas pela DIRII (SEADE), com 662 NV e da Secretaria Municipal da Saúde de Mauá (SIM, SINASC), 604. Com a exclusão dos óbitos obteve-se uma população total com baixo peso ao nascer de 535 crianças.

Também vale destacar que, os três sobreviventes com menos de $1000 \mathrm{~g}$ não foram localizados, um deles residente em outro município, outro foi a óbito e não referido no Sistema de Informação, e o último com endereço inexistente. Portanto, praticamente não houve bebês com menos de $1000 \mathrm{~g}$ sobreviventes.

Identificou-se pela DNV 16 crianças nascidas com má formações congênitas e foram excluídas da amostra aquelas que apresentaram síndromes relacionadas ao Sistema Neurológico.

Através do código desta variável identificaram-se os tipos de síndromes conforme a relação descrita a seguir (OMS, 1997):

- Q000- Anencefalia

- Q668- Outras deformidades congênitas do pé.

- Q709- Sindactilia, não especificada.

- Q189- Malformação congênita não especificada da face e do pescoço.

- Q909- Síndrome de Down não especificada ( Trissomia 21 SOE).

- Q039- Hidrocefalia congênita não especificada.

- Q718- Outros defeitos de redução do membro superior.

- Q898- Outras malformações congênitas especificadas, não classificadas em outra parte. 
- Q875- Outras síndromes com malformações congênitas com outras alterações do esqueleto.

- Q02- Microcefalia.

- Q731- Focomelia, membro(s) não especificado(s).

- Q521- Duplicação da vagina. Vagina septada.

Destes 16 nascidos vivos, nove foram a óbito e o restante não foi localizado, portanto, não fizeram parte da amostra crianças nascidas com malformação congênita diagnosticada pela DNV. Importante destacar que no período da coleta de dados uma das crianças foi referida como ser portadora de uma cardiopatia congênita e ter sido submetida à cirurgia. Esta criança não foi excluída da amostra por não corresponder ao critério determinado de exclusão, ou seja, as malformações associadas aos déficits neurológicos.

A estratégia da coleta de dados, descrita anteriormente, procurou atingir o número esperado, contudo, obteve-se um total de atendimentos inferior ao esperado, assim, caracterizou-se como amostragem de caráter não probabilístico por conveniência. 


\section{.Procedimentos para a localização da população}

Após a obtenção do total da população sobrevivente, procedeu-se à busca ativa mediante os endereços da residência da mãe por ocasião do nascimento; tal procedimento foi possível graças ao banco dos dados secundários obtidos pela DN, referido anteriormente. Também foi solicitada à coordenação da Atenção Básica de Saúde de Mauá a listagem de logradouros do Município, distribuídos por Regiões e UBS (Unidades Básicas de Saúde). Deste modo, realizou-se uma listagem através do Programa Microsoft Access, que processou os dois bancos de dados, originando uma listagem com dados facilitadores à localização das crianças, conforme modelo em anexo (Anexo 2).

Esta estratégia foi adotada tendo em vista que a Saúde de Mauá está municipalizada, composta por rede de Unidades Básicas de Saúde: 20 unidades, das quais 06 (seis) dotadas do Programa de Saúde da Família (PSF) e 14 do Programa do Agente Comunitário (PACs), alocadas em todo o município, conforme a relação a seguir apresentando as unidades por regiões.

\section{Região 1}

- USF Vila Carlina

- UBS Jardim Guapituba

- UBS Parque São Vicente

- USF Jardim Primavera

- UBS Vila Assis 


\section{Região 2}

- UBS Capuava

- UBS Magine ou Central

- USF Jardim Oratório

- USF Paranavaí

- UBS e UPA ( Unidade de Pronto Atendimento) Sônia Maria

\section{Região 3}

- USF Jardim Zaíra 1

- UBS e UPA Jardim Zaíra 2

\section{Região 4}

- UBS e UPA Jardim Flórida

- UBS Jardim Itapark

- USF Parque das Américas

- UBS Santa Lídia

\section{Região 5}

- USF Jardim Feital

- USF Jardim Mauá

- UBS Jardim Santista

- USF e UPA Vila São João

Estas unidades foram referências para a busca ativa das crianças definidas na amostra. Portanto, as listagens foram elaboradas seguindo esta lógica, localização dos 
endereços distribuídos pelas 20 unidades. Das listas processadas pelo Software Access for Windows, localizou-se por Unidades e Logradouros, 192 crianças; em relação às restantes, o programa não processou o cruzamento.

Esta primeira procura foi determinada pelo próprio coordenador da Atenção Básica de Saúde do Município aos Coordenadores das Unidades em questão. Por ocasião da devolução das listagens com os respectivos relatórios, agendou-se uma reunião geral com os coordenadores para explicar detalhadamente os objetivos da pesquisa e a metodologia da coleta dos dados, bem como das dificuldades identificadas na coleta. Desta busca, 77 crianças foram localizadas e 39 não foi possível encontrá-las.

O maior motivo relatado foi pela ocorrência de uma grande migração desta população, muitas vezes dentro da própria região, o que impediu a localização de grande parte das crianças. Por outro lado, foi observado que o sistema de comunicação entre unidades ocorre de maneira bastante positiva, pois várias crianças foram localizadas por uma região e relatado o seu novo destino, inclusive com seu novo número de matrícula do SUS.

Após este primeiro contato, o pesquisador principal dirigiu-se a todas as unidades, com agendamento prévio junto ao coordenador. Esta etapa teve o intuito de conhecer o local, verificar a disponibilidade de salas para a consulta e agendar a data da convocação das crianças, bem como definir, exatamente, quais as condições do serviço disponibilizar os agentes comunitários de saúde para executar a convocação. 


\section{. Convocação das mães}

$\mathrm{Na}$ execução deste procedimento foi necessário o uso de roteiros para a organizar todo o planejamento (anexos 3 e 4), neles identificou-se os dias de atendimento por respectiva unidade, e informações dos números de crianças a serem atendidas.

A relação dos endereços foi refeita, acrescentando outros endereços das listas dos não localizados. Isto foi possível, pois a nova busca ao banco de dados procedeu-se manualmente com auxílio do guia de endereços do município e dos próprios agentes comunitários que, por vezes, reconheciam logradouros correspondentes à sua região de abrangência.

Feito isto, os agentes comunitários de saúde possuíram em mãos a nova listagem e uma carta de convocação à mãe/ ou responsável da criança ( anexo 5) anexada a um lembrete do dia da entrevista e atendimento (anexo 6).

Os faltosos à primeira consulta foram convocados novamente, portanto, em todas as unidades houve uma segunda chamada. Alguns casos de interesse ao pesquisador, tal como os de muito baixo peso e que não compareceram ou não localizados, foram procurados pelo próprio pesquisador e assistentes.

Vale ressaltar que a região de abrangência dos agentes comunitários de saúde contempla todas as residências, independente se a família é ou não usuária do SUS, sendo assim, apareceram alguns casos de crianças usuárias de convênios médicos.

A Tabela $E$ mostra o total de crianças atendidas na pesquisa, por Unidades de Saúde. Foi verificado que na unidade Guapituba não se encontrou nenhuma criança 
nascida de baixo peso e no Parque São Vicente apenas uma, segundo relatos dos profissionais de saúde. A razão provável disso seria por estas regiões serem aquelas com melhores condições sociais, em que a população procura assistência médica em cidades vizinhas por possuírem serviços de saúde mais elitizados. Quanto à Unidade do Capuava, as crianças relacionadas não foram localizadas.

Tabela E. Amostra da população de crianças nascidas em 2001 na cidade de Mauá, com baixo peso ao nascer por Unidades Básicas de Saúde por Regiões, 2.004.

\begin{tabular}{|c|c|c|c|c|c|c|}
\hline \multirow{2}{*}{$\begin{array}{l}\text { Unidade Básica } \\
\text { de Saúde }\end{array}$} & \multicolumn{5}{|c|}{ REGIÁO } & \multirow[b]{2}{*}{ TOTAL } \\
\hline & 1 & 2 & 3 & 4 & 5 & \\
\hline Carlina & 4 & - & - & - & - & $4(4,7)$ \\
\hline Guapituba & 0 & - & - & - & - & $0(0,0)$ \\
\hline Pq. S. Vicente & 1 & - & - & - & - & $1(1,2)$ \\
\hline Primavera & 2 & - & - & - & - & $2(2,3)$ \\
\hline V. Assis & 2 & - & - & - & - & $2(2,3)$ \\
\hline Capuava & - & 0 & - & - & - & $0(0,0)$ \\
\hline Magine & - & 5 & - & - & - & $5(5,8)$ \\
\hline Oratório & - & 5 & - & - & - & $5(5,8)$ \\
\hline Paranavaí & - & 3 & - & - & - & $3(3,5)$ \\
\hline Sônia Maria & - & 3 & - & - & - & $3(3,5)$ \\
\hline Zaíra 1 & - & - & 7 & - & - & $7(8,1)$ \\
\hline Zaíra 2 & - & - & 4 & - & - & $4(4,7)$ \\
\hline Florida & - & - & - & 3 & - & $3(3,5)$ \\
\hline Itapark & - & - & - & 5 & - & $5(5,8)$ \\
\hline Pq. Américas & - & - & - & 6 & - & $6(7,0)$ \\
\hline Santa Lídia & -- & -- & - & 2 & & $2(2,3)$ \\
\hline Feital & - & - & - & - & 12 & $12(14,0)$ \\
\hline Jd. Mauá & - & - & - & - & 6 & $6(7,0)$ \\
\hline Santista & - & - & - & - & 8 & $8(9,3)$ \\
\hline São João & - & - & - & - & 8 & $8(9,3)$ \\
\hline TOTAL & $9(10,5)$ & $16(18,6)$ & $11(12,8)$ & $16(18,6)$ & $34(39,5)$ & $86(100,0)$ \\
\hline
\end{tabular}


Apesar do total de 86 crianças definidas para a amostra, compareceram à convocação 92. Destas, dois gêmeos que a mãe recusou o atendimento; uma foi embora antes de se encerrar a consulta; outra criança não havia nascido em 2001, entretanto, ela foi avaliada como as outras e a mãe foi orientada conforme a conduta. E, finalmente, duas outras crianças, que foram excluídas da amostra por apresentarem seqüelas graves após o nascimento.Uma apresentou aspiração por deficiência na sucção evoluindo para hipóxia e atualmente com paralisia cerebral, segundo relato da mãe. A segunda também apresenta déficit neurológico severo desenvolvido após o nascimento, mas a mãe não soube descrever o motivo.Os casos foram avaliados segundo o método estabelecido e estão descritos em anexo (Anexo 7).

Todo o processo, desde o primeiro levantamento dos dados até o início das convocações, ocorreu no período de junho a setembro de 2004. Algumas dificuldades surgiram, especialmente durante as reuniões com as unidades, porque a cidade estava em pleno processo final de eleição municipal e os coordenadores estavam com excesso de funções. Apesar disto, foi extremamente positiva a disponibilidade e colaboração de todas as equipes, sem exceção. Tal fato é merecedor de destaque, pois mostra o interesse e compromisso destes profissionais com a população. Esta pesquisa não seria possível sem esta preciosa ajuda.

A Figura 4 ilustra a distribuição da amostra desta população por todo o município e em seguida um fluxograma que sintetiza a busca e definição da amostra do estudo ( Figura 5). 
Figura 4. Distribuição da amostra de crianças nascidas em 2001 com baixo peso em todo o território do município de Mauá, SP, 2004.

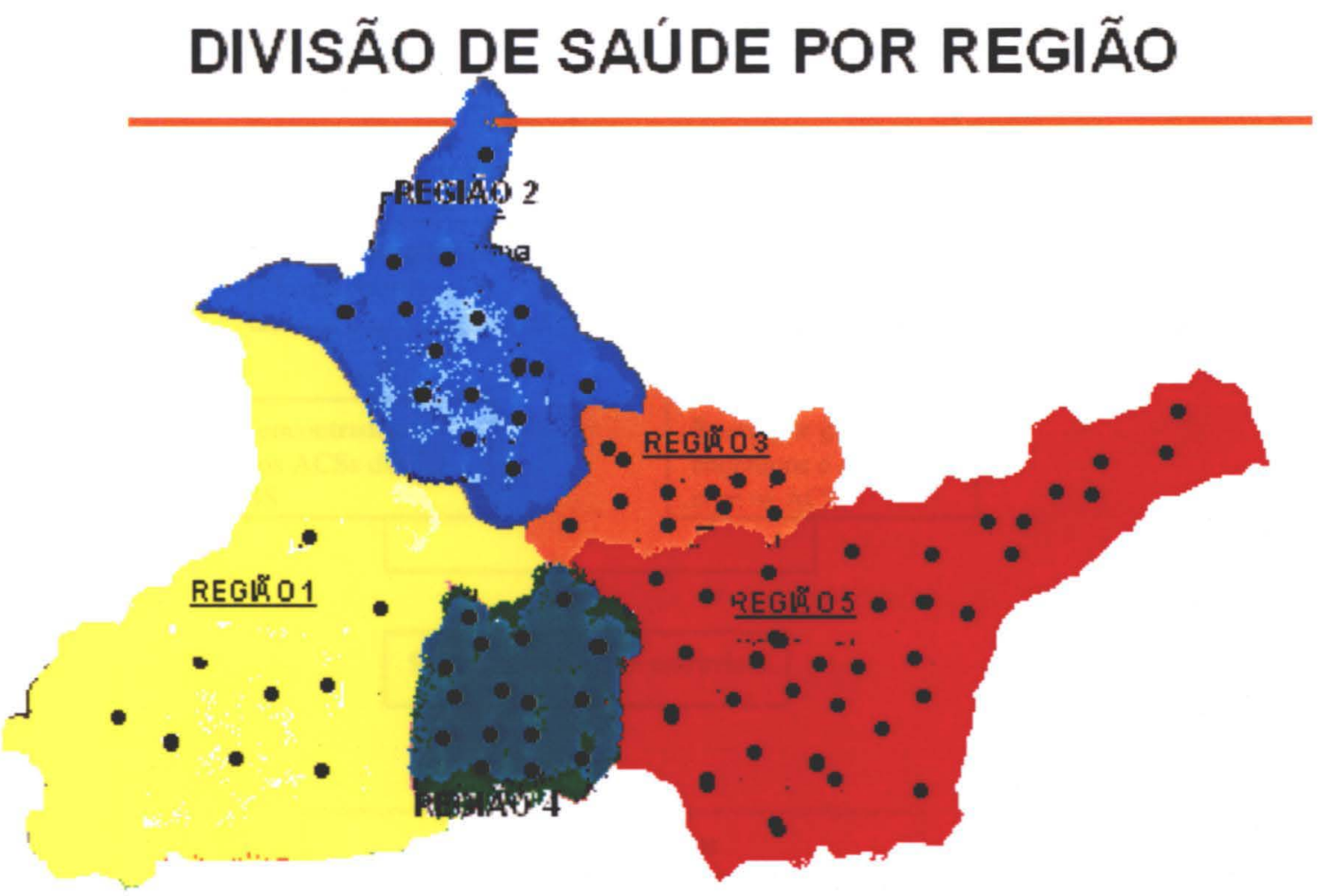

FONTE: SECRET ARIA DA SAÚdE DO MUNICÍPIO DE MAUÁ, SP.2004. (Documento modificado). 
Figura 5. FluXograma PARA DEFINIÇÃo dA AMOSTRA

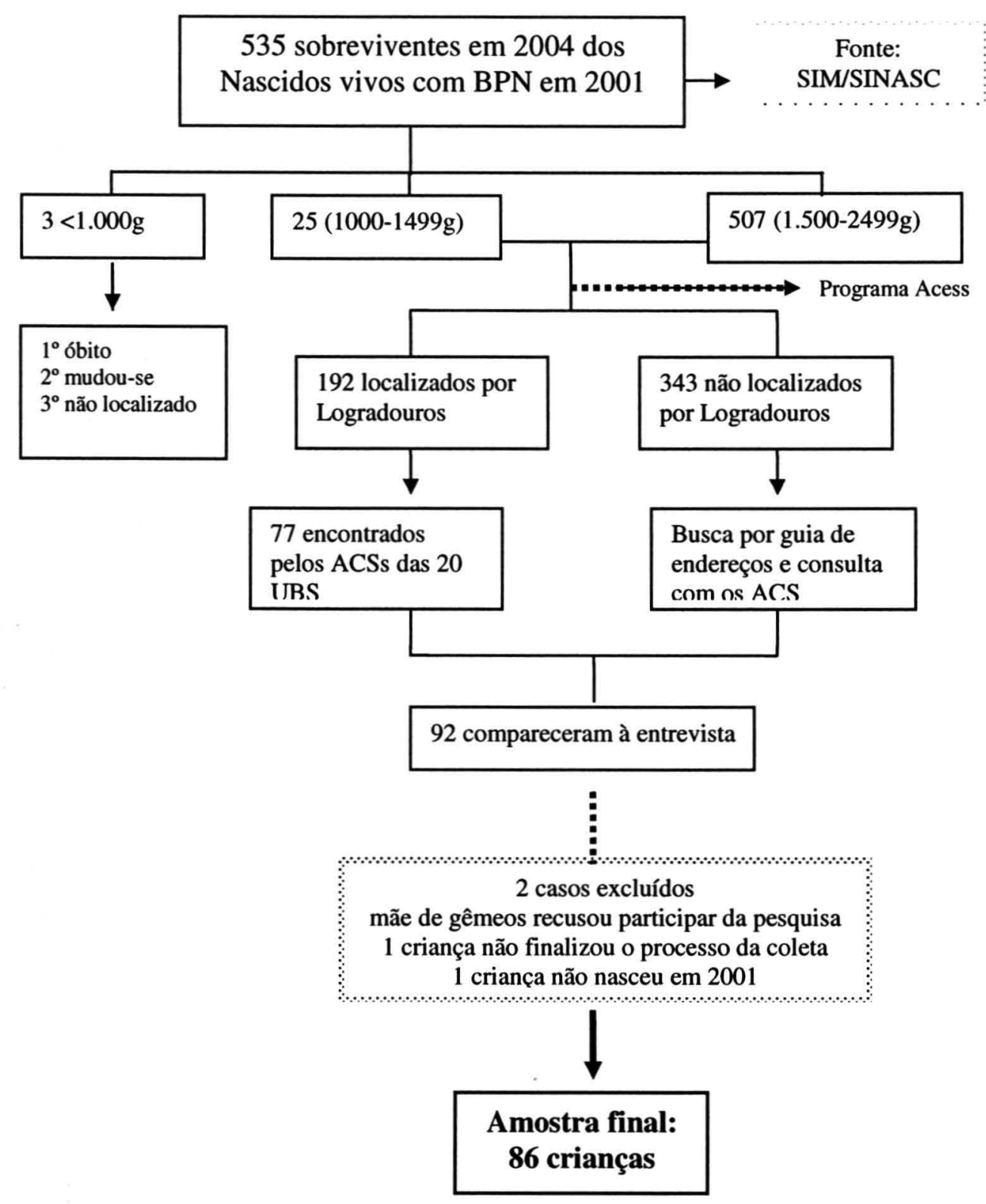




\subsection{Procedimentos da Coleta de dados}

Além do pesquisador principal, houve a necessidade de assistentes, portanto, os mesmos foram treinados quanto ao uso dos instrumentos e seus procedimentos para a coleta.

A coleta constituiu-se de quatro procedimentos: entrevista, antropometria, avaliação do desenvolvimento e avaliação do apego materno. Procurou-se agendar as mães com os filhos em horários alternados para evitar espera excessiva.

A entrevista e os outros procedimentos sempre foram realizados numa sala privativa, com a presença de mesa, cadeiras e divã. Quase sempre a consulta foi realizada em 2 salas, sendo que em uma delas havia os equipamentos para a aferição de peso e estatura, caso contrário, este procedimento ocorria na mesma sala.

\subsubsection{Entrevista}

Precedendo a entrevista, a mãe foi orientada quanto aos objetivos da pesquisa por meio do consentimento livre e esclarecido (Anexo 7), no qual aceitou ou não participar. Foi realizada uma entrevista (Anexo 8) com a mãe ou cuidador principal com o intuito de registrar informações acerca do histórico da criança, desde seu nascimento até sua vida atual. Neste questionário também se registraram os dados secundários obtidos através da DNV (Declaração de Nascidos Vivos) e registradas no banco de dados, 
conforme descrito anteriormente. Verificou-se o significado dos códigos das variáveis deste instrumento (Anexo 9) e as de interesse para a pesquisa foram selecionadas.

A entrevista era realizada em um espaço reservado pelo pesquisador principal e assistente. Optou-se por esta como primeiro procedimento, o que possibilitou um “aquecimento” para a descontração; na medida do possível, os brinquedos definidos pelo Manual do Denver II já eram oferecidos à criança com o intuito de iniciar a observação o mais precocemente possível.

Em seguida procedeu-se à realização do teste de desenvolvimento de Denver II (Anexo 10), ou o Denver Developmental Screening Test (FRANKENBURG E DODDS 1992).

\subsubsection{Teste de Triagem de Desenvolvimento de DenverII}

A estratégia segue a mesma adotada por FILIPINI (2000), que definiu ser o teste adequado para avaliar o crescimento e desenvolvimento do ponto de vista neuropsicomotor e, também que, por se tratar de uma triagem do desenvolvimento, pode ser realizado por profissionais de saúde, sem haver a necessidade de fazer o diagnóstico médico.

O teste de desenvolvimento de Denver (The Denver Developmental Screening Test - DDST) consiste em uma avaliação do desenvolvimento neuropsicomotor, elaborado por FRANKENBURG et al $(1967,1973)$, na cidade de Denver, Colorado, após a realização de um extenso estudo sobre desenvolvimento infantil em 1967. 
Originou-se de uma adaptação do método de avaliação do desenvolvimento criado por Gesell, da qual deu origem à sua teoria sobre o desenvolvimento infantil, sob o aspecto neuropsicomotor. Genericamente ele afirma que o crescimento e desenvolvimento infantil são resultados da interação entre fatores intrínsecos e extrínsecos a que a criança está sujeita, tais como as alterações nutricionais que podem ter sua etiologia tanto de ordem endócrina como por fatores ambientais. Suas conclusões surgiram de sua avaliação e para isto, dividiu-as em setores para os testes, linguagem, pessoal social, motor fino adaptativo e motor grosso (GESELL 1958, 1985).

FRANKENBURG e DODDS (1992) seguiram esta mesma estratégia, dividindo o teste pelos mesmos setores de Gesell, com um número total de 105 itens na primeira versão. Numa revisão desta versão verificaram que as investigações sobre a linguagem eram limitadas para as faixas etárias maiores, portanto, acrescentaram itens correspondentes a este fator e daí surgiu a segunda versão, o DDST II, com um total de 125 itens (FRANKENBURG e DODDS 1992; WADE 1992).

Esta pesquisa adotou como instrumento o Teste de Denver II porque sua população de estudo corresponde a crianças com idade de três a quatro anos, portanto, a linguagem se constitui como um item essencial para avaliar o progresso cognitivo. Esta versão foi traduzida do original, em inglês, para a língua portuguesa ( Anexo 10), de forma direta e sem adaptações, portanto, foi totalmente fiel à versão de FRANKENBURG e DODDS (1992). E a mesma conduta adotada por FILIPINI (2000), que traduziu o Denver I. Após a tradução o teste foi formatado e impresso graficamente, com espaços para registro de dados de interesse à pesquisa. 
A técnica e materiais utilizados no Denver I foram descritos por FILIPINI (2000). Acrescentou-se na versão II o uso de uma boneca e mamadeira, inexistente na primeira versão e todo o procedimento foi rigorosamente seguido por meio do manual de treinamento do Denver II (FRANKENBURG et al 1992).

A interpretação do teste manteve a orientação do manual, destacando-se que a primeira versão difere da segunda e, inclusive, está mais facilitada, como segue:

\section{NORMAL}

- Nenhum erro e o máximo de uma cautela.

Conduta: manter a rotina para a próxima visita.

\section{SUSPEITO}

- 2 ou mais cautelas e/ou um ou mais erros.

Conduta: repetir o teste em uma ou duas semanas.

\section{INTESTÁVEL}

- Recusa em 1 ou mais itens daqueles que estiverem à esquerda da linha da idade ou mais do que um presente na intersecção da linha da idade em $75 \%$ 90\% da área.

Conduta: repetir em uma ou duas semanas.

Observação: Se novamente o resultado for suspeito ou intestável, o encaminhamento a um serviço que possua um profissional médico ou psicólogo (FRANKENBURG e DODDS 1992). 


\subsubsection{ANTROPOMETRIA}

As aferições de peso e estatura seguiram as normas recomendadas pela Organização Mundial da Saúde (WHO, 1995) e descritas em trabalhos clássicos sobre desnutrição infantil (VICTORA et al 1994; VICTORA et al, 1998).

As crianças foram pesadas nuas sempre na mesma balança digital. Nos casos em que a criança recusou o procedimento normal, ela foi pesada no colo da mãe e depois se descontando os pesos, se obteve o peso da criança.

O comprimento foi realizado por meio de um Infantômetro, com a criança deitada em superfície rígida, posição dorsal, membros em extensão e superfície plantar em ângulo de $90^{\circ}$. Nos casos em que a criança ultrapassou 100 centímetros, a mesma foi aferida em pé, na régua da balança. 


\subsubsection{AVALIAÇÃO DO COMPORTAMENTO DE APEGO}

Esta avaliação constituiu-se em um outro formulário (Anexo 11), após a realização das avaliações descritas anteriormente, tendo em vista que a observação do comportamento da criança foi indispensável para interpretar as respostas dos itens desse questionário. Deter-se sobre a teoria do apego, enunciada por BOWLBY (2002) serviu como importante referencial teórico nas interpretações dos resultados sobre o comportamento de apego. 


\section{- Descrição do Método Q- Sort ou AQS (Attachment Q-Sort Method)}

O trabalho sobre o crescimento e desenvolvimento de crianças de um a 48 meses, em uma favela de São Paulo (FILIPINI 2000; FILIPINI e SIQUEIRA 2001), mostrou evidência que não só fatores desfavoráveis contribuíram para os déficits no desenvolvimento daquelas crianças, mas também a relação mãe e filho. Porém, a ausência de um instrumento adequado para validar esta hipótese impossibilitou inferências mais conclusivas, assim, ficou claro a necessidade de um método para avaliar o apego.

WATERS (1987) afirmou que pesquisar apego não é tão simples, pois depende de uma boa avaliação e a confiabilidade dos dados é essencial. Considerou a teoria de Bowlby adequada, pois o apego seguro pode ser testado e, ainda, pode-se estabelecer interpretações acerca do comportamento em situações estranhas. Reforça que o processo de medidas de validação do apego deve estar arrolado a esta teoria (WATERS 1897).

Com base nestas considerações realizou-se uma busca por um instrumento para tal finalidade e, mediante uma revisão de literatura não sistematizada, identificou-se um método, o Attachment $Q$-sort que pode ser utilizado para avaliar o comportamento de apego seguro, descrito a seguir.

WATERS $(2002,2004)$ e VAN IJZENDOORN et al (2004) afirmaram que os primeiros estudos observacionais acerca do comportamento de base segura, conforme se viu, foram realizados por Mary Ainsworth , em Uganda (1967) e um outro, longitudinal, 
entre mãe e filhos em Baltimore. Ambos, com objetivos de provar empiricamente a teoria do apego de Bolwby, revelaram a necessidade de um modelo tão complexo quanto o de seu trabalho e decisivos para o sucesso dos resultados. Por isso, até 1978, pesquisas sobre apego foram quase exclusivamente focadas sobre o sistema que Ainsworth implementou e que possibilitava acessar diferenças individuais sobre comportamento de base segura.Ultimamente, a validação da classificação do Strange Situation Procedure (SSP) se apóia na relação do comportamento de base segura ( WATERS 2002, 2004; VAN IJZENDOORN et al 2004).

Waters e Deane (1985) criaram um outro método para avaliar o apego seguro, o $\mathrm{AQS}$, que consistia de 100 itens distintos acerca do comportamento da criança entre $12 \mathrm{e}$ 48 meses de idade. Desta classificação verificou-se várias características, tais como comportamento de apego/ exploração, dependência, afetividade, resiliência e outros. E pelos escores apresentados consideraram três categorias de classificação: seguro, dependente e sociável (WATERS e DEANE 1985; VAN IJZENDOORN et al 2004; AINSWORTH 2004).

Posteriormente, WATERS (1987) adaptou este instrumento para uma nova versão do Apego Q -Set, a versão 3.0, com 90 itens (atualmente com versões em inglês e espanhol). Segundo o autor, este instrumento pode ser usado em todas as culturas e em estudos clínicos populacionais. VAN IJZENDOORN et al (2004) destacam que pode ser utilizado até em crianças com extremo distúrbio de comportamento, como o autista, e é válido para avaliar o apego seguro. 
O estudo de meta-análise realizado por VAN IJZENDOORN et al (2004) teve por objetivo validar o AQS como um instrumento alternativo e adequado para avaliar o apego seguro. O resultado deste trabalho, com 139 estudos totalizando 13.835 crianças, mostrou convergências válidas entre o AQS e o SSP e que a observação pelo AQS é uma medida válida para o apego. VAN IJZENDOORN et al (2004) apontam, inclusive, vantagens do AQS sobre o SSP, tal como sua aplicabilidade em culturas distintas.

\section{- Observação e a prática do AQS}

WATERS (2004) recomenda que o próprio pesquisador faça a observação ou treinamento dos assistentes Não é necessário seguir um método rígido; pode ser usado para descrever o comportamento seguro de um a cinco anos de idade, no ambiente familiar ou em lugares públicos, internos ou externos. E também não é preciso memorizá-los, mas, somente saber o suficiente para reconhecer um “comportamento mensurável".

Recomenda estar alerta a sinais variados da criança; visitas familiares ou atendimentos num tempo máximo de uma hora, especialmente no caso de estudos comparativos de um grupo populacional. WATERS (2004) descreve a necessidade de dois observadores para cada visita e em caso de intercorrências, repetir a visita; usar brinquedos/ atividades apropriados para a idade e que a mãe também possa interagir; dar preferência à avaliação sem a presença de visitas; adotar uma postura informal com a mãe sendo que ela não deve se sentir obrigada a falar; use momentos 
apropriados para discutir itens ou o resultado com a mãe e observar se está desconfortável e embaraçada.

\section{- Classificação do AQS}

Os itens foram classificados por uma escala de valores, de um a nove, distribuídos em fichas correspondentes a determinado comportamento. WATERS $(1987,2004)$ afirmou que nunca serão vistos exemplos de todos os itens durante uma única observação, pois os itens do Apego Q-set se referem a um tipo de comportamento num contexto específico.

O critério de classificação foi por escore ou contagem para descrever o sujeito "hipoteticamente mais seguro e dependência" e ordenados em itens, do Item um ao Item n. Assim, classificando-se crianças como "segura" ou "insegura" obteve informações sobre os diferentes significados dentro de cada grupo. Capturar estas diferenças foi a grande importância do método $Q$-sort.

Seu estudo obteve um escore para as crianças mais e menos seguras (WATERS 2004) e afirmou que um corte deste escore poderia gerar outro grupo proporcional de seguros e inseguros. E, certamente, a teoria do Apego não assume igual proporção de apego seguro e inseguro em todas as comunidades e culturas.

VAN IJZENDOORN et al (2004) afirmam que, inclusive, não há naturalmente um ponto de corte dividindo criança segura da insegura. 


\section{- Procedimentos para adaptação aplicação do AQS}

A tradução do inglês e do espanhol para o português, de todos os itens foi realizada (Anexo 12), e a seleção dos mesmos pelas sete categorias, estabelecidas por WATERS e DEANE (1985), foi realizada com o apoio e auxílio de outros profissionais de competência técnica para a elaboração do novo instrumento (Anexo 11).Todos os itens definidos foram extraídos de categorias pré-estabelecidas, conforme descritas a seguir.

A primeira denominaram-na de sistema de comportamento do apego com dois subgrupos: um, o equilíbrio entre exploração e apego, correspondendo a 12 itens e o outro como sendo as diferentes respostas aos pais, constituídos por 9 itens. A segunda categoria corresponde à afetividade, com 19 itens; a terceira pela interação social com 18 itens; a quarta sobre a manipulação de objetos com 14 itens; a quinta trata da independência/dependência, com 14 itens; a sexta acerca da perspicácia social, com oito itens e finalmente a nona sobre a resistência/ resiliência com seis itens no que totalizou os 100 itens. Observou-se que vários deles se assemelharam nas categorias, assim vislumbrou-se a possibilidade em reduzi-los e fazer uma adaptação, tornando-o viável e sua aplicabilidade mostrou-se apropriada.

VAN IJZENDOORN et al (2004) afirmaram que diferentes versões têm sido usadas por diferentes modos; desde a primeira versão com os 100 itens, vários 
ajustamentos no número de itens e frases têm sido realizados e não há muita clareza na dimensão dos efeitos nestas adaptações.

Optou-se, portanto, por criar uma versão baseada nas classificações encontradas no estudo de WATERS $(1987,2004)$, selecionando-se 31 itens que tiveram maior percentual de crianças que responderam positivamente a ele. Para estes ítens criaram-se três categorias: maior parte das vezes, muito pouco ou raramente e nunca, cuja somatória deles resultou no resultado final representado em percentual (anexo 11) ou:

\begin{tabular}{ll|}
\hline $\begin{array}{l}\Sigma \text { itens obtidos } \\
\text { Total de itens com valor máximo }\end{array}$ & $\mathrm{X} 100$ \\
$(31 \times 2=62)$ &
\end{tabular}

Recomenda-se que a análise limite-se à comparação entre a própria população estudada considerando as crianças mais seguras e menos seguras conforme seu escore obtido e compará-las.

Nesta pesquisa a avaliação foi realizada uma única vez e no mesmo consultório da Unidade Básica de Saúde, mas agendou-se retorno, quando foi detectado algum problema ou dúvidas do avaliador. A estratégia adotada procurou seguir a recomendada por WATERS $(1987,2004)$ mantendo-se a observação, como condição fundamental, durante a avaliação do apego seguro. O observador era acompanhado por um assistente como recomendado por WATERS $(1985,2004) \mathrm{e}$ VAN IJZENDOORN et al (2004) e ao final de cada sessão todos os casos eram discutidos para sanar possíveis dúvidas. 
Este instrumento, portanto, foi aplicado após um período de "aquecimento" considerado como uma fase de interação entre a mãe, criança, observador e assistente. Isto foi obtido devido às etapas da pesquisa, entrevista, antropometria, o Teste de desenvolvimento de Denver II e finalmente o AQS. O ato de brincar, base da técnica do Denver II foi uma estratégia fundamental. O brinquedo por várias vezes rompeu a barreira entre a criança, especialmente tímida, e o observador. 


\section{5 DESCRIÇÃO DAS VARIÁVEIS}

Foram definidas por meio dos instrumentos utilizados na coleta de dados, na maioria com respostas fechadas e algumas abertas e descritas a seguir.

\section{- Variáveis dos dados secundários obtidos das Declarações de Nascidos vivos (DNV) (anexo 9)}

As categorias foram estabelecidas de acordo com a proposta da DNV e foram recategorizas posteriormente para fins de análise e apresentação dos resultados.

\section{. Indicadores biológicos e sociais}

- Número da declaração de nascido vivo-com o intuito de facilitar a localização desta criança.

- Local de ocorrência do nascimento-para confirmar o nascimento em Mauá.

- Código do município de ocorrência do nascimento-para confirmar o município.

- Nome da mãe-para facilitar a localização da criança.

- Idade da mãe- em anos.

- Estado civil - solteira, casada, viúva, separada judicialmente/ divorciada.

- Escolaridade materna - em anos de estudo completo/incompleto.

- Número de filhos vivos e mortos em gestações anteriores.

- Tipo de gravidez- única; dupla; tripla ou mais. 
- Tipo de parto- vaginal; cesáreo.

- Duração da gestação ou idade gestacional ( IG):

- Pré- termo- nascidos entre 22 a 36 semanas de IG

- Termo- nascidos de 37 a 41 semanas de IG

- Pós- termo- nascidos com 42 semanas e mais de IG

- Número de consultas de pré-natal.

- Data de nascimento.

- Sexo do bebê- masculino e feminino.

- Vitalidade ao nascer: Índices de Apgar $1^{\circ}$ e $5^{\circ}$ minuto- diz respeito ao índice clássico sobre o estado vital e neurológico da criança, avaliando a freqüência cardíaca, movimentos respiratórios,tônus muscular, irritabilidade reflexa e cor da pele. Todos têm uma nota que varia de 0 a 2 , um valor de 7 e maispode significar um bom prognóstico ao bebê ( PERNETTA, 1990).

Adotou-se como categorias: $<7$ e 7 e mais.

- Peso ao nascer- em gramas.

- Presença de malformação congênita- descritos anteriormente.

Estas informações do nascimento apresentaram os dados sobre os antecedentes gestacionais e neonatais precoces. O seguimento da história de vida dos recém-nascidos foi obtido através da entrevista, com informações referidas 
da mãe e revisão do prontuário nos casos em que a criança possuísse matricula na Unidade Básica de Saúde.

\section{. Variáveis dos dados primários obtidos da entrevista (anexo 9)}

Das variáveis obtidas pela DNV, repetiram-se na entrevista aquelas que necessitaram de confirmação ou alteração do dado.

\section{Indicadores biológicos e sociais}

- Idade atual da mãe - em anos

- Escolaridade- destacam-se categorias para a escolaridade que foram adotadas segundo a classificação da Lei de Diretrizes e Bases ( Lei n 9394/96- 1997):

. Ensino fundamental completo: $1^{\mathrm{a}}$ a $8^{\mathrm{a}}$ série

. Ensino médio: $1^{\circ}$ a $3^{\circ}$ ano ( antigo $2^{\circ}$ grau)

. Ensino superior

- Estado civil atual materno-solteira; casada/união consensual e viúva.

- Presença de assistência de saúde privada/ convênio ou SUS dependente.

- Composição familiar- categorias de acordo com os membros familiares, compostas por pai, mãe e irmãos da criança denominada "Nuclear" ou se a família possui agregados consideradas “Quebrada ou Não tradicional” (FUNDAÇÃO SEADE 1994).

- Ocupação materna - tipo de ocupação remunerada. 
- Antecedentes gestacionais - Acrescentando aqui, além dos dados do nascimento que foram confirmados, hábito de fumar e álcool na gestação e complicações de saúde na gestação e parto descritos no capítulo da introdução. Os conflitos psicológicos foram considerados pertencentes a este grupo, tais como separação conjugal durante a gravidez.

\section{CRIANÇA}

Confirmando-se os dados da DNV e acrescentando-se as seguintes variáveis:

- Comprimento ao nascer - referido em centímetros.

- Complicações de saúde neonatais- conforme tratado na introdução, será considerado todas as afecções que acometem o recém-nascido no período neonatal, do nascimento até 28 dias de vida (LEONE et al 2003).

- Participação em programas de Follo -up ou de seguimento ( RUGOLLO 2003).

- Alimentação-incluindo-se aleitamento materno exclusivo e misto, introdução de outros alimentos e alimentação atual.

- Freqüência em escolas/ creches.

- Hospitalização- causa e freqüência.

- Relato de atividades diárias da criança - do ponto de vista das necessidades humanas básicas, o sono, repouso, higiene, lazer e eliminações fisiológicas.

- Antropometria - Tomando-se como padrão de referência a curva de crescimento da WHO (1995) e NCHS (1997), adotando os Índices Nutricionais como categorias para os déficits nutricionais: P/I ( peso/ idade); P/E ( peso/ estatura) e E/I ( estatura/ idade). 
Preconizou-se como antropometria anormal, os valores dos escores $\mathrm{z}$ para os índices quando apresentaram resultados $<-2$ ou $>+2$ (WHO 1995).

- Avaliação de Denver II - categorizados conforme descrito anteriormente durante a descrição do teste. Foram recategorizados como normal e a outra como intestáveis ou suspeitos ao desenvolvimento neuropsicomotor

- Avaliação do comportamento de apego seguro - categorizados de acordo comportamento do apego seguro e menos seguro conforme o percentual obtido na distribuição contínua, estabelecendo-se um ponto de corte na mediana somente para fins da análise:

Apego menos seguro- Mediana $>90,3$

Apego mais seguro - Mediana igual ou $<90,3$

Muito embora considerando que WATERS (2004) e VAN IJZENDOORN et al (2004) destacam que o ponto de corte não estabelece um critério determinado de apego seguro ou inseguro, isto é, um outro ponto de corte proporciona um outro grupo de seguros e inseguros. 


\section{ANÁLISE DOS DADOS}

Os dados foram processados no software Epi-info, versão 6.03 pelo programa Eped e a análise antropométrica por meio do programa Epi-nut, resultando nas variáveis Nutricionais que são: peso/ estatura; peso/ idade e estatura/idade.

Nas análises, foram utilizados os softwares Epi-Info 6.03 e Stata 7.0.

Os dados quantitativos foram representados em tabelas que contém média, desvio-padrão, valores mínimo e máximo. Os dados qualitativos estão dispostos em tabelas de frequiência absoluta e relativa (percentual).

A associação entre as variáveis foi calculada por meio do risco relativo (RR) e foram apresentados os respectivos níveis descritivos (p) e intervalos de confiança de $95 \%$ (Kleinbaum e cols. 1982).

Esse modelo considera a regressão de Poisson modificada para estimar o RR e os intervalos de confiança usando variância robusta (ZOU 2004). A seleção considerou variáveis que, na análise univariada, cotizaram o nível descritivo $\mathrm{p}<0,10$ (COLLETT 1991, HOSMER e LEMESHOW 1989).

O nível de significância considerado para os testes foi de $5 \%($ alfa $=0,05)$, níveis descritivos (p) inferiores a esse foram considerados significantes (KLEINBAUM et al 1982; LANG et al 1998). 


\section{CONSIDERAÇÕES ÉTICAS}

Este estudo como utilizou seres humanos, obedeceu à Resolução CNS/196/96 do Ministério da Saúde e foi submetido ao Comitê de Ética em Pesquisa com Seres Humanos da Faculdade de Saúde Pública da USP, filiado ao Conselho Nacional de Pesquisa com Seres Humanos (CONEP), através de carta e Ficha de Rosto para Pesquisa Envolvendo Seres Humanos (modelo-padrão do CONEP); e aprovado pelo Protocolo No. 850 (anexo 14). 


\section{RESULTADOS}

\subsection{Análise da coorte segundo dados secundários obtidos da declaração de nascidos vivos (DNV)}

As variáveis registradas na DNV foram analisadas quanto às suas características e são descritas a seguir.

\subsubsection{Caracterização materna}

A Tabela 1 mostra variáveis maternas por ocasião do parto com a média da idade materna em 20 anos, contudo o desvio padrão de 7,4 anos, idades mínima de 13 e máxima de 47 anos mostram heterogeneidade nas idades havendo desde adolescentes até grávidas maduras.

As mães têm uma média de filhos pequena não chegando a dois, muito embora o desvio padrão demonstre que há diferenças entre elas, como se observa pelo valor máximo de nove filhos. $\mathrm{O}$ número de filhos mortos variou de 0 a 5 filhos, com uma média inferior a 1 filho $(0,32)$. E pelos valores máximos os resultados mostram que existiram mulheres com alta paridade.

Importante destacar que a ausência desses dados na DNV foi significativa, inclusive para o número de filhos mortos. 
TABELA 1 - Média, valores mínimo, máximo e desvios- padrão das idades das mãe, número de filhos vivos e mortos de crianças com baixo peso ao nascer em 2001, Mauá, 2004.

\begin{tabular}{l|ccccc}
\hline VARIÁVEIS MATERNAS & N & Mínima & Máxima & Média & Desvio padrão \\
\hline Idade materna (anos) & 86 & 13 & 47 & 20 & 7,4 \\
\hline Número de Filhos Vivos & 77 & 0 & 9 & 1,6 & 1,8 \\
\hline Número de Filhos Mortos & 76 & 0 & 5 & 0,3 & 0,9 \\
\hline
\end{tabular}

Quanto ao pré-natal (Tabela 2), 50\% das crianças são filhas de mães que fizeram de 4 a 6 consultas; resultado que foi verificado posteriormente durante a entrevista mas por razão de muitas mães não se recordarem do número real optou-se por considerar o dado registrado da DNV. Pelo resultado se observa que a maioria realizou um pré-natal adequado, com $95,5 \%$ realizando quatro ou mais consultas.

TABELA 2- Distribuição do número de consultas de pré-natal de mães de crianças com baixo peso ao nascer em 2001, Mauá, 2004.

\begin{tabular}{ll|ccc}
\hline \multicolumn{2}{c|}{ VARIÁVEIS MATERNAS } & N & \% & \% Acumulada \\
\hline CONSULTAS & 1 a 3 consultas & 2 & 2,3 & 2,3 \\
de PRÉ-NATAL & 4 a 6 consultas & 43 & 50,0 & 52,3 \\
& 7 e mais & 40 & 45,5 & 98,8 \\
& Ignorado & 1 & 1,2 & 100,0 \\
TOTAL & & $\mathbf{8 6}$ & $\mathbf{1 0 0 , 0}$ & \\
\hline
\end{tabular}

Fonte: Declaração de Nascidos Vivos ( SIM/SINASC- Secretária Municipal da Saúde de Mauá; 2004) 
Na Tabela 3 pode-se observar que $68,6 \%$ das crianças eram filhas de mães cujo estado civil, na ocasião do parto, era a união consensual ou casada e a restante, solteira. Quanto à escolaridade, $48,8 \%$ das crianças são filhas de mães que possuíam de 4 a 7 anos completos de estudo ou com o ensino fundamental incompleto, mostrando que, de modo geral, o grupo de mães da coorte estudada possue um nível abaixo da média de escolaridade $(59,3 \%)$.

TABELA 3 - Distribuição de variáveis sócio-culturais maternas por ocasião do parto de crianças com baixo peso ao nascer em 2001, Mauá, 2004.

\begin{tabular}{ll|ccc}
\hline VARIÁ VEIS MATERNAS & N & $\%$ & $\begin{array}{c}\% \\
\text { Acumulada }\end{array}$ \\
& & & & 31,4 \\
ESTADO CIVIL & Solteira & 27 & 31,4 & 62,8 \\
& Casada & 27 & 31,4 & 100,0 \\
& União Consensual & 32 & 37,2 & \\
ESCOLARIDADE & Nenhum & & & 1,2 \\
( em anos completos) & 1 a 3 & 8 & 1,2 & 10,5 \\
& 4 a 7 & 42 & 9,3 & 59,3 \\
& 8 a 11 & 33 & 48,8 & 97,7 \\
TOTAL & 12 e mais & 2 & 38,4 & 100,0 \\
\hline
\end{tabular}

Fonte: Declaração de Nascidos Vivos ( SIM/SINASC- Secretária Municipal da Saúde de Mauá; 2004) 


\subsubsection{Caracterização do bebê}

\section{- Características da gestação e parto}

A Tabela 4 representa o grupo de crianças estudadas segundo o sexo e a idade. Como pode se notar, não há diferença significativa entre os dois sexos quanto à idade. Pela distribuição contínua a média de idade apresenta pouca variação em ambos os sexos e pelo desvio padrão se verifica que as idades variaram em torno de 3 meses. Um resultado esperado tendo em vista que todas nasceram no ano de 2001.

TABELA 4- Idade Média, mínimo, máximo e desvios- padrão e sexo de crianças com baixo peso ao nascer em 2001, Mauá, 2004.

\begin{tabular}{l|ccccc}
\hline \multirow{2}{*}{\multicolumn{1}{c}{ SEXO }} & \multicolumn{5}{c}{ IDADE EM MESES } \\
\cline { 2 - 6 } & $\mathrm{N}$ & Mínima & Máxima & Média & Desvio padrão \\
\hline Feminino & 46 & 34,8 & 46,7 & 41,4 & 3,3 \\
Masculino & 40 & 34,2 & 46,2 & 39,3 & 3,4 \\
& & & & & \\
\hline
\end{tabular}

Fonte: Declaração de Nascidos Vivos ( SIM/SINASC- Secretária Municipal da Saúde de Mauá; 2004) $\mathrm{X}^{2}=0,058 ; \mathrm{p}=0,809$

A Tabela 5 mostra o diferencial por sexo no qual se observa, percentualmente, que há um predomínio do sexo feminino ( 53,5\%).

No período perinatal, gestação e nascimento, houve predomínio de nascimentos por partos vaginais $(55,8 \%)$, mas com um percentual de cesáreas (43\%) elevado, sugerindo tratar-se de um grupo de risco. Dos tipos de parto, $86 \%$ nasceram de gravidez 
única. A maioria nasceu a termo, com $63 \%$ dos bebês nascidos com idade gestacional variando de 37 a 41 semanas (Tabela 5). Supõe-se que todos esses $63 \%$ tenham apresentado restrição no crescimento intra-uterino.

TABELA 5 - Distribuição do sexo e características da gestação e parto de crianças com baixo peso ao nascer em 2001, Mauá, 2004.

\begin{tabular}{|c|c|c|c|c|}
\hline \multicolumn{2}{|c|}{ Variáveis } & $\mathrm{N}$ & $\%$ & $\%$ Acumulada \\
\hline \multirow[t]{2}{*}{ SEXO } & Feminino & 46 & 53,5 & 53,5 \\
\hline & Masculino & 40 & 46,5 & 100,0 \\
\hline TIPO DE & Vaginal & 48 & 55,8 & 55,8 \\
\hline \multirow[t]{2}{*}{ PARTO } & Cesáreo & 37 & 43,0 & 98,8 \\
\hline & Ignorado & 1 & 1,2 & 100,0 \\
\hline TIPO DE & Única & 74 & 86,0 & 86,0 \\
\hline GRAVIDEZ & Dupla & 12 & 14,0 & 100,0 \\
\hline IDADE & 28 a 31 (PT) & 2 & 2,3 & 2,3 \\
\hline GESTACIONA & L* 32 a $36(\mathrm{PT})$ & 26 & 30,2 & 32,6 \\
\hline \multirow[t]{2}{*}{ (semanas) } & 37 a $41(\mathrm{~T})$ & 54 & 62,8 & 95,3 \\
\hline & Ignorado & 4 & 4,7 & 100,0 \\
\hline \multicolumn{2}{|l|}{ Total } & 86 & 100,0 & \\
\hline
\end{tabular}

Fonte: Declaração de Nascidos Vivos ( SIM/SINASC- Secretária Municipal deSaúde d2 Mauá; 2004)

* Idade gestacional pré- termo $(\mathrm{PT})=$ menor 37 semanas e a termo $(\mathrm{T})=$ maior ou igual 37 a 41 semanas . 


\section{- Características do peso ao nascer}

Tendo em vista que o peso ao nascer foi o critério de escolha da amostra compreendeu-se necessária uma análise sobre esta variável.

A Tabela6 apresenta a média dos pesos ao nascer, com 2.223 gramas, notando-se estar acima de $2.000 \mathrm{~g}$, muito embora o valor mínimo apresente valores inferiores, com 1.100 gramas. A distribuição contínua com todos os pesos em números absolutos e percentuais encontram-se em anexo ( Tabela $F$ ).

Cumpre observar que, como já foi dito, não foram incluídos na amostra bebês nascidos com menos de $1.000 \mathrm{~g}$, pois apenas três sobreviveram e na busca verificou-se que um foi a óbito, mas sem registro na DNV. Outro mudou de cidade e o último não foi localizado.

Pode-se notar que na Tabela 7 apenas duas crianças do estudo nasceram com menos de 1.500 gramas ou de muito baixo peso e outros 9 com menos de $2.000 \mathrm{~g}$ até $1.500 \mathrm{~g}$. No geral, isto representa que, além da não ocorrência de bebês de extremo baixo peso, há um número reduzido de muito baixo peso.

Algumas associações entre o peso ao nascer e as variáveis do nascimento apresentaram significâncias, conforme se observa na Tabela 7.

Cumpre assinalar que a caracterização isolada das variáveis não registradas na DNV e associadas ao BPN serão descritas posteriormente neste capítulo. 
Pelos resultados se observa que todos os bebês nascidos com menos de 2.000 gramas foram prematuros e as mães referiram ter apresentado complicações no período gestacional (ambos com 100\%).

Para os bebês com peso igual ou maior que $2.000 \mathrm{~g}$ ao nascimento a prematuridade diminui, com $28,2 \%$, mas as complicações gestacionais ainda mantêm números elevados de mulheres, 43 (57,3\%). As complicações neonatais também seguem esta mesma tendência, pois todos os com muito baixo peso tiveram problemas ao nascer e $77,8 \%$ entre os menores de 2000 e mais de 1500 gramas.

Fica evidente que quanto menor o peso maior proporção há entre as categorias de risco para estas variáveis, como se pode ver na Tabela 8 com os valores de p menores que 0,05 .

A condição da vitalidade ao nascer pode ser verificada pelo Apgar de $1^{\circ}$ e $5^{\circ}$ minutos de vida; o Apgar de $5^{\circ}$ com notas inferiores a sete também apresentou uma proporção maior entre os bebês com pesos menores de 2.000 gramas.

A mesma tabela mostra que escolaridade materna, por ocasião do parto, foi notada como significante entre aquelas mães que apresenta menor número de anos de atividade escolar.

TABELA 6-Média, valores mínimo, máximo e desvios- padrão do peso ao nascer de crianças com baixo peso ao nascer em 2001, Mauá, 2004.

\begin{tabular}{c|ccccc}
\hline VARIÁVEL & N & Mínima & Máxima & Média & Desvio padrão \\
\hline PESO AO NASCER & 86 & 1,1 & 2,5 & 2,2 & 0,3 \\
\hline
\end{tabular}

Fonte: Declaração de Nascidos Vivos ( SIM/SINASC- Secretária Municipal da Saúde de Mauá; 2004) 
TABELA 7 - Associação entre o peso ao nascer e variáveis por ocasião do parto de crianças com baixo peso ao nascer em 2001, Mauá, 2004.

\begin{tabular}{|c|c|c|c|c|c|}
\hline \multirow{2}{*}{$\begin{array}{c}\text { VARIÁ VEIS POR } \\
\text { OCASIÃO DO PARTO }\end{array}$} & \multicolumn{3}{|c|}{ PESO AO NASCER } & \multirow[b]{2}{*}{ TOTAL } & \multirow{2}{*}{ Valor de $\mathbf{P}$} \\
\hline & $\begin{array}{l}2.000 \mathrm{a} \\
2.499 \mathrm{~g}\end{array}$ & $\begin{array}{l}1.500 \mathrm{a} \\
<1.999 \mathrm{~g}\end{array}$ & $\begin{array}{c}1000 \\
\text { a1.499g }\end{array}$ & & \\
\hline IDADE GESTACIONAL $* *$ & $71(100,0)$ & $9(100,0)$ & $2(100,0)$ & $82(100,0)$ & $*<0,0001$ \\
\hline A termo & $51(71,8)$ & $0(0,0)$ & $0(0,0)$ & $51(62,2)$ & \\
\hline Pré- termo & $20(28,2)$ & $9(100,0)$ & $2(100,0)$ & $31(37,8)$ & \\
\hline APGAR $5^{\circ} *$ & $70(100,0)$ & $9(100,0)$ & $1(100,0)$ & $80(100,0)$ & $* 0,069$ \\
\hline 7 a 10 & $69(98,6)$ & $7(77,8)$ & $1(100,0)$ & $77(96,25)$ & \\
\hline$<7$ & $1(1,4)$ & $2(22,2)$ & $0(0,0)$ & $3(3,75)$ & \\
\hline ESCOLARIDADE MÃE** & $75(100,0)$ & $9(100,0)$ & $2(100,0)$ & $86(100,0)$ & $* 0,010$ \\
\hline 12 e mais anos & $1(1,3)$ & $1(11,1)$ & $0(0,0)$ & $2(2,3)$ & \\
\hline 8 a 11 anos & $31(41,3)$ & $1(11,1)$ & $1(50,0)$ & $33(38,4)$ & \\
\hline 4 a 7 anos & $38(50,7)$ & $3(33,3)$ & $1(50,0)$ & $42(48,8)$ & \\
\hline Até 3 anos & $5(6,7)$ & $4(44,4)$ & $0(0,0)$ & $9(10,50)$ & \\
\hline COMPL. GESTACIONAIS & $75(100,0)$ & $9(100,0)$ & $2((100,0)$ & $86(100,0)$ & * 0,008 \\
\hline Não & $32(42,7)$ & $0(0,0)$ & $0(0,0)$ & $32(37,2)$ & \\
\hline Sim & $43(57,3)$ & $9(100,0)$ & $2(100,0)$ & $54(62,8)$ & \\
\hline COMPL. NEONATAIS & $74(100,0)$ & $9(100,0)$ & $2(100,0)$ & $85(100,0)$ & * 0,001 \\
\hline Năo & $54(72.8)$ & $2(22,2)$ & $0(0,0)$ & $56(65,9)$ & \\
\hline Sim & $20(27,0)$ & $7(77,8)$ & $2(100,0)$ & $29(34,1)$ & \\
\hline
\end{tabular}

* Teste exato de Fisher.

** Fonte: Declaração de Nascidos Vivos ( SIM/SINASC- Secretária Municipal da Saúde de Mauá; 2004)

. Para as variáveis idade gestacional, apgar $5^{\circ}$ e afecções neonatais foram excluídos os dados ignorados. 


\subsection{Análise da coorte segundo dados da entrevista}

A seguir são apresentadas as características das variáveis obtidas por meio de entrevistas.

\subsubsection{Caracterização materna}

Exploraram-se outros dados acerca dos antecedentes gestacionais, tais como fumar na gravidez e outros hábitos.

Na Tabela 8 nota-se que $68,6 \%$ das crianças são filhas de mães que não fumaram nesta gravidez, assim, esta variável de risco ao BPN esteve presente em pouco mais de $30 \%$ das mulheres.

Hábito de beber e uso de drogas foram negados. Respectivamente, $98 \%$ e $100 \%$, referiram não possuir tais hábitos, mas estas variáveis foram desprezadas para a análise tendo em vista que as respostas obtidas apresentaram grande imprecisão.

A Tabela 8 apresenta, ainda os resultados obtidos quanto às afecções maternas durante a gravidez; de acordo com relatos, $62,8 \%$ delas tiveram problemas de saúde durante a gestação. Os problemas referidos são descritos a seguir.

Hipertensão arterial foi a afecção mais freqüente, cerca de $25(29 \%)$ mulheres citaram este problema, algumas com complicações mais severas como pré-eclâmpsia (3 casos) e crise convulsiva. Este é mais um dado sugestivo de tratar-se de gestações e bebês de risco. 
Hipotensão e desmaios foram freqüentes entre os citados. Muitos casos de anemia (mais de 15 casos), algumas com uso de Sulfato Ferroso; fraqueza, enjôo, vômito, inapetência e perda de peso na gestação.

Histórias de infecção do trato urinário e rotura prematura de membranas; "corrimento vaginal" e sangramento; um caso de toxoplasmose e dois casos de presença de mecônio em líquido amniótico.

Algumas mulheres citaram depressão, tendo como motivo, geralmente, a separação conjugal.

TABELA 8- Distribuição de variáveis retrospectivas gestacionais maternas segundo relato da mãe de crianças com baixo peso ao nascer em 2001, Mauá, 2004.

\begin{tabular}{lc|ccc}
\hline VARIÁVEIS GESTACIONAIS & & N & \% & \% Acumulada \\
\hline HÁBITO FUMAR NA & Sim & 27 & 31,4 & 31,4 \\
GRAVIDEZ & Não & 59 & 68,6 & 100,0 \\
COMPLICAÇÕES & Sim & 54 & 62,8 & 62,8 \\
GESTAACIONAIS & Não & 32 & 37,2 & 100,0 \\
TOTAL & & & & \\
\hline
\end{tabular}

A renda familiar não foi obtida pela DNV e por isso a informação se conseguiu pela entrevista; embora com respostas imprecisas, pode-se notar um diferencial importante entre a distribuição de renda nesta população. Como se vê na Tabela 9 e 10 , uma média de renda em torno de 540 reais, mas com um mínimo de 45 e máximo de 
2.000 reais e com $36,6 \%$ com renda de trezentos reais ou menos. Uma pequena parcela da população $(14,6 \%)$ com renda de mil reais ou mais. Tal como a escolaridade, nota-se que o grupo estudado tem uma renda familiar baixa, por volta de 3 salários mínimos.

TABELA 9 -Média, valores mínimo, máximo e desvios-padrão de renda familiar de crianças com baixo peso ao nascer em 2001, Mauá, 2004.

\begin{tabular}{c|ccccc}
\hline Renda familiar & N & Mínima & Máxima & Média & Desvio padrão \\
\hline $\begin{array}{c}\text { Renda Familiar } \\
\text { (em Reais) }\end{array}$ & 82 & 45,0 & $2.000,0$ & 540,0 & 383,4 \\
\hline
\end{tabular}

Na Tabela 10 observa-se que $71 \%$ das crianças são filhas de mães cuja situação conjugal atual é o casamento ou união consensual. Comparando-se com os dados, por ocasião do parto, verifica-se que algumas mulheres se separaram e uma ficou viúva, assim, o percentual de casadas ou por união consensual se mantém quase igual, $68,6 \%$ ao nascimento do bebê e atualmente com $70,9 \%$.

Por outro lado, diminuiu o número de solteiras, de $27(31,4 \%)$ para $10(11,6 \%)$. Parece, portanto, que dentre as casadas anteriormente algumas se separaram.

Quanto à escolaridade, na ocasião do parto e atualmente, quase não houve mudanças. Ao nascimento 55,3\% tinham o ensino fundamental incompleto e atualmente $63 \%$ das crianças são filhas de mães que têm o ensino fundamental completo ou incompleto. E atualmente poucas estão estudando (9,3\%). 
A mesma tabela indica que $45 \%$ possuem algum trabalho remunerado, seja ele no próprio domicílio ou não. Neste aspecto, as ocupações mais citadas foram: empregada doméstica, manicure e outras poucas assalariadas, que têm como funções mais freqüentes, operadoras de telemarketing e balconista.

O tipo familiar predominante foi família nuclear ou tradicional (64\%), compreendendo pai, mãe e filhos.

Importante notar que a situação conjugal não representa o tipo de família, como se vê pelo percentual de mulheres sem companheiro $(11,6 \%)$ menor que em famílias não tradicionais $(33,7 \%)$. Foram registrados vários relatos em que os casais compartilham o mesmo domicílio com parentes, como pais, tios, irmãos e até com pessoas sem laços de consangüinidade. 
TABELA 10 - Distribuição de variáveis sócio-culturais maternas atuais de crianças com baixo peso ao nascer em 2001, Mauá, 2004.

\begin{tabular}{|c|c|c|c|c|}
\hline \multicolumn{2}{|c|}{$\begin{array}{l}\text { VARIÁVEIS SÓCIO-CULTURAIS MATERNAS } \\
\text { ATUAIS }\end{array}$} & \multirow{2}{*}{$\begin{array}{l}\mathbf{N} \\
10\end{array}$} & \multirow{2}{*}{$\begin{array}{c}\% \\
11,6\end{array}$} & \multirow{2}{*}{$\begin{array}{c}\% \% \\
\text { Acumulada } \\
11,6\end{array}$} \\
\hline & Solteira & & & \\
\hline SITUAÇÃO & Casada/União Consensual & 61 & 70,9 & 82,6 \\
\hline \multirow[t]{3}{*}{ CONJUGAL } & Separada & 14 & 16,3 & 98,8 \\
\hline & Viúva & 1 & 1,2 & 100,0 \\
\hline & Analfabeta & 1 & 1,2 & 1,2 \\
\hline \multirow[t]{3}{*}{ ESCOLARIDADE } & Ens.Fundam.Comp/Inc. & 54 & 62,8 & 64,0 \\
\hline & Ens.Médio.Comp/Inc & 29 & 33,7 & 97,7 \\
\hline & Ens.Superior.Comp/Inc & 2 & 2,3 & 100,0 \\
\hline ESTUDA & Sim & 8 & 9,3 & 9,3 \\
\hline ATUALMENTE & Não & 78 & 90,7 & 100,0 \\
\hline OCUPAÇÃO & Do lar & 31 & 38,0 & 36,0 \\
\hline \multirow[t]{2}{*}{ ATUAL } & Trabalho remunerado & 39 & 45,3 & 81,4 \\
\hline & Desempregada & 16 & 18,6 & 100,0 \\
\hline TIPO DE & Nuclear ou tradicional & 55 & 64,0 & 64,0 \\
\hline \multirow[t]{2}{*}{ FAMÍLIA } & Não tradicional & 29 & 33,7 & 97,7 \\
\hline & Ignorada & 2 & 2,3 & 100,0 \\
\hline \multicolumn{5}{|c|}{ RENDA FAMILIAR(Reais) } \\
\hline 1.000 e mais & & 12 & 13,9 & 13,9 \\
\hline$<1000 \mathrm{a}>300$ & & 40 & 46,5 & 60,4 \\
\hline $300 a>150$ & & 20 & 23,3 & 83,7 \\
\hline$<150$ & & 10 & 11,6 & 95,3 \\
\hline ignorado & & 4 & 4,7 & 100,0 \\
\hline TOTAL & & 86 & 100,0 & \\
\hline
\end{tabular}




\subsubsection{Caracterização da criança}

Além das variáveis acerca das condições do bebê ao nascer, obtidas pela DNV, investigou-se também a presença de complicações neonatais. Estas informações foram obtidas da família e em alguns casos dos prontuários das crianças com matrícula nas UBS.

A Tabela 11 mostra que $65,1 \%$ crianças não tiveram complicações de saúde ao nascer.

Dos problemas neonatais referidos, $33,7 \%$, não se notaram casos graves; três mães referiram que o bebê nasceu com problemas cardíacos ao nascimento, mas estes dados não constavam nos registros da DNV.

O problema mais citado foi o baixo peso ao nascer, o que fez prolongar os dias de internação para ganhar peso, ficando no berço aquecido ou em incubadora.

Outro problema citado com freqüência foi icterícia fisiológica, que foi tratada com fototerapia em alguns casos.

Hipoglicemia, hérnias umbilical e inguinal também foram citados.

Verificaram-se poucos problemas de causa respiratória e apenas um caso grave foi registrado. Neste caso foi diagnosticada hérnia umbilical, que necessitou de cirurgia, evoluindo, segundo relato materno, em apnéia seguido de hipóxia. Durante a entrevista foi observado que esta criança apresentava déficits motores, com os membros inferiores assimétricos. 
TABELA 11 - Distribuição de complicações neonatais de crianças com baixo peso ao nascer em 2001, Mauá, 2004.

\begin{tabular}{l|ccc}
\hline COMPLICAÇÕES NEONATAIS & $\mathbf{N}$ & \% & \% Acumulada \\
\hline Sim & 29 & 33,7 & 33,7 \\
Não & 56 & 65,1 & 98,8 \\
Ignorado & 1 & 1,2 & 100,0 \\
Total & $\mathbf{8 6}$ & $\mathbf{1 0 0 , 0}$ & \\
\hline
\end{tabular}

Investigou-se a participação das crianças em programas de Follow-up ou programas similares. Apenas uma delas informou que seu filho vem sendo acompanhado desde o nascimento, mas este seguimento não se caracterizou como um programa estruturado, com características de Follow-up.

Importante dizer que apenas uma mãe referiu ser informada que seu bebê, por nascer com um baixo peso, seria caracterizado como um bebê de risco e que necessitaria de um acompanhamento mais intensivo.

Outras investigações sobre aspectos consideradas importantes na vida da criança foram registradas, como mostra a Tabela 12.

Quanto à hospitalização, as causas mais freqüentes foram doenças respiratórias, broncopneumonias, pneumonias, bronquites e bronquiolites; ocorrência em mais de 20 
crianças. Foi referido um caso com história de mais de 5 internações até os 2 anos de vida por motivos respiratórios.

Muitos destes problemas tinham como causas secundárias anemias, sendo que algumas estavam em tratamento nas UBS.

Uma criança foi citada estar no Programa do Leite e Óleo, programa este instituído pela Secretaria Estadual de Saúde para assistir crianças com déficits nutricionais e outra inserida no programa da Pastoral da Saúde.

Outros registros foram anotados, como viroses, diarréias, estomatite, anúria e um caso de meningite.

Poucas crianças com histórico cirúrgico. $\mathrm{O}$ caso já citado por hérnia inguinal e outra cardiopatia congênita, contudo esta malformação congênita não constava nos dados da DNV.

A freqüência à creche foi compreendida como qualquer serviço que possuísse uma estrutura igual ou similar a uma escola infantil. Houve poucas crianças freqüentando uma escolinha ou creche $(16,3 \%)$ e houve uma criança matriculada em uma escola de igreja. Muitas mães falaram que a matrícula à escolinha pública ocorreria no ano seguinte.

Apenas seis crianças ( Tabela 12) possuíam um convênio de saúde privado mas mantinham a matrícula na UBS. 
Quanto às regiões de moradia familiar (Tabela12), comentadas anteriormente por ocasião da definição da amostra, os locais com maior número de crianças atendidas foram as regiões $2(18,6 \%), 4(18,6 \%)$ e $5(39,5 \%)$.

Nestas regiões localizam-se as Unidades Básicas de Saúde e referência para a moradia e atendimento à saúde da família.

TABELA 12 - Distribuição de variáveis pós-neonatais de crianças com baixo peso ao nascer em 2001, Mauá, 2004.

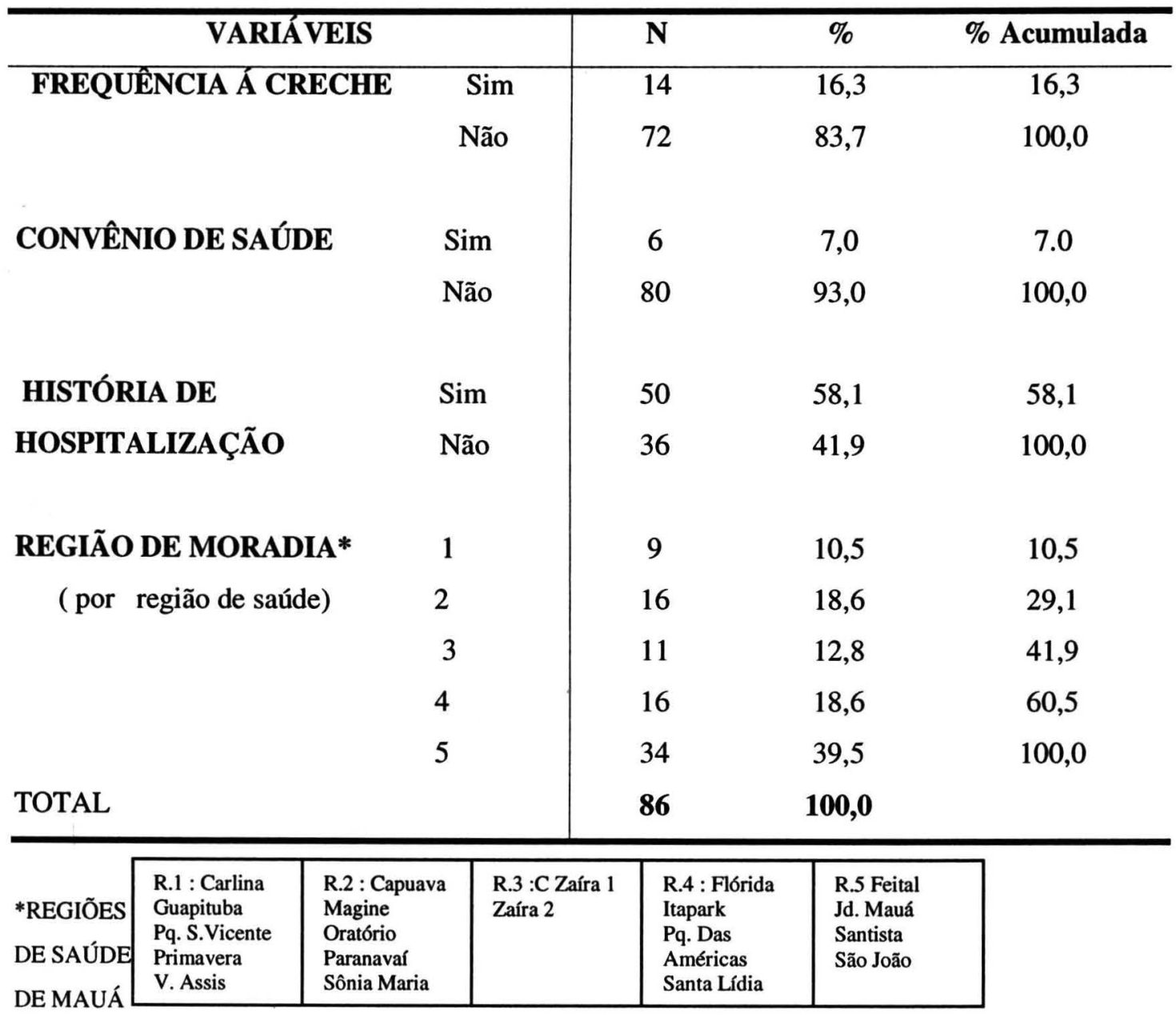




\section{Aleitamento materno e alimentação complementar}

Quanto à alimentação, as Tabelas 13 e 14 mostram o comportamento do aleitamento materno. Segundo relato familiar, $74,4 \%$ ( Tabela15) tiveram aleitamento materno exclusivo, o que à primeira análise parece ser um valor notável, porém o desvio-padrão alto representa certa heterogeneidade de tempos destinados a esta prática.

A Tabela 14 mostra que houve crianças que tiveram aleitamento exclusivo só um mês e outra por dois anos. Importante ressaltar que este dado, mamar até dois anos, foi confirmado com a mãe à entrevista e a mesma disse, inclusive, que teve muita dificuldade de introduzir outros alimentos e no momento da interrupção da amamentação ambas sofreram, mãe e filha. A mesma criança tem déficit nutricional com o índice de escore $\mathrm{Z}$ peso/ estatura menor que -2, em contrapartida foi bem no teste de Denver2 e com bom comportamento de apego seguro.

O tempo de aleitamento materno misto se refere ao tempo de amamentação que a criança só mamou no peito e após com mamadeira ou sempre tomou leite no seio materno e mamadeira.

Estas informações enfrentaram dificuldades de coleta dado pois a mãe ou o responsável não se lembravam do tempo certo. Apesar disso, o tempo médio foi mais preciso, desse modo um tempo máximo de 43 meses de amamentação chamou a atenção. 
Verificou-se que algumas crianças ainda são amamentadas ao seio materno ou a encerraram próximo aos três anos, especificamente, 12 (10,32\%). Duas destas crianças se destacaram na entrevista.

Uma apresentou um comportamento atípico quando ficou, durante todo o encontro, mamando na mamadeira da boneca utilizada no Teste de Denver2, Esporadicamente dirigia-se a outros brinquedos, mas logo repetia a ação anterior.

Uma outra criança (de 38 meses) manteve o aleitamento materno até os dois anos de idade e nunca aceitou mamadeira. Segundo a mãe e tia, ela mantém um comportamento que definiram como brava e arisca. Referiram que acorda mal humorada e nervosa, vai à creche e bate em muitas crianças, necessitando sempre de muito tempo para se acalmar, fica sempre isolada, não compartilha brinquedos com os irmãos e tem preferência por adultos. Come unha e papel e à noite dorme mal, só agarrada à mãe. Vale lembrar que ela tem história de hospitalizações ao nascimento $\mathrm{e}$ no primeiro e segundo anos de vida, com diagnósticos diferentes, icterícia fisiológica, diarréia, anemia e pneumonia.

À entrevista portou-se de maneira semelhante agindo com certa indiferença, especialmente nas brincadeiras. Ficou evidente que a criança tem a tia também como cuidador, pois a mãe trabalha e não possui um parceiro conjugal. Ao final constatou-se um resultado para o Teste de Denver II alterado, bem como apresentou um valor para o comportamento do apego seguro ( $71 \%$ ) inferior à mediana. $\mathrm{O}$ caso foi discutido $\mathrm{e}$ encaminhado. 
Quanto ao uso de mamadeira, de modo geral gostam de tomar e faz parte de sua rotina alimentar.

TABELA 13 - Distribuição da prática de aleitamento materno de crianças com baixo peso ao nascer em 2001, Mauá, 2004.

\begin{tabular}{lc|ccc}
\hline \multicolumn{2}{c|}{ ALEITAMENTO MATERNO } & N & \% & \% Acumulada \\
\hline LEITE MATERNO & Sim & 64 & 74,4 & 74,4 \\
EXLUSIVO & Não & 22 & 25,6 & 100,0 \\
LEITE MATERNO MISTO & & & & \\
& Sim & 24 & 27,9 & 27,9 \\
SEM LEITE MATERNO & Não & 62 & 72,1 & 100,0 \\
& & & & \\
TOTAL & Sim & 15 & 17,4 & 17,4 \\
\hline
\end{tabular}

TABELA 14 - Média, valores mínimo, máximo e desvio- padrão do tempo de aleitamento, e tempo de aleitamento misto de crianças com baixo peso ao nascer em 2001, Mauá, 2004.

\begin{tabular}{l|ccccc}
\hline VARIÁVEL & N & Mínimo & Máximo & Média & Desvio padrão \\
\hline $\begin{array}{l}\text { Tempo de aleitamento materno } \\
\text { exclusivo (em meses) }\end{array}$ & $64^{*}$ & 1 & 24 & 5,5 & 3,9 \\
\hline $\begin{array}{l}\text { Tempo de aleitamento misto } \\
\text { (em meses) }\end{array}$ & $25 *$ & 1 & 43 & 15,5 & 13,7 \\
\hline
\end{tabular}

* Foram excluídos os dados ignorados. 
Além do aleitamento materno, a pesquisa alimentar recordatória procurou identificar a prática da alimentação complementar no primeiro ano de vida e nos seguintes.

O início da introdução de outros alimentos variou de acordo com a prática do aleitamento materno conforme mostraram as Tabela 13 e 14. Evidenciou-se certa irregularidade especialmente para os alimentos sólidos como, por exemplo, uma criança que iniciou com 10 meses e outra com um ano, mas a maioria em torno de 5 ou 6 meses.

A maior parte referiu iniciar com um suquinho normalmente de laranja ou chá e seguido pela papa salgada. Os ingredientes variaram. Os mais citados foram batata, cenoura, chuchu, macarrão e abobrinha. A carne sempre foi citada como dependente da renda familiar e quanto está maior mais este alimento estava presente. Uma mãe referiu que a carne era para dar gosto.

$\mathrm{O}$ ovo foi o ingrediente menos citado e quando se perguntava sobre o hábito de comê-lo muitas revelavam espanto com aparente medo de oferecê-lo ao bebê. E algumas mães nunca ofereceram.

Em linhas gerais, a alimentação dos anos seguintes pareceu manter um padrão de deficiência quanto ao uso dos nutrientes essenciais. A carne mantém o mesmo padrão de dependência da renda familiar e em contrapartida há uma prática evidente de consumo de alimentos pobres em nutrientes e fáceis de preparar. Muito consumo de guloseimas, pão, batatas fritas, miojo, chocolate, iogurtes, mingau de Farinha Láctea, Neston, bolachas. As verduras sempre associadas a uma prática difícil. 
Genericamente, as respostas foram das mais diversas com muitas mães dizendo que os filhos comem de tudo até outras afirmando que tem que brigar para fazer o filho comer ou só come se der na boca.

Toda a alimentação e não somente a carne sugeriram dependência da renda. Uma mãe disse que seu filho come de tudo, mas nem sempre tem de tudo para comer.

\section{Situação nutricional}

A situação nutricional obtida por meio da antropometria está representada nas Tabelas 15 e 16 segundo o padrão de referência do NCHS ( OMS 1995; NCHS 1997) pelos índices nutricionais peso/ estatura, peso/ idade e estatura/ idade.

Os valores mínimos (Tabela 16) e os números absolutos e percentuais (Tabela 17) mostram que existem crianças desta coorte com déficits nutricionais.

O percentual maior de déficits nutricionais (escore $Z<-2$ ) aparece no índice de peso/ idade, $12,8 \%$, e para os outros índices o percentual ficou em 5,8\% para peso/ estatura e $4,65 \%$ para estatura/ idade. Cumpre observar que as médias (Tabela 16) apresentam certo desvio para a esquerda o que pode representar um grupo que tem um perfil de estatura e pesos menores que o percentil desejado, o P50. 
TABELA 15 - Distribuição dos escores $Z$ dos índices nutricionais de crianças com baixo peso ao nascer em 2001, Mauá, 2004.

\begin{tabular}{cc|ccc}
\hline ÍNDICES NUTRICIONAIS POR ESCORE Z & N & $\%$ & \% Acumulada \\
\hline PESO /ESTATURA & $\geq-2$ & 81 & 94,2 & 94,2 \\
& $<-2$ & 5 & 5,8 & 100,0 \\
PESO/ IDADE & $\geq-2$ & 75 & 87,2 & 87,2 \\
& $<-2$ & 11 & 12,8 & 100,0 \\
& & & & \\
ESTATURA/IDADE & $\geq-2$ & 82 & 95,35 & 95,4 \\
& $<-2$ & 4 & 4,65 & 100,0 \\
\hline
\end{tabular}

TABELA 16 - Mínimo, máximo e desvios-padrão dos escores $\mathrm{Z}$ dos índices nutricionais de crianças com baixo peso ao nascer em 2001, Mauá, 2004.

\begin{tabular}{l|ccccc}
\hline VARIÁVEL & N & Mínima & Máxima & Média & Desvio padrão \\
\hline Escore Z de Peso / Estatura & $\mathbf{8 6}$ & $-3,6$ & 3,6 & $-0,6$ & 1,1 \\
\hline Escore Z de Peso / Idade & $\mathbf{8 6}$ & $-3,7$ & 2,6 & $-0,8$ & 1,1 \\
\hline Escore Z de Estatura/ Idade & $\mathbf{8 6}$ & -3 & 1,4 & $-0,4$ & 0,9 \\
\hline
\end{tabular}




\section{Necessidades básicas}

Além da alimentação, outras necessidades básicas foram investigadas.

Informações significativas não foram observadas quanto à higienização corporal e bucal.

O próprio teste de Denver II possibilitou averiguar estes elementos, pois o setor pessoal-social avalia a prática de vestir-se, lavar as mãos, escovar os dentes. Notou-se que a evolução de tais práticas dependeu da freqüência à creche e da relação familiar.

Uma criança chamou a atenção pela aparência geral de má higiene, na entrevista notou-se que estava com pediculose e confirmado pela mãe, com uma história de precariedade de moradia; a casa possuindo piso de terra batida e sem água encanada. Notou-se uma mãe envelhecida e extremamente cansada. A mesma referiu que a filha é muito agressiva e tem o hábito de bater-lhe assim, ela disse: não consigo cuidar do seu piolho porque ela bate em mim.

Aparentemente a menina parecia totalmente desinteressada pelas atividades que lhe foram propostas e em nenhum momento sorriu ou expressou algum movimento de satisfação e tão pouco de medo.

O período do controle esfincteriano ficou impreciso. Muitas mães referiam que o controle ocorreu em torno dos 2 anos, mas, num dado momento, algumas acrescentavam que mantinham o uso noturno. 
A ausência da fralda também se associou à renda familiar. Várias mães referiram que o filho ainda não tem controle da micção, mas só usam fralda à noite ou para passear. Nenhuma mãe relatou uso de fralda não descartável.

De modo geral o que se notou é que a maioria adquiriu controle esfincteriano vesical e anal há pouco tempo. Não se verificou nenhum caso atípico.

O repouso diurno apareceu em poucas crianças, e, caso tenham outra atividade, tal como algum companheiro para brincar, o sono é afastado. Neste aspecto, a brincadeira em grupo já faz parte da vida da maioria delas e evidenciou-se crianças com maior dificuldade de socialização preferindo brincar isoladas ou ter companhia de adultos. 


\section{Comportamento de apego seguro}

A avaliação do comportamento de apego seguro mostrou muitas crianças com respostas semelhantes, como se pode ver nas Tabelas 17 e 18 . A pequena variação das respostas registradas, mediante a observação da criança e mãe ou cuidador, foi determinante no resultado final da avaliação. Assim, um mínimo de 67,7 e máximo de 98,4 representaram comportamentos distintos e responsáveis pela identificação de um comportamento sugestivo de apego inseguro.

Alguns itens apresentaram respostas similares como, por exemplo, os itens 8,12 e 23. No primeiro a criança está atenta à localização da mãe; o segundo brinca, mas volta sempre à mãe e o terceiro que fica feliz quando ela chega. Eles possibilitaram observar sua fase exploratória e a sua capacidade de se afastar ou não da presença da mãe.

O que pareceu foi que a maioria das crianças desta faixa etária está iniciando este processo de exploração, com comportamentos de dependência e independência. Frases de mães se referindo o filho como: é um grude surgiram mais de uma vez; ou pede o peito, chora ou frases significando um comportamento contrário como, está ficando independente.

Outros itens como o 6, 7 e 11 permitiram verificar capacidades de adaptação a situações adversas como obediência/ desobediência. O 6 se verifica se ele segue suas orientações; o item 7 se ele obedece a mãe caso ela peça alguma coisa e no 11 se verifica o quanto consegue atender ao "não" . 
Algumas falas foram, depende do humor ele obedece; tem que apanhar para obedecer; obedece porque tem medo de apanhar. Duas mães disseram, de forma humorada, receber a seguinte resposta: não sou sua empregada! Esta frase vinha sempre acompanhada com certo humor da mãe. Ou frases como: é carinhoso e obediente; é minha companheirinha...

Outro item relativo à socialização (22), em que se verifica seu carinho e amizade por adultos, mostrou que a criança, na maior parte das vezes, prefere outra criança para fazer amizades ao invés de adultos.

O item 15 favoreceu evidenciar a presença de vínculo entre os dois. Interrogando-se a reação da criança caso a mãe estivesse triste vinham respostas como, ele fica chateado também (o filho) ou, mãe, você está triste? E outras como, ele chora junto; não chora não mãe... Ou mães que não percebem a reação do filho.

Os itens 17 e 29, igualmente, permitiam observar vínculos entre mãe e filho. Por meio de brincadeiras, tal como gostar de fazer barulho ou alguém imitá-lo, se verificaram atitudes diferentes referidas pela mãe: ele fica bravo ou acha graça; faz para chamar a atenção e faz mais.

O apego à mãe pode ser verificado ainda em outros itens e através de frases como: me dá um beijo mãe; o tempo todo está atrás de mim; adora subir na mãe; a mãe é brincalhona com a filha e ela a adora (avó que também cuida respondendo).

A capacidade de adaptar-se a situações adversas ou resiliência, adquirir segurança, também se fizeram notar em outros itens e as reações se diferenciavam. 
Como no item 20, por exemplo, em que no caso da criança passar por uma situação conflitante ela confia no que a mãe diz. Durante a entrevista algumas delas comportaram-se de maneira extremamente assustada, choraram o tempo todo e precisaram ser pesadas no colo da mãe. Em contrapartida outras se recusavam encerrar a entrevista e queriam continuar com a brincadeira e o bate- papo.

O comportamento da criança na entrevista ofereceu outros dados interessantes acerca do apego à mãe e relação familiar. Num outro exemplo uma criança, enquanto conversava com os entrevistadores, ficou penteando o cabelo da mãe, carinhosamente, e em certo momento perguntou-lhe, mãe, qual o nome do teu namorado? E continuou a conversar com sua mãe e a equipe. Neste caso a mãe não mora com o pai, entretanto ele assumiu a paternidade e vê sempre a filha. Esta criança foi bem no teste de Denver II e obteve um bom percentual para o apego.

Este caso e outros semelhantes representaram alguns dos comportamentos notados durante as entrevistas. Por vezes se observou que a criança possuía mais de uma figura de apego, o pai, avós e tia. Importante destacar que uma delas reside somente com o pai e também respondeu bem ao teste.

Segundo uma mãe a sua filha é extremamente apegada à tia e à sua ausência, às vezes, tem febre. Segundo seus relatos (mãe e tia presentes), a mãe tinha medo de cuidar do bebê e assim os cuidados eram praticados pela tia.

Outro aspecto notado foi a presença de mães aparentemente tímidas, distraídas ou com dificuldade de se expressar, o que se refletia também nas atitudes da criança. 
Estas observações das reações familiares, em conjunto com o teste de Denver II, durante a entrevista, facilitaram a avaliação do comportamento do apego.

TABELA 17 -Média, valores mínimo, máximo e desvios-padrão do comportamento de apego seguro de crianças com baixo peso ao nascer em 2001, Mauá, 2004.

\begin{tabular}{lc|cccccc}
\hline VARIÁVEL & N & Mínima & Máxima & Média & Mediana & $\begin{array}{l}\text { Desvio } \\
\text { padrão }\end{array}$ \\
\hline $\begin{array}{l}\text { Comportamento } \\
\text { Apego Seguro }\end{array}$ & de & 86 & 67,7 & 98,4 & 90,1 & 90,3 & 6,2 \\
\hline
\end{tabular}


TABELA 18- Distribuição contínua dos comportamentos de apego seguro de crianças com baixo peso ao nascer em 2001, Mauá, 2004.

\begin{tabular}{|c|c|c|c|}
\hline COMPORTAMENTO DE APEGO SEGURO & $\mathbf{N}$ & $\%$ & \% Acumulada \\
\hline 67,7 & 1 & 1,2 & 1,2 \\
\hline 70,9 & 1 & 1,2 & 2,3 \\
\hline 72,6 & 1 & 1,2 & 3,5 \\
\hline 75,8 & 1 & 1,2 & 4,7 \\
\hline 80,6 & 2 & 2,3 & 7,0 \\
\hline 82,2 & 1 & 1,2 & 8,1 \\
\hline 82,3 & 1 & 1,2 & 9,3 \\
\hline 83,8 & 2 & 2,3 & 11,6 \\
\hline 83,9 & 5 & 5,8 & 17,4 \\
\hline 85,5 & 4 & 4,7 & 22,1 \\
\hline 87,1 & 7 & 8,1 & 30,2 \\
\hline 88,5 & 1 & 1,2 & 31,4 \\
\hline 88,7 & 7 & 8,1 & 39,5 \\
\hline 90,3 & 10 & 11,6 & 51,2 \\
\hline 91,9 & 6 & 7,0 & 58,1 \\
\hline 93,5 & 7 & 8,1 & 66,3 \\
\hline 93,6 & 2 & 2,3 & 68,6 \\
\hline 95,1 & 4 & 4,7 & 73,3 \\
\hline 95,2 & 11 & 12,8 & 86,0 \\
\hline 96,7 & 3 & 3,5 & 89,5 \\
\hline 96,8 & 7 & 8,1 & 97,7 \\
\hline 98,4 & 2 & 2,3 & 100,0 \\
\hline Total & 86 & 100,0 & \\
\hline
\end{tabular}




\subsection{Análise do crescimento físico}

Os dados a seguir apresentam a associação das variáveis de desfecho do crescimento, peso/estatura; peso/idade e estatura/idade com as variáveis independentes que apresentaram chance de risco com significância ao nível de 5\%.

As outras variáveis independentes não apresentaram significâncias e o valor dos riscos relativos obtidos estão descritos a seguir.

O que se observa pela Tabela 19 é que o diferencial por sexo apresentou um potencial $(\mathrm{p}=0,069)$ de chances a mais de risco para o sexo masculino em ter déficit nutricional de peso que entre as meninas.

$\mathrm{O}$ mesmo se verifica quanto à situação conjugal materna com um potencial $(\mathrm{p}=$ 0,054) de chances de risco a ter mais déficit nutricional de peso entre as crianças com mães sem companheiro. $O$ mesmo se observa na Tabela 20 para a estatura/idade em que aparece chance de risco para o déficit de altura entre as crianças filhas de mães sem companheiro.

Na Tabela 20 ainda se observa um potencial de chances de risco para déficits de altura entre aquelas com mães desempregadas. Quanto às mães que não fizeram prénatal, seus filhos apresentaram 10 vezes mais chances de risco quanto ao déficits de altura. Contudo, nesta amostra, apenas duas crianças pertencem a este grupo. 
TABELA 19-Associação e risco relativo de peso/idade segundo o sexo e situação conjugal por ocasião do parto de crianças com baixo peso ao nascer em 2001, Mauá, 2004.

\begin{tabular}{|c|c|c|c|c|c|c|}
\hline \multirow[b]{2}{*}{ Variáveis } & \multicolumn{2}{|c|}{ Peso/idade } & \multirow[b]{2}{*}{$\begin{array}{l}\text { Total } \\
\mathrm{N}(\%)\end{array}$} & \multirow[b]{2}{*}{$\mathbf{R R}$} & \multirow[b]{2}{*}{ Valor p } & \multirow[b]{2}{*}{ IC } \\
\hline & $\begin{array}{l}N(\%) \\
Z \geq-2\end{array}$ & $\begin{array}{l}N(\%) \\
Z<-2\end{array}$ & & & & \\
\hline SEXO* & $75(100,0)$ & $11(100,0)$ & $86(100,0)$ & & & \\
\hline Feminino & $38(50,7)$ & $2(18,2)$ & $40(46,5)$ & 1 & & \\
\hline Masculino & $37(49,3)$ & $9(81,8)$ & $46(53,5)$ & 3,9 & 0,069 & $0,9-17,1$ \\
\hline SIT.CONJUGAL & $75(100,0$ & $11(100,0)$ & $86(100,0)$ & & & \\
\hline Com parceiro & $56(74,7)$ & $5(45,45)$ & $61(70,9)$ & 1 & & \\
\hline Sem parceiro & $19(25,3)$ & $6(54,55)$ & $25(29,1)$ & 2,9 & 0,054 & $1-8,7$ \\
\hline
\end{tabular}

* os dados desta variável foram obtidos da DNV( SIM/SINASC- Secr. Saúde Mauá;2004) 
TABELA 20 -Associação e risco relativo de estatura/idade segundo consulta de pré-natal e situação conjugal atual de crianças com baixo peso ao nascer em 2001, Mauá, 2004.

\begin{tabular}{|c|c|c|c|c|c|c|}
\hline \multirow[b]{2}{*}{ Variáveis } & \multicolumn{2}{|c|}{ estatura/ idade } & \multirow[b]{2}{*}{$\begin{array}{l}\text { Total } \\
\mathbf{N}(\%)\end{array}$} & \multirow[b]{2}{*}{$\mathbf{R R}$} & \multirow[b]{2}{*}{ Valor $\mathbf{p}$} & \multirow[b]{2}{*}{ IC } \\
\hline & $\begin{array}{l}\mathrm{N}(\%) \\
\mathrm{Z} \geq \mathbf{- 2}\end{array}$ & $\begin{array}{l}N(\%) \\
Z<-2\end{array}$ & & & & \\
\hline PRÉ-NATAL* & $81(100,0)$ & $4(100,0)$ & $85(100,0)$ & & & \\
\hline 7 e mais & $38(46,9)$ & $2(50,0)$ & $40(47,1)$ & 1 & & \\
\hline 4 a 6 & $42(51,8)$ & $1(25,0)$ & $43(50,6)$ & 0,5 & 0,525 & $0,0-5$ \\
\hline 0 a 3 & $1(1,2)$ & $1(25,0)$ & $2(2,35)$ & 10 & 0,02 & $1,4-69,3$ \\
\hline SIT.CONJUGAL & $82(100,0$ & $4(100,0)$ & $86(100,0)$ & & & \\
\hline Com parceiro & $60(73,2)$ & $1(25,0)$ & $61(70,1)$ & 1 & & \\
\hline Sem parceiro & $22(26,8)$ & $3(75,0)$ & $25(29,1)$ & 7,32 & 0,078 & $0,8-67,0$ \\
\hline OCUPAÇÃO & $82(100,0)$ & $4(100,0)$ & $86(100,0)$ & & & \\
\hline Trab. remunerado & $38(46,3)$ & $1(25,0)$ & $39(45,35)$ & 1 & & \\
\hline Do lar & $31(37,8)$ & $0(0,0)$ & $31(36,05)$ & & & \\
\hline desempregada & $13(15,8)$ & $3(75,0)$ & $16(18,6)$ & 7,3 & 0,075 & $0,8-65,1$ \\
\hline
\end{tabular}

* os dados desta variável foram obtidos da DNV( SIM/SINASC- Secr. Saúde Mauá;2004)

As Tabelas 21, 22, 23 e 24 representam o resultado obtido da análise bivariada entre os índices nutricionais e as demais variáveis independentes. Observa-se que não foi verificada presença de risco entre as crianças expostas ou com déficits nutricionais com estas variáveis, assim optou-se por apenas apresentar os valores de p e qui-quadrado e esclarecendo-se que foram mantidas as mesmas categorias das variáveis.

Estes resultados podem significar a baixa prevalência obtida dos sujeitos expostos, ou seja, aqueles que apresentaram déficits nutricionais $(\mathrm{Z}<-2)$. 
TABELA 21 - Valor de p e qui-quadrado das associações entre os índices nutricionais e variáveis do período perinatal de crianças com baixo peso ao nascer em 2001, Mauá, 2004.

\begin{tabular}{|c|c|c|c|c|c|c|}
\hline \multirow{2}{*}{ Variáveis } & \multicolumn{2}{|c|}{ Peso/ estatura } & \multicolumn{2}{|c|}{ Peso/idade } & \multicolumn{2}{|c|}{ Estatura/idade } \\
\hline & Valor p & $\begin{array}{c}\text { Qui- } \\
\text { quadrado }\end{array}$ & Valor p & $\begin{array}{c}\text { Qui- } \\
\text { quadrado }\end{array}$ & Valor $\mathbf{p}$ & $\begin{array}{c}\text { Qui- } \\
\text { quadrado }\end{array}$ \\
\hline SEXO* & 0,991 & -- & -- & -- & 0,886 & 0,020 \\
\hline PARTO* & 0,11 & -- & 0,43 & -- & 0,588 & -- \\
\hline T. GRAVIDEZ* & 0,462 & -- & 0,171 & -- & 0,542 & -- \\
\hline ID.GESTACIONAL* & 0,37 & -- & 0,597 & -- & 0,52 & -- \\
\hline APGAR $1^{\circ}$ MIN* & 0,542 & -- & 0,280 & -- & 0,614 & - \\
\hline COMPL. NEONAT. & 0,161 & -- & 0,557 & -- & 0,578 & -- \\
\hline
\end{tabular}

*os dados desta variável foram obtidos da DNV( SIM/SINASC- Secr. Saúde Mauá;2004)

Nota: Resultados sem o valor do qui-quadrado realizou-se o teste exato de Fisher.

TABELA 22- Valor de p e qui-quadrado das associações entre os índices nutricionais e variáveis sociais e da gestação maternas de crianças com baixo peso ao nascer em 2001, Mauá, 2004.

\begin{tabular}{l|cccccc}
\hline \multirow{2}{*}{ Variáveis } & \multicolumn{3}{|c}{ Peso/ estatura } & \multicolumn{2}{c}{ Peso/ idade } & \multicolumn{2}{c}{ Estatura/ idade } \\
\cline { 2 - 7 } & Valor p & $\begin{array}{c}\text { Qui- } \\
\text { quadrado }\end{array}$ & Valor p & $\begin{array}{c}\text { Qui- } \\
\text { quadrado }\end{array}$ & Valor p & $\begin{array}{c}\text { Qui- } \\
\text { quadrado }\end{array}$ \\
\hline IDADE MÃE* & 0,17 & 3,54 & 0,718 & 0,66 & 0,688 & 0,75 \\
SIT.CONJUGAL* & 0,176 & -- & 0,31 & -- & 0,089 & -- \\
ESCOLARIDADE* & 0,532 & 2,20 & 0,272 & 3,9 & 0,724 & 1,32 \\
PRÉ-NATAL* & 0,707 & -- & 0,213 & 3,09 & -- & -- \\
AFECÇ. GESTAC. & 0,647 & -- & 0,527 & -- & 0,647 & -- \\
HÁBITO FUMAR & 0,497 & -- & 0,490 & -- & 0,214 & - \\
\hline
\end{tabular}

* os dados desta variável foram obtidos da DNV( SIM/SINASC- Secr. Saúde Mauá;2004)

Nota: Resultados sem o valor do qui-quadrado realizou-se o teste exato de Fisher. 
TABELA23 - Valor de p e qui-quadrado das associações entre os índices nutricionais e aleitamento materno de crianças com baixo peso ao nascer em 2001, Mauá, 2004.

\begin{tabular}{l|cccccc}
\hline \multirow{2}{*}{ Variáveis } & \multicolumn{3}{|c}{ Peso/ estatura } & \multicolumn{2}{c}{ Peso/ idade } & \multicolumn{2}{c}{ Estatura/ idade } \\
\cline { 2 - 7 } & Valor p & $\begin{array}{c}\text { Qui- } \\
\text { quadrado }\end{array}$ & Valor p & $\begin{array}{c}\text { Qui- } \\
\text { quadrado }\end{array}$ & Valor p & $\begin{array}{c}\text { Qui- } \\
\text { quadrado }\end{array}$ \\
\hline L.M.EXCLUSIVO & 0,620 & -- & 0,573 & -- & 0,731 & -- \\
L.M. MISTO & 0,13 & -- & 0,635 & -- & 0,310 & -- \\
SEM L.M & 0,374 & -- & 0,388 & -- & 0,457 & - \\
\hline
\end{tabular}

Nota: Resultados sem o valor do qui-quadrado realizou-se o teste exato de Fisher.

TABELA 24- Valor de p e qui-quadrado das associações entre os índices nutricionais e variáveis da vida pós natal e atual da criança daquelas com baixo peso ao nascer em 2001, Mauá, 2004.

\begin{tabular}{l|cccccc}
\hline \multirow{2}{*}{ Variáveis } & \multicolumn{3}{|c}{ Peso/ estatura } & \multicolumn{2}{c}{ Peso/ idade } & \multicolumn{2}{c}{ Estatura/ idade } \\
\cline { 2 - 7 } & $\begin{array}{c}\text { Valor } \\
\text { p }\end{array}$ & $\begin{array}{c}\text { Qui- } \\
\text { quadrado }\end{array}$ & Valor p & $\begin{array}{c}\text { Qui- } \\
\text { quadrado }\end{array}$ & Valor p & $\begin{array}{c}\text { Qui- } \\
\text { quadrado }\end{array}$ \\
\hline HOSPITALIZAÇÃO & 0,653 & -- & 0,081 & -- & 0,441 & -- \\
CRECHE & 0,185 & -- & 0,253 & -- & 0,122 & -- \\
CONVÊNIO & 0,69 & -- & 0,428 & -- & 0,745 & -- \\
REGIÃO MORADIA & 0,546 & -- & 0,558 & -- & 0,622 & -- \\
APEGO MATERNO & 0,522 & -- & 0,934 & 0,01 & 0,616 & -- \\
\hline
\end{tabular}

Nota: Resultados sem o valor do qui-quadrado foram realizados o teste exato de Fisher. 
TABELA 25 - Valor de p e qui-quadrado das associações entre os índices nutricionais e variáveis maternas da vida atual da criança com baixo peso ao nascer em 2001, Mauá, 2004.

\begin{tabular}{l|cccccc}
\hline \multirow{2}{*}{ Variáveis } & \multicolumn{3}{|c}{ Peso/ estatura } & \multicolumn{2}{c}{ Peso/ idade } & \multicolumn{2}{c}{ Estatura/ idade } \\
\cline { 2 - 7 } & Valor p & $\begin{array}{c}\text { Qui- } \\
\text { quadrado }\end{array}$ & Valor p & $\begin{array}{c}\text { Qui- } \\
\text { quadrado }\end{array}$ & Valor p & $\begin{array}{c}\text { Qui- } \\
\text { quadrado }\end{array}$ \\
\hline FILHOS ATUAL & 0,595 & -- & 0,145 & -- & 0,280 & -- \\
ESCOLAR. ATUAL & 0,866 & 0,73 & 0,851 & 0,79 & 0,952 & 0,34 \\
ESTUDO ATUAL & 0,606 & -- & 0,318 & -- & 0,328 & -- \\
OCUPAÇÃO ATUAL & 0,176 & 3,47 & 0,196 & 3,25 & 0,017 & 9,07 \\
RENDA* (Reais) & 0,233 & 4,28 & 0,105 & 2,627 & 0,736 & 0,113 \\
FAMÍLIA & 0,217 & 1,5265 & 0,134 & 2,245 & 0,990 & -- \\
\hline
\end{tabular}




\subsection{Análise do desenvolvimento neuropsicomotor}

Os resultados a seguir apresentam a caracterização das crianças quanto ao seu comportamento durante o teste de Denver II. Em seguida realizou-se a análise bivariada entre a variável de desfecho e as variáveis independentes associadas para identificação de prováveis riscos.

\section{Teste de Denver II}

A realização do teste de Denver II possibilitou identificar, além de atrasos de desenvolvimento neuropsicomotor, o comportamento da criança e família tendo em vista que seu procedimento ocorre de modo descontraído, dialogando-se por meio de brincadeiras.

A Tabela 26 representa o número e percentual de crianças que, possivelmente, apresentam atrasos para o desenvolvimento lembrando que não é de competência do teste diagnosticar alguma deficiência neurológica ou psíquica.

Apesar disso os resultados mostram um número considerável de crianças suspeitas ou intestáveis (57\%) e, conforme recomendações de FRANKENBURG et al (1992), foram reconvocadas à repetir o teste mas apenas uma retornou. Deste modo, considerou-se estes valores como verdadeiros.

A Tabela 27 destaca os setores que mais apresentaram falhas; como se vê, a linguagem foi o setor com maior número $(47,7 \%)$ seguido da motricidade fina adaptativa 
( $30,2 \%)$. O setor pessoal social apresentou o menor número de falhas (14\%), inferior ao motor grosso ( $23,3 \%)$.

Importante ressaltar que o setor pessoal social possui vários itens em que a mãe pode referir, independente dele ser observado, tal como ter conhecimento acerca do nível de independência da criança. Escovar os dentes, vestir uma peça de roupa, foram exemplo de itens não observados, mas informados.

A linguagem merece destaque no sentido de que o grande motivador da segunda versão para teste de Denver II surgiu, justamente, da necessidade de aumentar os itens neste setor. Ficou evidente que a proporção de estímulos oferecidos à criança correspondeu ao número de falhas ou acertos particularmente neste item e nos outros dois. Crianças praticamente da mesma idade apresentaram diferenças significativas como, por exemplo, reconhecer e nomear figuras, cores e responder às perguntas relacionadas a adjetivos e preposições.

Perguntas como, quando está com sede o que você faz? Algumas crianças não respondiam nada ou com respostas limitadas e curtas. Ou o contrário, crianças com frases bem elaboradas como eu pego uma cadeira e pego água com o copo ou, e quando você está cansada? Respostas como, durmo na minha cama sozinha ou vou assistir televisão.

E outras perguntas sobre o uso de objetos como, para que serve um prato? Resposta, mamãe põe comida, ovo e feijão. 
A relação familiar se evidenciava durante o teste; uma mãe se emocionou e chorou quando seu filho acertou alguns dos itens.

Quanto ao motor grosso, algumas evidências mostraram que as dificuldades apresentadas pareciam ser de origem intrínsecas como, por exemplo, a dificuldade de realizar movimentos que exigiam equilíbrio e rapidez.

Outra diferenciação do teste de Denver II diz respeito ao quadro de avaliação do comportamento da criança como apresentado na Tabela 28. Estas observações sobre o medo, cooperação, interesse e nível de atenção no teste possibilitaram interagir com a avaliação do comportamento de apego, haja visto que se trata de elementos que possibilitam responder a questões como a capacidade da criança em adaptar-se a situações adversas.

Pode-se notar que tanto o medo quanto a cooperação apresentaram maior proporção à reação moderada; 47,7\% mostraram-se pouco distraídos, o que se justifica pela fase de interesse exploratório da criança. Assinalando-se que a diferença se fazia notar quando à abordagem da criança ao realizar uma brincadeira em grupo permitia ao examinador observar seu interesse e distração. A tabela mostra que a maioria esteve alerta durante todo o teste $(80,2 \%)$.

A Tabela 29 representa estes quatro comportamentos associados à classificação do teste e se pode constatar que quanto mais o comportamento apresentou alteração, maior foi o número de crianças com atraso no desenvolvimento, todos significantes estatisticamente. 
TABELA 26 - Distribuição do Teste de Denver II de crianças com baixo peso ao nascer em 2001, Mauá, 2004.

\begin{tabular}{c|ccc}
\hline DENVER & $\mathbf{N}$ & \% & \% Acumulada \\
\hline Normal & 37 & 43,0 & 43,0 \\
Suspeito & 37 & 43,0 & 86,0 \\
Intestável & 12 & 14,0 & 100,0 \\
Total & $\mathbf{8 6}$ & $\mathbf{1 0 0 , 0}$ & \\
\hline
\end{tabular}

TABELA 27 - Distribuição do Teste de Denver II por setores de crianças com baixo peso ao nascer em 2001, Mauá, 2004.

\begin{tabular}{lc|ccc}
\hline \multicolumn{2}{c|}{ SETORES COM ATRASO } & N & $\%$ & \% Acumulada \\
\hline PESSOAL SOCIAL & Não & 74 & 86,0 & 86,0 \\
& Sim & 12 & 14,0 & 100,0 \\
MOTOR FINO ADAPTATIVO & Não & 60 & 69,8 & 69,8 \\
& Sim & 26 & 30,2 & 100,0 \\
LINGUAGEM & & & & \\
& Não & 45 & 52,3 & 52,3 \\
& Sim & 41 & 47,7 & 100,0 \\
MOTOR GROSSO & & & & 76,7 \\
Total & Não & 66 & 76,7 & 100,0 \\
\hline
\end{tabular}


TABELA 28 - Distribuição dos tipos de comportamento no Teste de Denver II de crianças com baixo peso ao nascer 2001, Mauá, 2004.

\begin{tabular}{ll|ccc}
\hline TIPO DE COMPORTAMENTO & N & $\%$ & \% Acumulada \\
\hline \multirow{2}{*}{ MEDO } & Nenhum & 30 & 58,1 & 58,1 \\
& Moderado & 32 & 37,2 & 95,3 \\
& Extremo & 4 & 4,7 & 100,0 \\
& & & & \\
DURAÇÃO & Apropriado & 35 & 40,7 & 40,7 \\
DA ATENÇÃO & Pouco distraído & 41 & 47,7 & 88,4 \\
& Muito distraído & 10 & 11,6 & 100,0 \\
& & & & \\
COOPERAÇÃO & Usual & 45 & 52,3 & 52,3 \\
& Rara & 33 & 38,4 & 90,7 \\
INTERESSE PELO & Alerta & 8 & 9,3 & 100,0 \\
QUE O CERCA & Pouco interesse & 14 & 16,3 & 96,5 \\
& Nenhum interesse & 3 & 3,5 & 100,0 \\
TOTAL & & $\mathbf{8 6}$ & 100,0 & \\
\hline
\end{tabular}


TABELA 29 -Associação entre o Teste de Denver II e comportamento no teste de crianças com baixo peso ao nascer 2001, Mauá, 2004.

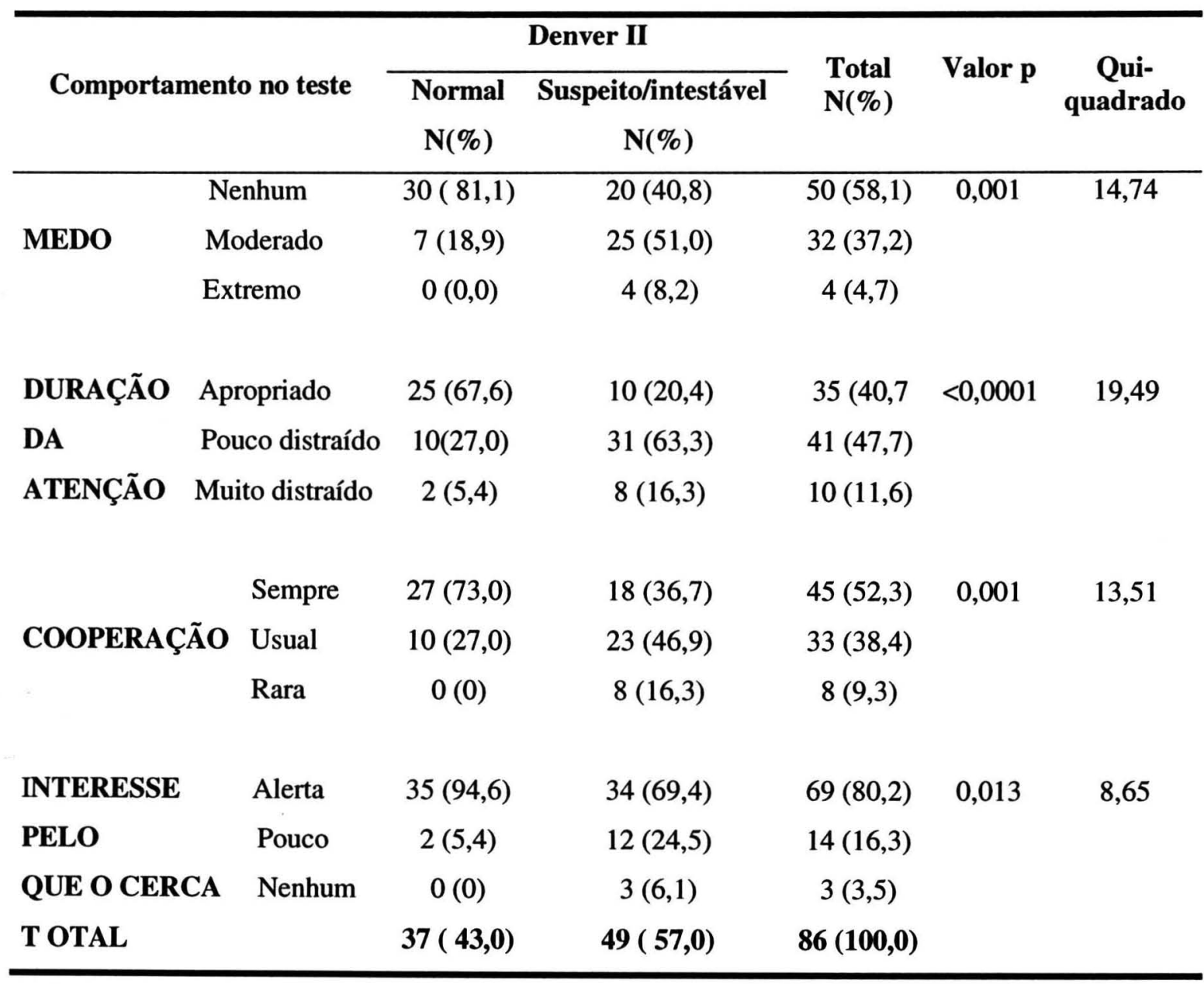


. Relação do desenvolvimento com variáveis por ocasião do parto da criança

As associações observadas na Tabela 30 mostram que o diferencial entre os sexos não representa riscos para o desenvolvimento neuropsicomotor.

Esta mesma tabela apresenta as variáveis por ocasião do parto como o tipo de parto, tipo de gravidez, idade gestacional e capacidade vital (Apgar $1^{\circ}$ ) e como se vê, também não apresentaram associação e risco para o desenvolvimento infantil. Complicações apresentadas no período neonatal apontam para um risco $(R R=1,393)$ mas não foi significante ao nível de $95 \%$ ( $\mathrm{p}=0,07$ ). Pode-se supor que talvez o tamanho amostral não confira poder suficiente para avaliar os riscos.

O peso ao nascer foi associado como variável quantitativa e em categorias. As Tabelas 31 e 32 não mostram significâncias e entre os diferenciais de baixo peso ao nascer e risco para o desenvolvimento. Observam-se médias de peso iguais para crianças com e sem atraso no desenvolvimento ( Tabela 31) e na Tabela 32 apresenta, inclusive, crianças que nasceram com menor peso e, proporcionalmente, estão um pouco melhores no desenvolvimento. 
TABELA 30-Associação e risco relativo entre o Teste de Denver II e variáveis biológicas e por ocasião do parto de crianças com baixo peso ao nascer 2001, Mauá, 2004.

\begin{tabular}{|c|c|c|c|c|c|c|}
\hline \multirow{3}{*}{ Variáveis } & \multicolumn{2}{|c|}{ Denver II } & \multirow[b]{2}{*}{ Total } & \multirow{3}{*}{$\mathbf{R R}$} & \multirow{3}{*}{$\mathbf{P}$} & \multirow{3}{*}{ IC } \\
\hline & Normal & $\begin{array}{l}\text { Suspeito/ } \\
\text { intestável }\end{array}$ & & & & \\
\hline & $\mathbf{N}(\%)$ & $\mathbf{N}(\%)$ & $\mathbf{N}(\%)$ & & & \\
\hline SEXO* & $37(100,0)$ & $49(100,0)$ & $86(100,0)$ & & & \\
\hline Feminino & $19(51,4)$ & $27(55,1)$ & $46(53,5)$ & 1 & & \\
\hline Masculino & $18(48,6)$ & $22(44,9)$ & $40(46,5)$ & 0,9 & 0,731 & $0,6-1,4$ \\
\hline PARTO* & $37(100,0)$ & $48(100,0)$ & $85(100,0)$ & & & \\
\hline Vaginal & $18(48,65)$ & $30(62,5)$ & $48(56,5)$ & 1 & & \\
\hline Cesáreo & $19(51,35)$ & $18(37,5)$ & $37(43,5)$ & 0,8 & 0,216 & $0,5-1,2$ \\
\hline T. GRAVIDEZ* & $37(100,0)$ & $49(100,0)$ & $86(100,0)$ & & & \\
\hline Única & $31(83,8)$ & $43(87,8)$ & $74(86,05)$ & 1 & & \\
\hline Gemelar & $6(16,2)$ & $6(12,2)$ & $12(13,95)$ & 0,9 & 0,622 & $0,5-1,6$ \\
\hline ID.GESTACIONAL* & $36(100,0)$ & $46(100,0)$ & $82(100,0)$ & & & \\
\hline Termo & $24(66,7)$ & $27(58,7)$ & $51(62,2)$ & 1 & & \\
\hline Pré-termo & $12(33,3)$ & $19(41,3)$ & $31(37,8)$ & 1,2 & 0,451 & $0,8-1,7$ \\
\hline APGAR $1^{\circ}$ MINUTO* & $36(100,0)$ & $44(100,0)$ & $80(100,0)$ & & & \\
\hline 7 e mais & $33(91,7)$ & $38(86,4)$ & $71(88,75)$ & 1 & & \\
\hline$<7$ & $3(8,30$ & $6(13,6)$ & $9(11,25)$ & 1,2 & 0,399 & $0,7-2,1$ \\
\hline COMPL. NEONAT. & $37(100,0)$ & $48(100,0)$ & $85(100,0)$ & & & \\
\hline Não & $28(75,7)$ & $28(58,3)$ & $56(65,9)$ & 1 & & \\
\hline $\operatorname{sim}$ & $9(24,3)$ & $20(41,7)$ & $29(34,10$ & 1,4 & 0,078 & $0,9-1,97$ \\
\hline
\end{tabular}

* os dados destas variáveis foram obtidos da DNV( SIM/SINASC- Secr. Saúde Mauá;2004) 
TABELA 31 - Associação entre oTeste de DenverII e peso ao nascer segundo médias, mínimo, máximo, desvio padrão e valor p de crianças com baixo peso ao nascer 2001, Mauá, 2004.

\begin{tabular}{l|ccccccc}
\hline VARIÁVEL DENVERII & N & Mínima & Máxima & Média & $\begin{array}{r}\text { Desvio } \\
\text { padrão }\end{array}$ & P \\
& & & & & 2,3 & 0,253 & 0,2 \\
\hline Peso ao Normal & 37 & 1,6 & 2,5 & 2,2 & 0,264 & \\
nascer ( gr)* & Susp./intest. & 49 & 1,1 & 2,5 & 2,2 & \\
\hline
\end{tabular}

* Dados obtidos da DNV-SIM/SINASC, Secret. Saúde Mauá,2004.

TABELA 32 - Associação e risco relativo entre oTeste de DenverII e classificação e peso ao nascer de crianças com baixo peso ao nascer 2001, Mauá, 2004.

\begin{tabular}{lcccccc}
\hline \multirow{2}{*}{ Variáveis } & \multicolumn{2}{c}{ Denver II } & & & \\
\cline { 2 - 4 } & Normal & $\begin{array}{c}\text { Suspeito/ } \\
\text { intestável }\end{array}$ & Total & RR & P & IC \\
& $\mathbf{N}(\%)$ & $\mathbf{N}(\%)$ & $\mathbf{N}(\%)$ & & & \\
\hline PESO AO NASCER* & $\mathbf{3 7 ( 1 0 0 , 0 )}$ & $\mathbf{4 9 ( 1 0 0 , 0 )}$ & $\mathbf{8 6 ( 1 0 0 , 0 )}$ & & & \\
$2.000 \mathrm{~g} .-2.500 \mathrm{~g}(1)^{* *}$ & $31(83,8)$ & $44(89,8)$ & $75(87,2)$ & 1 & 1 & 1 \\
$<2.000 \mathrm{~g}$ & $6(16,2)$ & $5(10,2)$ & $11(12,8)$ & 0,8 & 0,459 & $0,4-1,5$ \\
\hline
\end{tabular}

* Dados obtidos da DNV-SIM/SINASC, Secret. Saúde Mauá,2004. 


\section{. Análise do desenvolvimento segundo variáveis pós-natais}

O aleitamento materno foi associado ao desenvolvimento e não se notou significância entre eles como se observa na Tabela 33 tanto para o aleitamento exclusivo, misto e a ausência dele. O que se observa é uma discreta proporção de crianças que tiveram mais história de amamentação, apresentando, atualmente, mais atrasos no desenvolvimento.

TABELA 33 - Associação e risco relativo de crianças nascidas entre o doTeste de DenverII e aleitamento materno de crianças com baixo peso ao nascer 2001, Mauá, 2004.

\begin{tabular}{|c|c|c|c|c|c|c|}
\hline \multirow{3}{*}{ Variáveis } & \multicolumn{2}{|c|}{ Denver II } & \multirow[b]{2}{*}{ Total } & \multirow{3}{*}{$\mathbf{R R}$} & \multirow{3}{*}{$\mathbf{P}$} & \multirow{3}{*}{ IC } \\
\hline & Normal & $\begin{array}{l}\text { Suspeito/ } \\
\text { intestável }\end{array}$ & & & & \\
\hline & $\mathbf{N}(\%)$ & $\mathbf{N}(\%)$ & \multirow[t]{2}{*}{$\mathbf{N}(\%)$} & & & \\
\hline \multicolumn{6}{|c|}{ L.M.EXCLUSIVO } & \\
\hline Sim & $26(70,3)$ & $38(77,6)$ & $64(74,4)$ & 1 & & \\
\hline Não & $11(29,7)$ & $11(22,4)$ & $22(25,6)$ & 0,8 & 0,468 & $0,5-1,3$ \\
\hline \multicolumn{7}{|l|}{ L.M. MISTO } \\
\hline Não & $26(70,3)$ & $36(73,5)$ & $62(72,1)$ & 1 & & \\
\hline Sim & $11(29,7)$ & $13(26,5)$ & $24(27,9)$ & 0,7 & 0,209 & $0,3-1,26$ \\
\hline \multicolumn{7}{|l|}{ SEM L.M } \\
\hline Não & $28(75,7)$ & $43(87,8)$ & $71(82,6)$ & 1 & & \\
\hline Sim & $9(24,3)$ & $6(12,2)$ & $15(17,4)$ & 0,9 & 0,748 & $0,6-1,4$ \\
\hline TOTAL & $37(43,0)$ & $49(57,0)$ & $86(100,0)$ & & & \\
\hline
\end{tabular}


Os índices nutricionais ( Tabela 34) não mostraram significância e risco para o desenvolvimento infantil, muito embora se observe que entre as crianças com déficits nutricionais, ou com escore $\mathrm{z}$ menor que -2 , estão em maior número entre aquelas consideradas em atraso (suspeitas ou intestáveis).

TABELA 34 -Associação e risco relativo entre o Teste de DenverII e a classificação e índices nutricionais de crianças com baixo peso ao nascer 2001, Mauá, 2004.

\begin{tabular}{|c|c|c|c|c|c|c|}
\hline \multirow{3}{*}{$\begin{array}{c}\text { ÍNDICES } \\
\text { NUTRICIONAIS }\end{array}$} & \multicolumn{2}{|c|}{ Denver II } & \multirow[b]{2}{*}{ Total } & \multirow{3}{*}{$\mathbf{R R}$} & \multirow{3}{*}{$\mathbf{P}$} & \multirow{3}{*}{ IC } \\
\hline & Normal & $\begin{array}{l}\text { Suspeitol } \\
\text { intestável }\end{array}$ & & & & \\
\hline & $\mathbf{N}(\%)$ & $\mathbf{N}(\%)$ & $\mathrm{N}(\%)$ & & & \\
\hline \multicolumn{7}{|l|}{ PESO /ESTATURA } \\
\hline$\geq-2(1)$ & $35(94,6)$ & $46(93,9)$ & $81(94,2)$ & 1 & & \\
\hline$<-2$ & $2(5,4)$ & $3(6,1)$ & $5(5,8)$ & 1,1 & 0,884 & $0,5-2,2$ \\
\hline \multicolumn{7}{|l|}{ PESO/ IDADE } \\
\hline$\geq-2(1)$ & $33(89,2)$ & $42(85,7)$ & $75(87,2)$ & 1 & & \\
\hline$<-2$ & $4(10,8)$ & $7(14,3)$ & $11(12,8)$ & 1,1 & 0,609 & $0,7-1,9$ \\
\hline \multicolumn{7}{|l|}{ ESTATURA/IDADE } \\
\hline$\geq-2(1)$ & $36(97,3)$ & $46(93,9)$ & $82(95,3)$ & 1 & & \\
\hline$<-2$ & $1(2,7)$ & $3(6,1)$ & $4(4,7)$ & 1,3 & 0,341 & $0,7-2,4$ \\
\hline TOTAL & $37(100,0)$ & $49(100,0)$ & $86(100,0)$ & & & \\
\hline
\end{tabular}

A freqüência à creche, presença de convênio médico privado e local de moradia familiar não mostraram significância e risco com o desenvolvimento deste grupo.

A Tabela 35 representa estes resultados mostrando um diferencial nas crianças que possuem convênio de saúde privada em que apenas uma está com atraso no 
desenvolvimento. Evidente que não houve associação, mas vale notar que estas famílias apresentam condições sócio-econômicas melhores.

Seria esperado que a freqüência à creche apresentasse um resultado melhor entre aquelas que a freqüentam, contudo das 14 crianças 8 delas apresentaram déficits para o desenvolvimento, mas não houve significância.

As regiões de saúde, utilizadas como referência de moradia da criança, foram categorizadas em novos grupos por características de infra-estrutura e condições sociais. Não houve significância, porém deve-se notar que em todas as regiões o número de crianças esteve maior entre aquelas consideradas em atraso.

Quanto à história de hospitalização, os dados da Tabela 35 mostraram que a chance de risco destas crianças que foram hospitalizadas durante este período de vida e ter atraso no desenvolvimento foi de 1,6 comparada às crianças que nunca foram hospitalizadas. Nota-se pela tabela que os valores são inversamente proporcionais à criança exposta e à não exposta à internação hospitalar. 
TABELA 35 - Associação e risco relativo entre o teste de DenverII e variáveis de seguimento de vida de crianças com baixo peso ao nascer 2001, Mauá, 2004.

\begin{tabular}{|c|c|c|c|c|c|c|c|c|c|}
\hline \multirow{3}{*}{\multicolumn{2}{|c|}{ Variáveis }} & \multicolumn{3}{|c|}{ Denver II } & & & \multirow{3}{*}{$\mathbf{R R}$} & \multirow{3}{*}{ Valor $\mathbf{p}$} & \multirow{3}{*}{ IC } \\
\hline & & \multirow{2}{*}{$\begin{array}{l}\text { Normal } \\
\mathrm{N}(\%) \\
\end{array}$} & \multicolumn{2}{|c|}{$\begin{array}{l}\text { Suspeito/ } \\
\text { intestável }\end{array}$} & \multicolumn{2}{|c|}{ Total } & & & \\
\hline & & & \multicolumn{2}{|c|}{$\mathbf{N}(\%)$} & \multicolumn{2}{|c|}{$\mathbf{N}(\%)$} & & & \\
\hline \multicolumn{10}{|l|}{ CRECHE } \\
\hline \multicolumn{2}{|l|}{ Sim } & $6(16,2)$ & \multicolumn{2}{|c|}{$8(16,3)$} & \multicolumn{2}{|c|}{$14(16,3)$} & 1 & & \\
\hline \multicolumn{2}{|l|}{ Não } & $31(83,8)$ & \multicolumn{2}{|c|}{$4183,7)$} & \multicolumn{2}{|c|}{$72(83,7)$} & 0,9 & 0,9965 & $0,6-1,6$ \\
\hline \multicolumn{10}{|l|}{ CONVÊNIO } \\
\hline \multicolumn{2}{|l|}{ Sim } & $5(13,5)$ & \multicolumn{2}{|c|}{$1(2,1)$} & \multicolumn{2}{|c|}{$6(6,0)$} & 1 & & \\
\hline \multicolumn{2}{|l|}{ Não } & \multirow[t]{2}{*}{$32(86,5)$} & \multicolumn{2}{|c|}{$48((98,0)$} & \multicolumn{2}{|c|}{$8093,0)$} & 0,2 & 3,6 & $0,6-21,7$ \\
\hline \multicolumn{9}{|c|}{ HOSPITALIZAÇÃO } & \\
\hline Não & & $21(56,9)$ & \multicolumn{2}{|c|}{$15(30,6)$} & \multicolumn{2}{|c|}{$36(41,9)$} & 1 & & \\
\hline Sim & & $16(43,2)$ & \multicolumn{2}{|c|}{$34(69,4)$} & \multicolumn{2}{|c|}{$50(58,1)$} & 1,6 & 0,026 & $1,1-2,5$ \\
\hline REGIÃO MO & RADIA & & & & & & & & \\
\hline 1 & & $4(10,8)$ & 5( & $0,2)$ & $9(10$ & & 1 & & \\
\hline 4 e 5 & & $23(62,2)$ & 27 & $5,1)$ & $50(5 \varepsilon$ & & 0,97 & 0,930 & $0,5-1,8$ \\
\hline $2 \mathrm{e} 3$ & & $0(27,0)$ & 17 & $4,7)$ & $27(31$ & & 1,1 & 0,707 & $0,6-2,2$ \\
\hline TOTAL & & $37(100,0)$ & $49(1$ & $0,0)$ & $86(10$ & & & & \\
\hline $\begin{array}{l}\text { Regiões de } \\
\text { saúde }\end{array}$ & $\begin{array}{l}\text { R.1: Carlina } \\
\text { Guapituba } \\
\text { Pq. S.Vicente } \\
\text { Primavera } \\
\text { V. Assis } \\
\end{array}$ & $\begin{array}{l}\text { R.2: Cap } \\
\text { Magine } \\
\text { Oratório } \\
\text { Paranavaí } \\
\text { Sônia Ma } \\
\end{array}$ & & $\begin{array}{l}\text { R.3:C } \\
\text { Zaira 2 }\end{array}$ & Zaíra 1 & $\begin{array}{l}\text { R.4 } \\
\text { Itapa } \\
\text { Pq. I } \\
\text { Ame } \\
\text { Sant }\end{array}$ & $\begin{array}{l}\text { lorida } \\
\text { s } \\
\text { cas } \\
\text { cídia }\end{array}$ & $\begin{array}{l}\text { R.5 Feital } \\
\text { Jd. Mauá } \\
\text { Santista } \\
\text { São João }\end{array}$ & \\
\hline
\end{tabular}




\section{. Análise do desenvolvimento segundo variáveis maternas por ocasião do parto e pós natal.}

Pela Tabela 36 se observam associações com variáveis sócio-culturais da mãe por ocasião do parto. A condição conjugal não apresentou significância com o desenvolvimento da criança e a escolaridade por ocasião do parto aponta para risco (com $\mathrm{RR}=1,4259$ ) mas sem significância a nível de 95\% ( $\mathrm{p}=0,085)$. Observa-se, porém, que as mães com menos escolaridade tiveram mais filhos com atraso no desenvolvimento.

O número de filhos apresentou risco para o desenvolvimento infantil o que permite afirmar que as mães com 4 a 9 filhos tem 1,7 vezes mais de chance de risco de apresentar filhos com déficit no desenvolvimento do que as que tiverem menos filhos.

Outras variáveis gestacionais, número de consultas de pré-natal, complicações de saúde maternas durante a gravidez e hábito de fumar na gravidez, não apresentaram associação com atrasos no desenvolvimento atual da criança (Tabela 37).Mães que referiram problemas na gravidez apresentaram proporcionalmente um percentual maior de filhos com Denver suspeito ou intestável, no entanto não significante estatisticamente. 
TABELA 36 - Associação e risco relativo entre o teste de DenverII e variáveis sócio-culturais maternas por ocasião do parto de crianças com baixo peso ao nascer 2001 , Mauá, 2004.

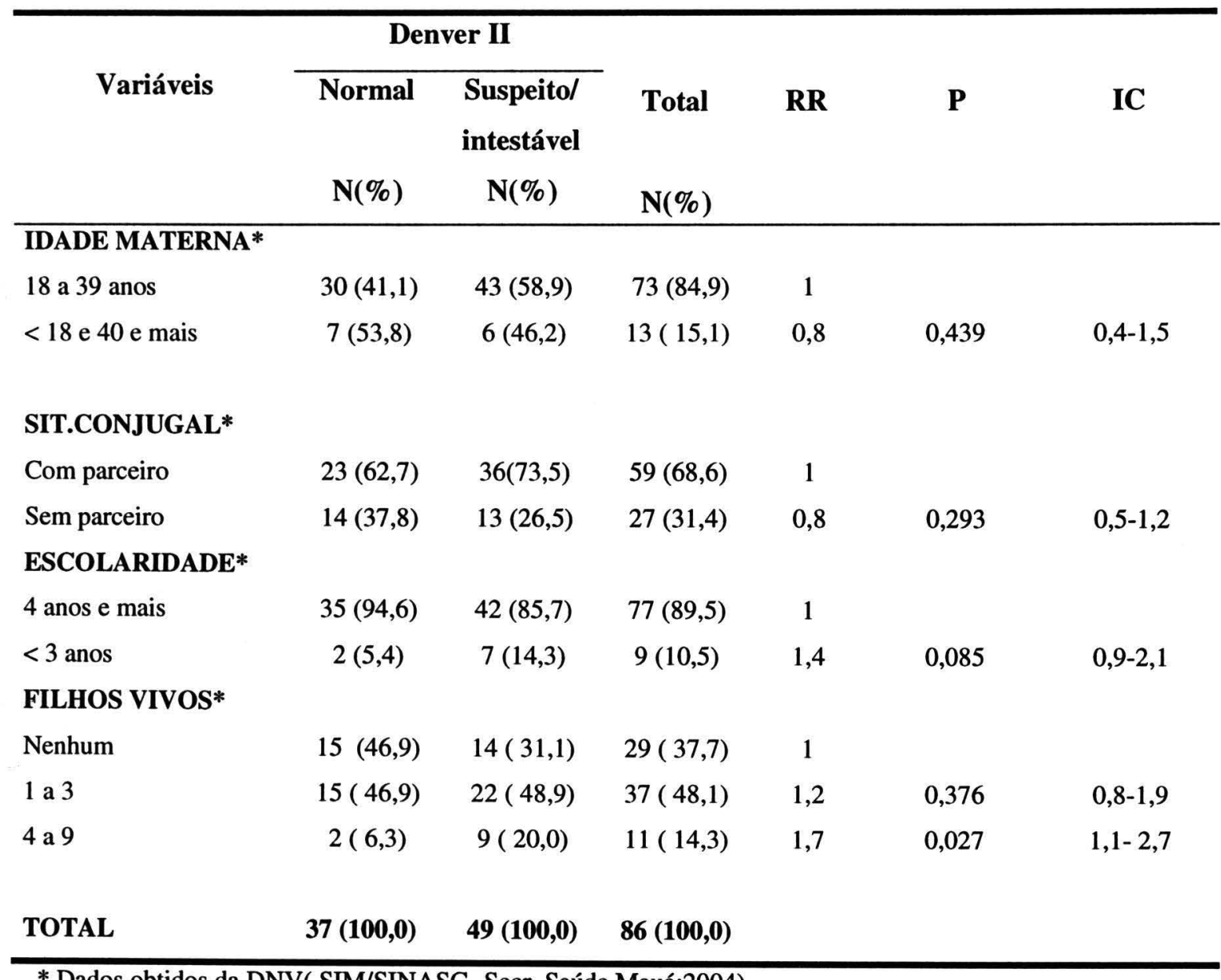

* Dados obtidos da DNV( SIM/SINASC- Secr. Saúde Mauá;2004) 
TABELA 37- Associação e risco relativo entre o teste de DenverII e variáveis gestacionais de crianças com baixo peso ao nascer 2001, Mauá, 2004.

\begin{tabular}{|c|c|c|c|c|c|c|}
\hline \multirow{3}{*}{ Variáveis } & \multicolumn{2}{|c|}{ Denver II } & \multirow{3}{*}{ Total } & \multirow{3}{*}{$\mathbf{R R}$} & \multirow{3}{*}{$\mathbf{P}$} & \multirow{3}{*}{ IC } \\
\hline & Normal & $\begin{array}{l}\text { Suspeito/ } \\
\text { intestável }\end{array}$ & & & & \\
\hline & $\mathbf{N}(\%)$ & $\mathbf{N}(\%)$ & & & & \\
\hline PRÉ-NATAL* & $37(100,0)$ & $48(100,0)$ & $85(100,0)$ & \multirow[b]{2}{*}{1,00} & \multirow[b]{3}{*}{0,142} & \multirow[b]{3}{*}{$0,5-1,1$} \\
\hline 7 e mais & $14(37,8)$ & $26(54,2)$ & $40(47,1)$ & & & \\
\hline 4 a 6 & $22(59,5)$ & $21(43,7)$ & $43(50,6)$ & 0,8 & & \\
\hline 0 a 3 & $1(2,7)$ & $1(2,1)$ & $2(2,35)$ & 0,8 & 0,714 & $0,2-3,1$ \\
\hline AFECÇÕES GESTAC. & $37(100,0)$ & $49(100,0)$ & $86(100,0)$ & \multirow[b]{2}{*}{1,00} & \multirow[b]{3}{*}{0,586} & \multirow[b]{3}{*}{$0,8-1,7$} \\
\hline Não & $15(40,5)$ & $17(34,7)$ & $32(37,2)$ & & & \\
\hline Sim & $22(59,5)$ & $32(65,3)$ & $54(62,8)$ & 1,1 & & \\
\hline HÁBITO FUMAR & $37(100,0)$ & $37(100,0)$ & $86(100,0)$ & \multirow{3}{*}{$\begin{array}{l}1,00 \\
0,9\end{array}$} & \multirow{3}{*}{0,858} & \multirow{3}{*}{$0,6-1,4$} \\
\hline Não & $25(67,6)$ & $34(69,4)$ & $59(68,6)$ & & & \\
\hline Sim & $12(32,4)$ & $15(30,6)$ & $27(31,4)$ & & & \\
\hline
\end{tabular}

* Dados obtidos da DNV( SIM/SINASC- Secr. Saúde Mauá;2004). 
A Tabela38 apresenta variáveis sociais da mãe no momento atual e como se pode perceber o número de filhos manteve o risco para atraso no desenvolvimento da criança ou que atualmente há 1,5 chances de risco de mães com 4 a 9 do que as que tiverem menos ( com significância estatística a nível do $\mathrm{p}=0,032$ ).

A escolaridade aproximou-se mais da significância, com o $p=0,056$. Supõe-se que os dados estão apontando para um risco 1,4 vezes mais de chance de mães com menor escolaridade terem filhos com atrasos.

O fato de a mãe ter ou não um companheiro não apareceu como significante para o desenvolvimento da criança, o mesmo se aplica à ocupação e característica da família, se nuclear ou não tradicional.

A renda familiar apresentou um risco de 2,2 vezes entre aqueles com renda menor que 150 reais de ter crianças com atraso do que as de maior renda familiar. 
TABELA 38 - Associação e risco relativo entre o teste de Denver II características atuais da mãe e família de crianças com baixo peso ao nascer 2001, Mauá, 2004.

\begin{tabular}{|c|c|c|c|c|c|c|}
\hline \multirow[b]{2}{*}{ Variáveis } & \multicolumn{2}{|c|}{ Denver II } & \multirow[b]{2}{*}{$\begin{array}{l}\text { Total } \\
\mathbf{N}(\%)\end{array}$} & \multirow[b]{2}{*}{$\mathbf{R R}$} & \multirow[b]{2}{*}{$\mathbf{P}$} & \multirow[b]{2}{*}{ IC } \\
\hline & $\begin{array}{l}\text { Normal } \\
\mathbf{N}(\%)\end{array}$ & $\begin{array}{c}\text { Susp/ intest. } \\
\mathrm{N}(\%)\end{array}$ & & & & \\
\hline SIT.CONJUGAL & $37(100,0)$ & $49(100,0)$ & $86(100,0)$ & & & \\
\hline Com companheiro & $26(70,3)$ & $35(71,4)$ & $61(70,9)$ & 1 & & \\
\hline Sem companheiro & $11(29,7)$ & $14(28,6)$ & $25(29,1)$ & 0,9 & 0,907 & $0,6-1,5$ \\
\hline FILHOS ATUAL & $37(100,0)$ & $49(100,0)$ & $86(100,0)$ & & & \\
\hline 1 a 3 & $31(83,8)$ & $32(65,3)$ & $63(73,3)$ & 1 & & \\
\hline 4 a 9 & $6(16,2)$ & $17(34,7)$ & $23(26,7)$ & 1,5 & 0,032 & $1,0-2,1$ \\
\hline ESCOLARIDADE & $37(100,0)$ & $49(100,0)$ & $86(100,0)$ & & & \\
\hline Ens. médio e mais & $18(48,65)$ & $13(26,5)$ & $31(36,05)$ & 1 & & \\
\hline Ens. Fundam. ou menos & $19(51,35)$ & $36(73,5)$ & $55(63,9)$ & 1,6 & 0,056 & $0,9-2,5$ \\
\hline ESTUDO ATUAL & $37(100,0)$ & $49(100,0)$ & $86(100,0)$ & & & \\
\hline Sim & $6(16,2$ & $2(4,1)$ & $8(9,3)$ & 1 & & \\
\hline Não & $31(83,8)$ & $47(95,9)$ & $78(90,7)$ & 2,4 & 0,155 & $0,7-8,1$ \\
\hline OCUPAÇÃO ATUAL & $37(100,0)$ & $49(100,0)$ & $86(100,0)$ & & & \\
\hline Trabalho remun. & $20(54,05)$ & $19(38,8)$ & $39(45,4)$ & 1 & & \\
\hline Do lar & $11(29,7)$ & $20(40,8)$ & $31(36,0)$ & 1,3 & 0,184 & $0,9-2,0$ \\
\hline Desempregada & $6(16,2)$ & $10(20,4)$ & $16(18,6)$ & 1,3 & 0,327 & $0,8-2,1$ \\
\hline RENDA FAMILIAR(Reais) & $36(100,0)$ & $46(100,0)$ & $82(100,0)$ & & & \\
\hline $1.000 \mathrm{e}$ mais & $7(19,40$ & $5(10,9)$ & $12(14,6)$ & 1 & & \\
\hline$<1000 a>300$ & $20(55,6)$ & $20(43,5)$ & $40(48,8)$ & 1,2 & 0,628 & $0,6-2,5$ \\
\hline $300 \mathrm{a}>150$ & $8(22,2)$ & $12(26,1)$ & $20(24,4)$ & 1,4 & 0,346 & $0,7-3,1$ \\
\hline$<150$ & $1(2,8)$ & $9(19,6)$ & $10(12,2)$ & 2,2 & 0,031 & $1,1-4,4$ \\
\hline FAMÍLIA & $37(100,0)$ & $49(100,0)$ & $86(100,0)$ & & & \\
\hline Nuclear & $24(66,7)$ & $31(64,6)$ & $55(65,5)$ & 1 & & \\
\hline Não tradicional & $12(33,3)$ & $17(35,4)$ & $29(34,5)$ & 1,0 & 0,841 & $0,7-1,5$ \\
\hline
\end{tabular}




\section{Análise da relação mãe e filho}

Já tratado anteriormente acerca do comportamento seguro as Tabelas 39 e 40 também se referem a esta variável e representam associações quanto ao padrão de comportamento de apego da criança com o teste de Denver II.

A Tabela 39 apresenta a associação com o apego como uma variável contínua o que permite se observar uma diferença de médias importante. Os dados mostram significância estatística com o valor de $\mathrm{p}<0,0001$. Na Tabela 40 verifica-se que há uma chance 3,3 vezes maior de risco entre as crianças com comportamento de apego seguro baixo para o desenvolvimento do que para as que tiverem apego mais seguro.

TABELA 39- Associação entre oTeste de DenverII e comportamento de apego seguro segundo médias, mínimo, máximo, desvio padrão e valor p de crianças com baixo peso ao nascer 2001, Mauá, 2004.

\begin{tabular}{ll|cccccccc}
\hline VARIÁVEL & DENVERII & N & Mínima & Máxima & Média & Mediana & $\begin{array}{c}\text { Desvio } \\
\text { padrão }\end{array}$ & P \\
& & & & & & & & \\
\hline APEGO & Normal & 37 & 82,2 & 98,4 & 94,2 & 95,2 & 3,6 & $<0,0001^{*}$ \\
SEGURO & Susp./intest. & 49 & 67,7 & 96,7 & 87,0 & 88,7 & 5,9 & \\
\hline
\end{tabular}

* Variância não homogênea, utilizado o Teste de Mann- Whitney. 
TABELA 40- Associação e risco relativo entre o Teste de Denver II com o comportamento de apego seguro de crianças com baixo peso ao nascer 2001, Mauá, 2004.

\begin{tabular}{ccccccc}
\hline \multirow{2}{*}{ Variáveis } & Normal & $\begin{array}{c}\text { Suspeito/ } \\
\text { intestável }\end{array}$ & Total & RR & p & IC \\
\cline { 2 - 5 } & & & & & \\
& $\mathbf{N}(\%)$ & $\mathbf{N}(\%)$ & $\mathbf{N}(\%)$ & & & \\
\hline APEGO SEGURO & $\mathbf{3 7 ( 1 0 0 , 0 )}$ & $\mathbf{4 9 ( 1 0 0 , 0 )}$ & $\mathbf{8 6}(\mathbf{1 0 0 , 0})$ & & & \\
$>$ mediana (90,3) & $31(83,8)$ & $11(22,55)$ & $42(48,8)$ & 1 & & \\
$\leq$ mediana $(90,3)$ & $6(16,2)$ & $38(77,55$ & $44(51,2)$ & 3,3 & $<0,0001$ & $1,9-5,6$ \\
\hline
\end{tabular}




\subsection{Regressão múltipla}

Foi feita uma aplicação de um modelo de regressão de Poisson para modelar o risco relativo de Denver II "não normal” para um conjunto de variáveis selecionadas. A seleção considerou variáveis que, na análise univariada, cotizaram o nível descritivo p $<0,10$ (COLLET 1991, HOSMER E LEMESHOW 1989). A análise foi feita a partir de um modelo com todas as variáveis explicativas que vão sendo retiradas baseando-se no valor do nível descritivo (p). Os passos da modelagem se encontram no Anexo 13.

Após a análise multivariada, somente a variável apego permaneceu no modelo, conforme a Tabela 41 .

Tabela 41. Análise multivariada de apego materno com déficit de desenvolvimento pelo Teste deDenverII de crianças com baixo peso ao nascer 2001, Mauá, 2004.

\begin{tabular}{cccccc}
\hline Variável & RR & Erro padrão & Z & p & IC 95\% \\
\hline APEGO SEGURO & & & & & \\
$>$ mediana $(90,3)$ & 1 & & & & \\
$\leq$ mediana $(90,3)$ & 3,3 & 0,88 & 4,46 & $<0,0001$ & $1,9-5,6$ \\
\hline
\end{tabular}




\section{DISCUSSÃO}

As crianças que participaram deste estudo produziram sentimentos semelhantes ao experimentado por DEL PRIORE (2002) quando comenta sobre a história das crianças no Brasil e se interroga sobre o que é a infância e a adolescência. Sentimentos, ora de angústia e preocupação e outros de otimismo quanto ao futuro que as espera.

Em sua apresentação esta autora julga haver ainda uma distância entre o discurso político e a realidade, no sentido em que muita coisa ainda há por fazer. Considera que "o mundo que a criança deveria ser ou ter é diferente daquele onde ela vive, ou no mais das vezes, sobrevive" (p.8). Se assim o estiver afirma, o momento do "riso e brincadeira" será pouco.

O interesse pela história de crianças brasileiras também foi objeto deste estudo e representado pelo seguimento de bebês que nasceram de baixo peso no ano de 2001 no município de Mauá. A mesma autora cita Gilberto Freyre que dizia, em 1921:

escrever uma história do menino, da sua vida- dos seus brinquedos, dos seus vícios- brasileiro, desde os tempos coloniais até hoje.....é um grande assunto. E creio que só por uma história desse tipo- história sociológica, psicológica, antropológica e não cronológica- será possível chegar-se à uma idéia sobre a personalidade do brasileiro. É o menino que revela o homem. ( DEL PRIORE 2002, p.12).

Evidente que este estudo retrospectivo conserva uma expectativa limitada no que se refere aos objetivos propostos, mas as palavras de Gilberto Freire parecem apropriadas quanto à justificativa deste estudo. 
Do total de nascidos vivos em 2001 em Mauá segundo os dados da Fundação Seade, obteve-se uma proporção de $9,4 \%$ (Tabelas $B$ e $C$ ) de bebês com baixo peso ao nascer. Um trabalho recente realizado com o objetivo de resgatar a tendência secular do peso ao nascer em São Paulo, 1993 a 1998, destacou que a média obtida de baixo peso ao nascer foi de 9,8\% (MONTEIRO et al, 2000). ALMEIDA et al (2002) reafirmam esta tendência e destacam que a proporção de BPN não se alterou significativamente e confirmam que gira em torno de $9,2 \%$, sendo mais elevado que nos países desenvolvidos.

Apesar desta tendência, valores menores foram observados. No estudo realizado num conjunto de municípios do Estado de São Paulo, Itararé, Marília, Pariquera-Açú, São José dos Campos e Santo André, a média de prevalência de baixo peso ao nascer observada foi de 7,5\% (COSTA E GOTLIEB 1998) e em outro realizado em duas maternidades de Florianópolis (SOUZA et al 1988) a prevalência foi de 5,3\%. Estes último num patamar semelhante ao dos países desenvolvidos que deve ser em torno de $4 \%$ a $6 \%$ ( MONTEIRO et al 2000a).

O que se nota, portanto, é que o município de Mauá, em 2001, situou-se na média estimada ao país para nascidos de baixo peso. A análise do estudo de SOUZA et al (1988) mostrou que a qualidade e acesso aos serviços de saúde tinham relação com o perfil de peso observado. Provavelmente nesta cidade sejam pelas mesmas razões. Uma outra questão é que a amostra não apresenta bebês de extremo e de muito baixo peso tendo em vista que não sobreviveram sendo que o grupo representativo está mais próximo dos $2.500 \mathrm{~g}$. 
No que se refere à amostra, de caráter não probabilístico, é importante salientar que ela pode não representar o perfil das crianças deste município, embora se verifique pelo mapa de Mauá ( Figura 2) que a distribuição se deu maneira quase homogênea por toda a cidade. Neste sentido, todo o processo de busca para conseguir uma amostra maior foi explicitado na metodologia no qual mostrou que, apesar de seu rigor, obteve um número de crianças suficientes apenas para resultados com baixas prevalências.

A análise realizada a partir dos dados obtidos do Sistema de Informação sobre Nascidos Vivos (SINASC) mostrou que a qualidade das informações foi satisfatória; uma prática adotada em grandes estudos ( VICTORA et al 2004; ALMEIDA e MELLO JORGE 1998; COSTA e GOTLIEB 1998; ALMEIDA et al 2002).

Os dados que foram confirmados mediante entrevista recordatória, mas pouco confiáveis, foram excluídos, sendo que esta conduta foi a mesma adotada por MONTEIRO et al (2000b). Como por exemplo, a idade gestacional em que várias mães afirmavam que o filho nasceu prematuro e no sistema constava como a termo, com discrepâncias entre o relatado e o registrado, assim como o comprimento ao nascer que as mães referiam valores duvidosos.

Uma questão que suscitou interesse foi o desconhecimento da mãe quanto aos riscos advindos do fato de seu bebê ter nascido de baixo peso. A confusão dela em associar o baixo peso com a prematuridade corrobora a suspeita sobre seu desconhecimento quanto às razões do seu bebê ser de risco. Apenas uma das mães referiu ter sido alertada para o fato. 
Estas observações iniciais sobre a falta de conhecimento da mãe implicam numa aparente ausência de programas de Follow-up ou de seguimento não por responsabilidade materna, mas dos serviços de saúde. Este programa determina que no planejamento da alta hospitalar do bebê os pais já precisam ter envolvimento e preparo nos cuidados com o recém-nascido (RUGOLO 2003).

As características da gestação e nascimento apresentaram resultados parecidos com os que a literatura descreve, com evidências de causalidade em todos os níveis dos determinantes, proximal, intermediário e distal (MONTEIRO et al 2000a) entre estes bebês que nasceram de baixo peso.

Conforme os resultados, o peso ao nascer apresentou na distribuição contínua uma média (2.223g, Tabela 6$)$ de pesos que se pode considerar razoável, pois os de muito baixo peso não fizeram parte da amostra tendo em vista que dos nascidos em 2001 apenas dois sobreviveram. Entre aqueles com muito baixo peso, ou menores de $1.500 \mathrm{~g}$, e menores de $2.000 \mathrm{~g}$ todos nasceram com idade gestacional menor que 37 semanas ( Tabela 7).

A dependência do baixo peso ao nascer com um dos determinantes proximais, a idade gestacional, se evidencia à associação significante que apareceu entre eles $(\mathrm{p}<0,0001)$, pois quanto menor foi o peso menor a idade gestacional.

A possibilidade destes bebês e aqueles que nasceram a termo e com baixo peso terem apresentado retardo de crescimento intra-uterino parece provável. Geralmente o RCIU está associado aos problemas de saúde na gestação e à desnutrição materna no 
período gestacional (SIQUEIRA 1981; SIQUEIRA et al 1986; KRAMER et al 1990; HORTA et al 1996; BARROS 1996a; WHO 2000).

Outros dados intensificam esta suposição tendo em vista que houve significância estatística do BPN com complicações maternas e neonatais $(\mathrm{p}=0,008$ e $\mathrm{p}=0,001$, Tabela 8). Entre os bebês que nasceram com menos de $2.000 \mathrm{~g}$ todas as mães referiram complicação no período gestacional e estes bebês, na grande maioria, tiveram complicações no período neonatal precoce.

As complicações maternas e neonatais referidas neste estudo se assemelham às complicações descritas na literatura (SIQUEIRA 1981; RAMOS et al 2003; BITTAR e ZUGAIB 2003; LEONE et al 2003).

Dentre os vários fatores de risco maternos ao retardo do crescimento intra-uterino citam-se a anemia, falta de apetite, emagrecimento, infecções e a cardiopatia que, por sinal, muito referida entre as complicações e descritas na literatura ( BITTAR, RAMOS e LEONE 2003). A grande proporção $(62,8 \%$, Tabela 7 e 8$)$ de complicações sugere tratar-se de um grupo de gestantes de risco.

Quanto ao bebê, a hipoglicemia e icterícia fisiológica são algumas das causas citadas e que podem estar associadas ao retardo do crescimento intra-uterino (Siqueira 1981; RAMOS et al 2003b ).

A capacidade vital do bebê avaliada pelo índice de Apgar teve certo diferencial entre as variações de peso, mas de modo geral se obteve um percentual de notas inferiores sete bastante reduzidas, 3,75\% (Tabela 7), o que pode se considerar como um 
bom prognóstico ao recém-nascido. Já as menores notas estiveram entre os bebês menores reforçando a hipótese de que quanto menor ele for mais riscos pode apresentar. MARINO (2001) comenta que o índice de Apgar está associado à sobrevida, mas entre os muito prematuros e de baixo peso há controvérsias quanto ao seu uso como medida da morbimortalidade no período perninatal.

A escolaridade materna apresentou associação significante com o baixo peso ao nascer ( $\mathrm{p}=0,01$, Tabela 7 ) em que se notou uma proporção importante com o baixo nível escolar entre pesos menores. De modo geral, quase metade das mães não tinham o ensino fundamental completo. Resultado parecido com outros estudos sobre o baixo peso ao nascer (MONTEIRO et al 2000a; ALMEIDA et al 2002).

É fato que a escolaridade materna vem sendo apontada como uma das grandes causas, do ponto de vista social, para o baixo peso ao nascer. Segundo MONTEIRO (2000) a renda e a escolaridade aparecem como variáveis independentes quanto à chance de risco para o baixo peso ao nascer apesar de pertencerem aos determinantes distais do peso ao nascer.

As outras variáveis maternas por ocasião do parto e considerados determinantes intermediários do baixo peso ao nascer por MONTEIRO (2000) não apresentaram significância com o peso. Contudo, notou-se que mais de 50\% (Tabela 2) das mulheres fizeram seis ou menos consultas de pré-natal sendo que o preconizado é justamente o contrário, fazer seis ou mais, no entanto este número pode estar associado ao bebê prétermo que teve um parto antecipado. $\mathrm{O}$ número de mulheres sem companheiro $(31,4 \%$, Tabela 3) por ocasião do parto também pode significar desajustes na gravidez. Um 
estudo de BARBIERI et al (2000) acerca dos fatores de risco para o baixo peso ao nascer concluiu que houve um aumento nestes nascimentos pelo incremento de prétermos e nas mães sem companheiro tendo como um dos motivos o estresse psicossocial e uso de drogas ilícitas.

O hábito de fumar na gravidez foi referido em cerca de $31 \%$ (Tabela 8 ) das mulheres e já é consenso que este fator predispõe ao risco de nascimentos com baixo peso (SIQUEIRA 1981; ALMEIDA et al 2002; SILVA et al 2003; BITTAR 2003; ZAMBONATO et al 2004).

Os dados acerca da idade materna e o número de filhos, por ocasião do parto, mostraram que há uma representatividade em todas as faixas etárias, inclusive, com um percentual pequeno entre as mais jovens, muito embora na distribuição contínua a média represente um grupo de mães jovens.

Pelos resultados apresentados notou-se que, com uma média de filhos vivos menor que dois, e de filhos mortos com uma média menor que um ( Tabela 1), o que representa uma paridade baixa entre o grupo estudado. Entretanto, observando-se pelos valores máximos a paridade pode ser elevada o que leva a pensar na presença de mais um fator de risco para o baixo peso ao nascer.

Alguns autores associam maior risco em ter BPN entre aquelas mulheres com maior paridade e muitas vezes associado ao pequeno intervalo interpartal e não somente pelo número de filhos (ALMEIDA et al 2002; RAMOS 2003). Além disso, o maior número de filhos supõe condições sócio-econômicas mais desfavoráveis. 
Predominou o sexo feminino com baixo peso o que condiz com outros achados de literatura. COSTA e GOTLIEB (1998) afirmam que os meninos apresentam uma tendência na distribuição de pesos ao nascer maiores que as meninas; o estudo que realizaram encontrou uma prevalência de peso ao nascer maior entre as meninas com associação significativa entre o sexo e baixo peso ao nascer.

Uma taxa de parto cesariana de $43 \%$ (Tabela 5) reforça a hipótese de tratar-se de gestações de risco. Na pesquisa realizada por ALMEIDA et al (2002) o parto cesárea apareceu como fator de proteção aos bebês e destaca que isto pode significar que a escolha pelo melhor procedimento deveu-se a boa qualidade na assistência.

O estudo de RIBEIRO et al (2000) identificou a cesárea como fator responsável pelo aumento das proporções dos baixos pesos ao nascer no município de Ribeirão Preto e também associa à assistência prestada. Outros estudos em Ribeirão Preto e sul do Brasil fizeram esta relação (HORTA et al 1996; SILVA et al 2003; BARBIERI et al 2000). No grupo estudado a razão da alta proporção de cesáreas pode ter estes mesmos motivos.

O percentual de partos gemelares ( $14 \%$, Tabela 5 ) também pode ser associado a uma outra causa para o BPN. Apesar de não aparecer significância possivelmente pelo tamanho da amostra, é descrito em literatura como fator de risco ao BPN, além de ser considerado como risco para a mortalidade perinatal (JAN RICHARDUS et al 1998).

Monteiro et al (2000) afirmam que entre 1981 a 1991, nos Estados Unidos, houve um aumento do baixo peso ao nascer atribuído em parte aos partos múltiplos. Em estudos mais recentes o aumento se atribuiu, seguramente, aos partos múltiplos 
ocorridos em mulheres com mais de 35 anos e com nível superior; provavelmente neste grupo havia mulheres com reprodução assistida. Apesar destas evidências acredita-se não ser o caso deste grupo de estudo dado que as características sociais apontadas mostram uma população, em geral, mais pobre.

Em última análise, a ocorrência dos recém-nascidos de baixo peso e as condições ao nascer teve um comportamento bastante semelhante aos determinantes de risco para o baixo peso ao nascer. Assim, parece que o grupo se caracteriza, desde o nascimento, com riscos quanto ao prognóstico para o crescimento e desenvolvimento.

O seguimento destes bebês permitiu analisar alguns efeitos dos determinantes do BPN no crescimento e desenvolvimento como também outros fatores a eles associados.

Como se observou nos resultados, os efeitos durante estes três ou quatro anos de vida foram os atrasos no crescimento e desenvolvimento neuropsicomotor representados pelas variáveis de desfecho, os índices nutricionais e o teste de Denver II.

Para o crescimento físico os resultados identificaram crianças com déficits nutricionais pelos escores $\mathrm{Z}$ menor que menos dois pelo padrão do NCHS (1997) para os três índices (Tabela 17) Do mesmo modo, as médias observadas apresentaram uma tendência de desvio para a esquerda supondo que estas crianças são, na maioria, pequenas (Tabela 16).

Uma outra questão, como nasceram de baixo peso e muitos deles eram pequenos para a idade gestacional, já apresentam por esta razão uma forte tendência em ter uma estatura e peso menor. À análise do desenvolvimento somático de pequenos para idade 
gestacional um estudo notou que nos primeiros meses é possível recuperar o peso, ou"catch-up", mas a partir daí não houve mudanças e $35 \%$ de crianças estavam com pesos abaixo do percentil 3 por volta dos 2 anos de idade ( RAMOS et al 2003b).

VICTORA et al (1998) afirmaram que o valor de peso/altura esperado para qualquer população bem nutrida é em torno de $2,5 \%$ na distribuição normal. Mais recentemente MONTEIRO e CONDE (2000) afirmaram que déficits de altura não devem ultrapassar 3,9\%. Nesta pesquisa realizada em crianças de 0 a 59 meses em São Paulo, 1995 a 1996 obteve os índices altura/ idade, peso/ altura respectivamente com uma prevalência de 2,4 e 0,6 .

Outro estudo de MONTEIRO et al (2000) mostrou uma tendência secular ( 1974 -1996) positiva no crescimento de crianças menores de 5 anos em São Paulo. O valor negativo das médias observadas foi inferior a este estudo como, por exemplo, o índice altura/idade foi de $-0,123 \mathrm{z}$ e também obteve desvios padrão menores.

Este estudo, apesar da amostra não ser probabilística, mostra resultados de uma população com os valores de déficits maiores; em número absolutos são pequenos, mas em percentual são para peso/estatura, peso/idade e estatura/idade, respectivamente, 5,8; 12,8 e 4,65 .

Estes autores relacionaram o papel dos determinantes intermediários (saneamento, renda, escolaridade) a estas mudanças, contudo afirmam que entre as classes sociais ainda existem diferenças importantes e há necessidade de muito mais tempo para que não existam mais diferenças nos tamanhos entre as crianças. 
Assim também, a alimentação, componente do determinante proximal para o crescimento, exerceu um papel limitador para o crescimento. Isto foi notado pelo inquérito alimentar e ficou evidente sua dependência aos determinantes intermediários.

A investigação alimentar constituída pelo aleitamento materno e alimentação complementar apresentou dados importantes. De acordo com recordações da mãe, evidenciou-se uma prática de amamentação exclusiva razoável com uma média observada em torno de 5,5 meses (Tabela 14); além do aleitamento materno misto que esteve presente numa grande parte dos bebês.

È indiscutível a importância do aleitamento materno no primeiro ano de vida. NÓBREGA (2000) destaca que além do valor nutricional o leite materno tem um importante papel no vínculo materno.

Estas considerações levam a pensar em porquê neste estudo não se verificou significância com as variáveis de desfecho do crescimento e desenvolvimento. É provável que este fato possa estar ligado a vários fatores. Um deles seria talvez a própria alimentação suplementar que se sobrepôs ao fator protetor do leite, pois pela idade atual da criança o aleitamento não é a prática comum diferentemente da alimentação na qual verificaram-se falhas importantes, tanto pela disponibilidade quanto pela qualidade do alimento, durante os depoimentos das mães.

A prática alimentar pareceu aquém do desejado. Evidências mostraram que a oferta dos nutrientes essenciais dependeu de dois fatores, um primeiro ligado às condições sociais, como a renda insuficiente para a provisão alimentar e segundo aparentemente relacionado ao cuidado materno. 
Num outro aspecto, o fato de crianças com cerca de 3 a 4 anos ainda mamarem no seio materno também não representou diferença no cenário e, até, evidenciou-se algumas com apego inseguro. Outro fator diferencial pode ser a própria idade. No estudo realizado por FILIPINI (2000) e FILIPINI e SIQUEIRA (2001) sobre o crescimento e desenvolvimento de crianças, de 1 a 24 meses, residentes em favela, apareceu associação significante entre o leite materno com o índice $P / E(p=0,03)$ e maior proporção de crianças com menos atraso no desenvolvimento entre as que mamaram maior tempo. Assim, uma questão a ser levantada seria identificar em que momento o leite materno deixa de ser o fator essencial para o desenvolvimento e crescimento.

Para MONTEIRO e CONDE (2000) as causas do declínio da desnutrição dependem da adequação do consumo de alimentos e do nível da exposição da criança às doenças. Mas dependem, também, da disponibilidade e acesso aos alimentos e cuidados.

Vale lembrar que a teoria do apego de BOWLBY (2002) evidencia que o alimento não é a base do apego, mas ele pode ser um dos sinais de aproximação que promoverá a criação de um vínculo de afeição e assevera que dependerá da qualidade do cuidado. E a propósito, os padrões de apego poderão modificar-se em resposta ao tipo de cuidado (WATERS E DEANE 1985).

A importância do cuidado materno está implícita em toda a teoria de Bowlby, a exemplo de sua seguinte frase "a avidez da criança pelo amor e a presença da mãe é tão grande quanto a fome de alimento".

No momento da análise bivariada, com o uso dos índices como variáveis de desfecho, apareceram poucas associações com as variáveis independentes. Talvez isto se 
deva à quase homogeneidade dos índices e, por conseguinte diferenças não se fizeram notar.

Muito embora se verificou significância potencial de chance de risco (Tabela 20) em ter filhos com déficit nutricional para o peso/idade $(p=0,054)$ e a estatura/idade $(\mathrm{p}=0,07)$ entre as mães sem um companheiro permanente e como também chance de risco para déficit de estatura em filhos de mães com um reduzido número de consultas de pré-natal. Importante notar o papel que os determinantes intermediários exerceram sobre o crescimento e que a ausência de companheiro tem novamente peso na saúde da criança. Estas variáveis associadas à desnutrição pregressa (E/I) sugerem que o cuidado materno possa ter participação nos resultados.

$\mathrm{Na}$ análise apareceu um potencial de chances de risco para o déficit de peso $(p=0,07)$ nas crianças do sexo feminino. $O$ mesmo padrão observado ao nascimento quanto ao diferencial entre os sexos se manteve no decorrer destes anos.

MONTEIRO e CONDE (2000) falam do efeito intergerações da desnutrição; mães que tiveram retardo do crescimento intra-uterino na infância terão baixa estatura e com mais risco de gerar crianças de baixo peso e estas terão retardo do crescimento e com mais risco de produzir outros recém-nascidos de baixo peso. Apesar de que a prevalência dos déficits serem baixos e não ter apresentado significância com o desenvolvimento ( Tabela 34), o perfil identificado quanto ao crescimento físico e os depoimentos maternos sobre as necessidades básicas da criança permitem inferir que a possibilidade do efeito intergerações ter ocorrido ao grupo não é de todo remota. 
Como já foi dito, os resultados obtidos do teste de triagem de Denver II apresentaram uma proporção elevada de crianças suspeitas de atraso no desenvolvimento neuropsicomotor; 57\% (Tabela 26) delas foram avaliadas como suspeitas ou intestáveis no teste. Importante considerar as limitações do teste havendo a necessidade de exames neurológicos específicos para constatar um possível diagnóstico clínico.

Outros trabalhos foram realizados com a mesma metodologia. Tal como o primeiro, de FRANKENBURG et al (1988), que identificaram 19,4\% com atraso de um total de 2.343 crianças americanas.Um outro realizado por HALPERN et al (2002) com crianças de um ano de idade e usando da mesma técnica identificou $34 \%$ de atraso entre 1.363 delas. O trabalho de HALPERN et al (2002) apontou para algumas variáveis que se apresentaram com mais chance de risco ao atraso e foram o baixo peso ao nascer $(\mathrm{OR}-4,0)$ e idade gestacional menor que 37 semanas (OR-1,6). Afirmam que os resultados obtidos mostraram que havia redução no atraso do desenvolvimento à medida que o peso aumentava.

O estudo realizado por FILIPINI e SIQUEIRA (2000; 2001) das 142 crianças de um mês a 2 anos encontrou $25,4 \%$ com déficit de atrasos e destes, $38,5 \%$ nasceram com baixo peso e $60 \%$ prematuros $(\mathrm{p}=0.016)$. O trabalho de EICKMANN et al (2002) comparou o desenvolvimento mental e motor de bebês de um ano a termo e com baixo peso e identificaram mais atrasos naqueles de baixo peso ao nascer.

O baixo peso ao nascer aparece em evidência como um dos fatores de risco em potencial ao atraso no desenvolvimento. Assim, é inegável dissociar o resultado desta 
pesquisa com o baixo peso ao nascer na medida em que estes trabalhos mostraram que esta variável aparece entre aquelas que mais apresentam risco para o atraso no desenvolvimento ( MONTEIRO e CONDE 2000 ; HALPERN 1996, 2002; EICKMAN 2002).

Questões como as diferenças entre as amostras estudadas, seu tamanho e características particulares devem ser considerados, mas o que se pôde notar é que conforme aumenta a idade da criança outros fatores aparecem com novas chances de riscos ao desenvolvimento.

O modelo transacional de desenvolvimento de Sameroff e Chandler citados por HALPERN et al (2002) considera que o desenvolvimento ocorre com o entrelaçamento de fatores tal como a família, meio ambiente e sociedade e que até o biológico, determinante ao atraso cognitivo, pode ser modificado por estar exposto a todos eles.

Estes autores destacam que o perfil do grupo estudado apresentou coerência com outros trabalhos que associam a determinação do atraso às características multifatoriais, ou seja, o "acúmulo de fatores de risco determina um maior impacto no desenvolvimento da criança". Outras peculiaridades do teste foram observadas, como o percentual de erros por setores. Neste trabalho ficou evidente que a linguagem foi o grande diferencial nos atrasos observados seguido pelo motor fino adaptativo. O estudo de HALPERN et al (2002) realizou-se com crianças de 12 meses e o setor mais atingido foi o motor grosso e o menor foi a linguagem (menos de $1 \%)$.

Resultados esperados tendo em vista que o desenvolvimento da linguagem se acelera a partir dos dois anos de idade e a ausência de estímulos pode retardar este 
processo. A presença do estímulo se fez notar especialmente na realização do teste de DenverII entre as crianças que obtiveram mais acertos com a participação implícita da família. Um estudo realizado por ALVES et al (1997) com bebês prematuros verificou que aqueles que receberam após um tempo estímulo materno apresentaram melhor desenvolvimento cognitivo.

O trabalho de HALPERN et al (2002) utilizou um modelo teórico hierárquico de determinação de risco de atraso no desenvolvimento que foi utilizado como o objetivo de controlar os efeitos dos riscos em vários níveis. No primeiro nível desta escala fizeram parte os fatores socioeconômicos que mostraram evidências de seu controle no grupo estudado.

A caracterização do perfil da população deste estudo igualmente destacou um grupo social e familiar inferior ao desejável. As condições sócio-econômicas atuaram de forma significativa no período de vida das crianças, o que se pressupõe tendo em vista tratar-se de um estudo de coorte. A escolaridade materna atual manteve o mesmo perfil existente por ocasião do parto em que predominou o ensino fundamental e a renda familiar mostrou que a média fica em torno de três salários mínimos. Uma grande parte das mulheres não tem trabalho remunerado, são donas de casa e poucas estão estudando (Tabela 10).

A análise bivariada mostrou que as crianças com famílias que possuem menos de 150 reais de renda mensal apresentaram 2,2 vezes mais risco para atraso no desenvolvimento neuropsicomotor. $\mathrm{O}$ mesmo se verificou com a escolaridade materna. Nesta análise verificou-se que entre mães com o ensino fundamental ou menos, seus 
filhos tiveram 1,5 vezes de risco a mais para o atraso no desenvolvimento que filhos de mães com maior escolaridade (Tabela 38).

Nos trabalhos de HALPERN et al (1996; 2002) os resultados foram parecidos a este estudo, com um risco igual para a renda e um pouco menos de risco quanto à escolaridade. O mesmo verificado no estudo de EICKEMANN (2002), com risco entre escolaridade materna com o atraso no desenvolvimento e associação significante no trabalho de FILIPINI e SIQUEIRA (2000; 2001). Para MONTEIRO e CONDE (2000) a escolaridade materna é um determinante que "proporciona racionalidade à família em operacionalizar adequadamente sua renda".

Foi observado que apesar da grande maioria ter um companheiro $(70,9 \%$, Tabela 38) algumas pertencem a famílias não tradicionais ou residem numa mesma área com mais de uma casa. A região de moradia mostrou sinais de classes sociais distintas pelo próprio número de crianças distribuídas entre elas. Naquelas consideradas "melhores" não apareceram crianças com baixo peso como, por exemplo, os bairros das UBS de Guapituba e Parque São Vicente que pertencem à região 1 e são considerados como os “melhores". Estas duas variáveis, apesar de não terem apresentado associação, dão indícios de que os determinantes sociais mantêm sua influência entre o grupo estudado.

Igualmente, pela análise bivariada verificou-se que entre as mães com mais de três filhos os mesmos tiveram 1,5 vezes mais risco para o atraso no desenvolvimento que os outros (Tabela 38). Importante lembrar que esta variável apresentou significância estatística com o baixo peso ao nascer, além do que, este resultado pode significar que o número maior de filhos corresponda a uma menor exclusividade ao cuidado materno. 
Isto remete mais uma vez à teoria de BOLWBY (2002) no qual assevera que a necessidade da criança em obter atenção e carinho da mãe é tão fundamental quanto o alimento. Importante lembrar que o desenvolvimento precisa de estímulos e nesse sentido supõe-se que o tempo disponível da mãe é menor quanto mais filhos ela tiver. Vários autores, citados por BOWLBY (2002), revelaram a imensa capacidade de interação do bebê desde os primeiros minutos de vida e ele mesmo quando diz que bebês com mães mais responsivas se desenvolverão diferentemente daqueles com mães menos responsivas.Evidenciam que as crianças se discriminam mediante estímulos.

Outras características consideradas pelo modelo de HALPERN et al (2002) como fatores relacionados à atenção à criança foram a aquisição de convênio de saúde privado e freqüência à creche. Os dados encontrados reforçam a hipótese da característica social desfavorável da população em estudo, pois se notou que uma pequena minoria tem acesso a estes benefícios (Tabela 12).

Não obstante, a freqüência à creche não apresentou significância com ausência de atraso ao desenvolvimento ( Tabela 35) e uma outra questão a se ponderar é o fato que este serviço não se constitui, necessariamente, um fator protetor. Isto somente se obterá se houver qualidade no serviço da instituição como o tipo de cuidado prestado às crianças, bem como à existência de uma proposta educativa correta.

Um trabalho realizado com serviços de cuidado infantil encontrou maior risco de adquirir infecções respiratórias e diarréia entre as crianças que freqüentam creche (BARROS 1999). E um outro realizado em três creches consideradas de bom padrão concluiu que a creche pode ter contribuído para o bom desempenho da linguagem e 
comportamento pessoal-social observados (REZENDE et al 2003). Nota-se que os dois estudos encontraram resultados diferentes.

Outras características a respeito das necessidades básicas, higiene; sono e repouso; lazer, também mostraram dependência aos determinantes sociais e cuidados maternos. Apesar da aparente semelhança das informações registradas, associadas às observações durante os testes, diferenças foram notadas entre as crianças. A frase dita de jeito diferente por mais de uma mãe come de tudo, mas nem sempre tem de tudo pra comer e o caso da criança com pediculose que bate na mãe podem servir de exemplos.

O estudo de SILVA et al (2002) pesquisou a sensibilidade materna durante o banho. Baseados na teoria do apego procuraram identificar fatores sociais entre as relações e encontraram menores freqüências de comportamentos menos sensíveis entre as mães de mais baixa classe social. Estas possuíam menos escolaridade, menor idade e não tinham com quem dividir o cuidado.

Impressões semelhantes foram observadas neste estudo como a descrição de casos de mães visivelmente cansadas durante a entrevista. Isto remete outra vez ao número de filhos, reforçando a hipótese de que talvez seja um dos fatores responsáveis pelas diferenças no cuidado prestado.

Conforme se comentou anteriormente, o interesse ao se investigar a influência do vínculo mãe e filho sobre o crescimento se iniciou durante a pesquisa realizada com as crianças residentes em favela ( FILIPINI 2000; FILIPINI e SIQUEIRA 2001). Os resultados mostraram que havia crianças de condições sócio-econômicas parecidas, 
porém com diferentes evoluções no desenvolvimento. Uma das razões apontadas referiuse ao tipo de vínculo materno.

Por tais razões, este trabalho procurou incluir esta variável entre as outras definidas como fatores de exposição ao risco ao desenvolvimento e crescimento. Contudo, a dificuldade ao encontrar um instrumento que pudesse avaliar o apego de maneira "quantitativa" foi deveras difícil. O caminho para a descoberta do Attachment Q-sort trilhou por diálogos com profissionais especializados até a busca à literatura.

Como este estudo não era de caráter psicológico, no sentido estrito da palavra, o instrumento original pareceu inviável para o objetivo proposto e por esta razão a sua adaptação, descrito em forma detalhada na metodologia. A confiança quanto ao novo modelo surgiu do fato de que o objetivo não dizia respeito a diagnósticos, mas apenas de interpretação, por meio do escore, dos comportamentos de apego das crianças e comparar suas semelhanças.

Além do que, os itens traduzidos e avaliados proporcionaram momentos de reflexão quanto a sua coerência à teoria de Bowlby assegurando que a estratégia adotada foi apropriada.

A inter-relação entre a avaliação do comportamento da criança e o teste de Denver II certificou a legitimidade do teste do apego, pois garantiu os momentos de observação exigidos pelos autores do Attachment Q-sort. Contudo, a impressão é que o conjunto de atividades, entrevista (facilitando o aquecimento), antropometria e o teste de Denver II compuseram os elementos facilitadores à observação. 
Como a idade observada foi quase homogênea, entre três ou quatro anos, facilitou a comparação entre os mesmos, sugerindo que a comparação só é possível entre idades próximas.

Os resultados apresentados evidenciaram diferenças entre as crianças que as definiu com um comportamento de apego materno mais ou menos seguro ( Tabelas $39 e$ 40). Nesse sentido importante lembrar que esta avaliação não deveria ter um ponto de corte, portanto ele foi estabelecido apenas para fins comparativos. Por isso, para garantir a confiabilidade nos resultados, inclusive a distribuição contínua foi realizada e constatada significância entre os valores com menos apego seguro. E na análise as crianças com menos comportamento de apego seguro apareceram com 3,3 vezes mais risco para o atraso no desenvolvimento neuropsicomotor que entre aquele com mais apego seguro ( Tabela 40 ).

Quanto ao modelo utilizado para a análise multivariada, apenas o apego permaneceu com o risco de 3,3 vezes ( Tabela 40). O resultado corrobora as afirmações de que um apego seguro pode levar a um bom prognóstico do desenvolvimento, não só afetivo, como social e cognitivo (RAMIRES 2003; BOLWBY 2002; BRUM e SCHERMANN 2004).

Um outro enfoque diz respeito aos cuidadores secundários, avós e tios, e que para BOLWBY (2002) são as figuras de apego secundário à criança que contribuem tão quanto a mãe na formação de um comportamento seguro e que a figura materna referese a principal pessoa que cuida da criança. Importante destacar a referência de BOWLBY (2002) sobre um estudo de Vaughn et al com populações em que os cuidados 
parentais não tinham característica de continuidade, pois, as famílias eram pobres e em má situação econômica. $\mathrm{O}$ que observaram foi que houve uma mudança no padrão de comportamento de crianças ansiosas para seguras com a chegada de uma avó, portanto concluíram que sua chegada exerceu uma ação benéfica a elas. A população desse estudo, pelas suas próprias características, várias famílias não tradicionais, mães solteiras ou separadas, favoreceram este tipo de vida familiar e os comportamentos foram parecidos, tendo em vista os casos relatados em que a avó ou tia participam do cuidado infantil.

$\mathrm{Na}$ análise do teste de Denver II existe uma interpretação do comportamento da criança e que, por sinal, é um outro diferencial desta versão. A significância entre os comportamentos não esperados como medo, desatenção, hiperativos, etc, com o resultado do atraso no desenvolvimento asseveram que o desempenho cognitivo pode ser prejudicado pelo componente comportamental (Tabela 28 e 29). MONDARDO e VALENTINA (1998) descrevem um estudo de caso que detectou uma possibilidade de transtorno de déficit de atenção por hiperatividade associada ao vínculo materno.

Em suma, a questão do apego materno é um fator que suscitou reflexões acerca da sua magnitude ao desenvolvimento na medida em que ele se apresentou tão significante. A sua relação com as outras variáveis despertou interesse, contudo por não ser objeto deste estudo fica como proposta para uma nova pesquisa.

A morbidade foi representada no estudo pela hospitalização, ficando no quinto nível da escala de riscos da proposta de HALPERN et al (2002). No decorrer da vida dos bebês este fator apareceu de modo significativo pelo número e freqüência $(58,1 \%$, 
Tabela 12); na maioria por causas respiratórias e infecciosas. Pela análise bivariada as crianças observadas e que tiveram histórias de hospitalização no decorrer da vida, apresentaram 1,6 mais chance de risco de terem atraso no desenvolvimento ( Tabela 35).

O baixo peso ao nascer é descrito como uma das causas da hospitalização na infância (CAETANO et al 2002) e, além de ser um determinante biológico, ela é descrita como responsável pelo estresse emocional à criança marcadamente com relação à ausência materna (MARTINS et al 1998).

A teoria de Bowlby trata a questão da separação materna, especialmente nos primeiros anos de vida, como traumática, a ponto de deixar seqüelas ao desenvolvimento da personalidade e, neste caso, é possível considerar a hospitalização como um fator de separação. É possível afirmar que a conduta ao preservar e garantir a mãe nas instituições hospitalares infantis é tão necessária quanto o tratamento que ela está recebendo.

Outras associações com variáveis classicamente reconhecidas de risco para o baixo peso ao nascer, como por exemplo, a renda e escolaridade materna (Tabelas $36 e$ 38), na qual esta permaneceu como risco, do nascimento à vida atual, garantiram as hipóteses de que o crescimento e desenvolvimento sofreram influência interfatorial.

Por outro lado, acredita-se que o baixo peso ao nascer continua exercendo um papel isolado de risco ao desenvolvimento. Não obstante, a participação dos outros fatores indicou que este nascimento pode ser, no mínimo, atenuado se houver a possibilidade de controlá-los, tal como a hospitalização que representou certamente um risco à sua qualidade de vida. 
Simultaneamente, a escolaridade conserva-se singular. Um artigo, recentemente publicado no jornal a Folha de São Paulo por DIMENSTEIN (2005), descreve que de acordo com classificação Índice de Desenvolvimento Humano (IDH) que utilizou os critérios de renda, expectativa de vida e escolaridade, os judeus e japoneses brasileiros tiveram as melhores posições comparadas ao de nossa população. Contudo, em suas considerações afirma que a suposição por uma superioridade étnica neste grupo é inconsistente, ele destaca que a tradição cultural de ambos sempre valorizaram o saber e acredita que isto seja o principal motivo para o progresso vertiginoso destas duas origens.

Para estes desafios os programas de seguimento ou follow-up apresentam-se como a melhor alternativa de impacto para o controle dos fatores de risco que garantam, desde o nascimento, condições favoráveis ao crescimento e desenvolvimento aos bebês nascidos de baixo peso.

É certo que o apego materno esteja associado ao cuidado. BOWLBY (2002) comenta que "a evidência que temos quanto ao padrão de apego desenvolvido por uma criança confirma claramente o papel importante de quem dispensa cuidados"(p.455). Isto equivale considerar que esta ação pode gerar efeitos, quando inadequados, danosos ao desenvolvimento da criança, nesse caso, o cuidado deveria ser tratado como um outro problema de saúde pública e articulado às suas práticas. 


\section{CONSIDERAÇÕES FINAIS}

O desafio ao realizar este trabalho transformou-se em motivação que se pode atribuir a um conjunto de fatores, particularmente de ordem operacional, os quais determinaram o interesse pela temática e pelos resultados que, acredita-se, poderão contribuir com as políticas de saúde do município de Mauá.

Constatou-se que a população do estudo constituiu-se, na grande maioria, de condições sócio-econômicas desfavoráveis, muito embora a amostra agregou todos os níveis sociais. Imaginou-se, até, que a estratégia da coleta poderia ter influenciado na seleção da amostra, já que a referência foi o Programa de Saúde da Família. Contudo, todos as crianças localizadas foram convocadas sem nenhum critério pré-determinado, tal como pelo referencial econômico.

Somado a isto, a certeza de que a amostra pode ser representativa se consolidou a partir do perfil sócio e econômico da população, que se constituí, em grande parte, por operários das indústrias da região do $\mathrm{ABC}$ ou por trabalhadores da indústria informal. Aliado aos relatos sobre a parcela desta população com condições sociais melhores, que procuram os recursos de saúde nos hospitais privados em outros municípios, os mais próximos e em São Paulo. Deste modo, ficou claro a dependência ao SUS que se confirmou por ocasião das visitas às unidades durante a coleta de dados.

Os resultados identificaram alguns pontos favoráveis, tais como: 
- Apesar de ter apresentado significância com as variáveis de desfecho, é possível concluir que de modo geral houve boa cobertura do pré-natal constatada pelo percentual obtido criando uma expectativa favorável à prevenção do baixo peso ao nascer.

- Empenho das equipes de saúde, particularmente as equipes do Programa de Saúde da Família, tanto pela auto-estima destes profissionais como pela organização de algumas equipes.

Por isto, recomenda-se a preservação destas equipes e garantir a capacitação permanente, em especial para as estratégias de seguimento aos bebês com baixo peso ao nascer.

O ideal seria que estas equipes agissem em consonância com os programas de seguimento, implementados por meio de uma equipe multidisciplinar capacitada e com acesso a recursos materiais adequados.

A escolaridade materna suscitou preocupação por vários motivos. Inicialmente pelo percentual elevado de mulheres com escolaridade regular ou baixa e pelo risco que ela apresentou, proporcionalmente, entre bebês com menos peso e mães com pouca escolaridade. Uma outra razão se deve à dificuldade em reverter este quadro tendo em vista que depende de mudanças profundas na sociedade atual.

Nesse sentido, seria necessário que seus percursos fossem reconstituídos e, acredita-se, será possível modificá-lo se houver apoio de todas as instâncias da sociedade, com um governo de ação tripartite e participação da comunidade. 
O grupo do estudo não representou um grupo de alto risco e, talvez por isso os resultados mostraram que os fatores do nascimento, especialmente os biológicos não ofereceram tanto impacto sobre o desenvolvimento infantil quanto os fatores do período neonatal, significativamente ligado aos cuidados maternos. Somente a hospitalização, que pode ser considerada de caráter biológico, teve um peso importante e pode também ser associado ao cuidado materno.

Já se tem conhecimento das estratégias para se oferecer o pré-natal, escolaridade, etc. Porém, criar oportunidades para que o outro seja cuidadoso e com capacidade de oferecer afeto dependerá de fatores de ordem emocional, discutidos ainda timidamente nos serviços de saúde, muito embora eles venham obtendo espaço por meio da área de saúde mental e pela abordagem do tema Humanização.

Recomenda-se, finalmente, que estes programas sejam incorporados e efetivamente executados para que possam contribuir com a qualidade de vida da família e criança. 


\section{REFERÊNCIAS BIBLIOGRÁFICAS}

- Ainswoth M. On security. 2004. Disponível em

<http: www.psychology.sunysb.edu/waters/on-line PDF/security.pdf [05/07/2004]

- Alexander JM, Mercer BM, Miodovnik M, Thurnau GR, Goldenberg RL, Das AF et al. The impact of digital cervical examination on expectantly managed preterm rupture of membranes. Am J Obstet Gynecolog. 2000; 183: 1003-1007.

- Almeida MF. Mortalidade neo- natal em Santo André. São Paulo; 1995. [Tese de Doutorado - Faculdade de Saúde Pública da Universidade de São Paulo].

- Almeida MF e Mello Joge MHP. Pequenos para idade gestacional: fator de risco para mortalidade neonatal. Rev Saúde Pública. 1998; 32: 217-24.

- Almeida MF, Novaes HMD, Alencar GP, Rodrigues LC. Mortalidade neonaltal no Município de São Paulo: influência do peso ao nascer e de fatores sóciodemográficos e asssistenciais. Rev.Bras. Epidemiol.2002; 5(1):93-107.

- Barbieri MA, Silva AAM, Bettiol H, Gomes, VA. Risk factors for the increasing trend in low birth weight among live births born by vaginal delivery, Brazil. Rev Saúde Pública. [periódico on line]. 2000; 34(6). Disponível em $<$ http://www.scielo.br/scielo> [acesso 2002 Jul 23].

- Barros FC. Fatores de risco para baixo peso ao nascer, em uma comunidade rural do sul do Brasil. Jornal de Pediatria. 1996a; 72(6): 360-1.

- Barros FC. Fatores de risco de natimortalidade em Fortaleza; um estudo de caso controle. Jornal de Pediatria. 1996b; 72(6): 361-2.

- Barros, AJD. Child-care attendance and common morbidity: evidence of association in the literature and questions of design. Rev Saúde Pública. 1999; 33(1): 98-106. 
- Belsey MA. Child health and development: health of the newborn. In: Baun JD. Birth risks. New York: Raven Press-Nestlé Nutrition workshop series; 1993. v.31.

- Bittar RE e Zugaib M. Parto prematuro: Fatores predisponentes e prevenção. In: Marcondes E, Vaz FACV, Ramos JLA, Okay Y. Pediatria básica. Pediatria geral e neonatal. Tomo I. $9^{\mathrm{a}}$ ed.São Paulo: Sarvier; 2003. p.337-45.

- Bossi E. Secondary posnatal care of the newborn. In: Baun JD. Birth risks. New York: Raven Press-Nestlé Nutrition workshop series; 1993. v.31.

- Bowlby J. Apego. A natureza do vínculo.3ª ed. São Paulo: M. Fontes; 2002.v. 1.

- Brum EHM e Schermann L Vínculos iniciais e desenvolvimento infantil: abordagem teórica em situação de nascimento de risco. Ciência \& Saúde Coletiva. 2004; 9(2): 457467.

- Caetano JRM, Bordin IAS, Puccini RF, Peres CA. Fatores associados á internação hospitalar de crianças menores de cinco anos, São Paulo,SP. Rev.Saúde Pública. 2002; 36(3): 285-91.

- Capurro H, Konichezky S, Fonseca D, Caldeyro-Barcia R. Método simplificado para el diagnostico de la edad gestacional en el recien nacido. Pub. Cient (CLAP). 1978; 732:168- 175 .

- Cesar CLG. Fatores de risco associados à mortalidade infantil em duas áreas da região metropolitana de São Paulo (Brasil), 1984- 1985. Proposta de instrumentos preditivos. Rev.Saúde Pública.1990; 24:300-10.

- Cesar CLG. Enfoque de risco em saúde pública. In: Barreto, ML Epidemiologia, serviços e tecnologias em saúde. Rio de Janeiro: FIOCRUZ/ABRASCO; 1998.

- Collett D. Modelling binary data. New York: Chapman e Hall; 1991. 
- Costa HPF, Marba ST (Coord). O recém-nascido de muito baixo peso. São Paulo: Atheneu; 2003.

- Del Priore M. História das crianças no Brasil. 3ª ed. São Paulo: Contexto, 2002.

- Dimenstein G. Judeus e japoneses são mais inteligentes? Folha de S. Paulo 2005 abr 24; cad C8.

- Eickmann SH, Lira PIC, Lima MC. Desenvolvimento mental e motor aos 24 meses de crianças nascidas a termo com baixo peso. Arq. Neuropsiquiatr. 2002; 60(3-b): 748-754.

- Fanaroff K. Care of the high- risk neonate. Philadelphia: W.B. Saunders; 1993.

- Farr V, Mittchell RG. Estimation of gestational age in the newborn infant. Am. J. Obst. \& Gynecolog. 1969; 103(3): 380-83.

- Filipini R. Crescimento e desenvolvimento de crianças residentes em uma favela do município de São Paulo. São Paulo; 2000. [Dissertação de mestrado Faculdade de Saúde Pública da Universidade de São Paulo].

- Filipini R, Siqueira AAF. Crescimento e desenvolvimento de crianças residentes em uma favela do município de São Paulo. In: Anais do $7^{\mathbf{0}}$ Congresso Paulista de Saúde Pública; 2001 set/out 29-03; Santos, Brasil. Santos: Associação Paulista de Saúde Pública; 2001. p.54.

- Fiocruz. Mortalidade perinatal e neonatal no Brasil. RADIS-TEMA. Assistência perinatal e neonatal no Brasil. Um desafio para os serviços de saúde. 1999; 17(2): 6-17.

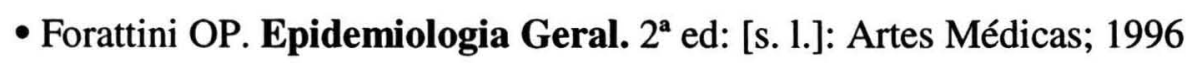


- Fraire MES, Moran MR, Romero JFG. Associación de ruptura prematura de membranas com morbilidad y mortalidad perinatal tipo I. Rev. Med. IMSS (Mex).1977; 35(2): 111-115.

- Frankenburg WK e Dodds JB. The Denver developmental screening test. The Journal of Pediatrics. 1967; 71(2): 181-191.

- Frankenburg WK et al. Denver developmental screening test. Manual Workbook for nursing \& paramedical personnel. Colorado: University of Colorado Medical Center; 1973.

- Frankenburg WK, Ker CY, Enfelke S, Schaefer ES, Thornton SM. Validation of key Denver developmental screening test items: a peliminary study. The Journal of Pediatrics. 1988; 112(4)

- Frankenburg WK, Dodds JB. Denver II Training Manual. Colorado: Denver Developmental Materials: Colorado; 1992.

- Frankenburg WK, Dodds J, Archer P, Shapiro H, Bresnick B.The Denver II: A major revision and restandardization of the Denver Development screening test. Pediatrics. 1992; 89 (1):91-97.

- Fundação Seade. Sistema Estadual de Análise de Dados. Pesquisa de condições de vida na região Metropolitana de São Paulo - Primeiros Resultados. São Paulo; 1994.

- Garelli JC, Montuori E. Vínculo afectivo materno-filial em la primeira infância y teoria Del attachment. Archarg Arg Pediatr. 1997; 95(122): 122-125.

- Gesell A. El niño de 1 a 5 años. Argentina: Piados; 1858a.

- Gesell A. A criança dos 0 aos 5 anos. São Paulo: Martins Fontes; 1885 b. 
- Halpern R, Barros FC, Horta BL, Victora CG. Desenvolvimento neuropsicomotor aos 12 meses de idade em uma coorte de base populacional no Sul do Brasil: diferenciais conforme peso ao nascer e renda familiar. Cad. Saúde Pública, 1996; 12 (supl 1): 73-78.

- Halpem R, Giuliani ERJ, Victora CG, Barros, FC, Horta BL. Fatores de risco para supeita de atraso no desenvolvimento neuropsicomotor aos 12 meses de vida. Rev. Chil. Pediatr. 2002; 73(5): 529-539.

- Hawkins DF, Di Renzo GC, Cosmi EV. Recent advances in Perinatal Medicine. Ettore Majorana International Life Sciences Series. 1993; 10: 1-21.

- Hércules, $\mathrm{S}$ et al. O município de Mauá. Políticas e organização de serviços de saúde. Texto apresentado no curso de especialização em gestão de Sistemas e Serviços de Saúde. Mauá, 2003. ( Mimeografado)

- Honig AS. Secure relationships. Nurturing Infant / Toddler. Attachment in Early Care Settings. Washington: National Association. for the Education of Yong Children; 2002.

- Horta BL, Barros FC, Halpern R, Victora CG. Baixo peso ao nascer em duas coortes de base populacional no Sul do Brasil. Cad. Saúde Pública.1996; 12(supl1) [on line]. Disponível em <http://www.scielo.br/scielo > .[2002jul 23]

- Hosmer DW, Lemeshow S. Applied logistic regression. New York: Wiley, 1989.

- Instituto Brasileiro de Geografia e Estatística e DataSUS. Estimativas demográficas e Ministério da Saúde - Sistema de Informações sobre Mortalidade (SIM). Brasília: 2001.

- Kleinbaum DG, Kupper LL, Morgenstern H. Epidemiologic Research. New York: Van Nostrand Reinhold; 1982. 
- Kramer MS, Olivier M, Mc Lean FH, Dougherty GE, Willis DM, Usher RH. Determinants of fetal growth and body proportionality. Pediatrics. 1990; 86(1): 1826.

- Lang JM, Rothman KJ, Cann CI - That Confounded P-Value .Epidemiology. 1998, 9(1):7-8.

- Laurenti R, Buchalla CM, Costa Jr ML. Estudo da morbidade e da mortalidade perinatal em maternidades. 1- Descrição do projeto e resultados gerais. Rev. Saúde. Pública. 1984; 18: 436- 47.

- Leone CR. Epidemiologia, desafios e perspectivas. In: Costa HPF, Marba ST. O recém nascido de muito baixo peso. São Paulo: Atheneu; 2003.p. 3-10.

- Lopes SMB, Lopes JMA. Folow up do RN de alto risco. Rio de Janeiro: Medsi; 1999.

- Lubchenco LO, Hansman C, Dressler M, Boyd E.. Intrauterine growth as estimated from liveborn birth - weight data at 24 to 42 weeks of gestation. Pediatrics. 1963; 32: 793- 800 .

- Lubchenco LO. Assessment of gestational age and development at birth. Pediatric Clinics of North America. 1970; 17(1): 125-145.

- Marino WT. Estudo descritivo dos recém-nascidos de muito baixo peso em uma maternidade de nível terciário São Paulo; 2001. [Dissertação de mestrado Faculdade de Saúde Pública da Universidade de São Paulo].

- Martins FRT, Sherlock MSM, Araújo TL. Opinião de crianças hospitalizadas sobre a permanência da mãe durante a hospitalização. Pediatria atual. 1998; 11(5):50-58.

- Mauá-São Paulo. Perfil do Município de Mauá-SP. [on line] 2005. Disponível em <http://www.maua.sp.gov.br/perfil> .[acesso em 2005jan 15] 
- Menezes AM, Barros FC, Victora CG, Tomasi E, Halpern R, Oliveira ALB. Fatores de risco para mortalidade perinatal em Pelotas, RS, 1993. Rev.Saúde Pública.1998; 32(3) :209- 16.

- Ministério da Saúde. Manual de Instruções para o Preenchimento da Declaração de Nascidos Vivos. $3^{\mathrm{a}}$ ed: Brasília-DF, 2001a.

- Ministério da Saúde. Manual de Procedimentos do Sistema de Informações sobre Nascidos Vivos. Brasília, 2001b.

- Ministério da Saúde. Sistemas de informações sobre Mortalidade (SIM) e Nascidos Vivos (SINASC) para os profissionais do Programa de Saúde da Família. $2^{\mathrm{a}}$ ed. Brasília-DF; 2004.

- Mondardo AH e Valentina DL. Psicoterapia infantil: ilustrando a importância do vínculo materno para o desenvolvimento da criança. Psicol. Reflex. Crit. 1998;11(3).

- Monteiro CA. Saúde infantil: tendência e determinantes na cidade de São Paulo na segunda metade do século XX. Rev. Saúde Pública. 2000; 34(6 Supl): 1-4.

- Monteiro CA, Benicio MHA e Ortiz LP. Tendência secular do peso ao nascer na cidade de São Paulo (1976-1998). Rev. Saúde Pública. 2000; 34(6 Supl): 26-40.

- Monteiro CA e Conde WL. Tendência secular da desnutrição e da obesidade na infância na cidade de São Paulo (1974-1996). Rev. Saúde Pública. 2000; 34 (6 Supl): 52-61.

- Morsch DS. Prematuridade e desenvolvimento afetivo e cognitivo.In: Lopes SMB. JMA. Folow up do RN de alto risco. Rio de Janeiro: Medsi; 1999.

- National Center for Health Statistics NCHS. Growth curves for children birth-18 years. Vital and Health Statistics Series. 1977; 11(165)---. 
- Naufel HG. Crescimento fetal, peso ao nascer e avaliação clínica de idade gestacional do recém-nascido: estudo crítico da literatura. São Paulo;1998. [Tese de Doutorado - Faculdade de Saúde Pública da Universidade de São Paulo].

- Naufel HG.Avaliação física e classificação. In: Costa HPF, Marba ST. O recém nascido de muito baixo peso. São Paulo: Atheneu; 2003.p. 61-72..

- Newcombe N. Desenvolvimento emocional e social na primeira infância. Desenvolvimento infantil. Abordagem de Mussen. $8^{\text {a }}$ ed. Porto Alegre: Artmed; 1996.

- Newman RB, Goldenberg RL, Moawad AH, Iams JD, Méis PJ, Das A, Miodovnik $\mathbf{M}$ et al. Occupational fatigue and preterm premature rupture of membranes. Am J Obstet Gynecolog. 2001; 184(3): 438-446.

- Nóbrega, FJ. A importância nutricional do leite materno. In: Rego,JD. Aleitamento materno.São Paulo.Rio de janeiro.Belo Horizonte;2002.p.59-82.

- Nóbrega FJ, Campos ALR, Nascimento CFL. Distúrbios nutricionais na infância e fraco vínculo mãe/filho.Rio de Janeiro. EdRevinter; 2000.p.37-64.

- Organização Mundial da Saúde. Manual da classificação estatística internacional de doenças e problemas relacionados à saúde: 10 revisão. São Paulo: EDUSP; 1997.

- Ovalle SA, Martinez MA, Gomes R, Saez CJ, Menares VI, Aspillaga MC, Enrique J et al. Parto prematuro com membranas intactas: microbiologia del líquido amniótico y tacto genital inferior y su relacíon com los resultados materno neonatales. R. Méd de Chile. 2000; 128 (9). ISSN 0034-9887 [ acesso 2001 nov 11].

- Pendry P. Ethological attachment theory: a great idea in personality? Northwestern university [periódico on line]. 1998. Disponível em $<$ http://www.personalityresearch.or/papers/pendry.html> [acesso $2004 \mathrm{dez} 11$ ]. 
- Pereira MG. Epidemiologia teoria e prática. Rio Janeiro: Guanabara Koogan; 1995.

- Pernetta C. Semiologia pediátrica. 5a ed. Rio de Janeiro: Guanabara Koogan; 1990.

- Porto MAS. O prematuro com retardo de crescimento intra- uterino. In: Lopes SMB; Lopes JMA. Folow up do RN de alto risco. Rio de Janeiro: Medsi; 1999.

- Ramos LAR. O recém-nascido normal. In: Marcondes, E; Vaz, FACV; Ramos, JLA; Okay, Y. Pediatria básica. Pediatria geral e neonatal. Tomo I. $9^{a}$ ed.São Paulo: Sarvier; 2003. p.315-20.

- Ramos LAR, Corradini HB, Vaz. FACV, Barros JCR, Novo ACCF.Avaliação da idade gestacional e da adequação do crescimento intra-uterino. In: Marcondes, E; Vaz, FACV; Ramos, JLA; Okay, Y. Pediatria básica. Pediatria geral e neonatal. Tomo I. $9^{a}$ ed.São Paulo: Sarvier; 2003a. p.321-29.

- Ramos LAR, Vaz.FACV, Calill, VMLT. O recém-nascido pequeno para a idade gestacional. In: Marcondes, E; Vaz, FACV; Ramos, JLA; Okay, Y. Pediatria básica. Pediatria geral e neonatal. Tomo I. $9^{\mathrm{a}}$ ed.São Paulo: Sarvier; 2003b. p.353-60.

- Ramires VRR. Cognição social e teoria do apego: possíveis articulações.Porto Alegre. Psicol. Reflex. Crit. [periódico on line]. 2003; 16(2). Disponível em <VRL: http://www.scielo.br/scielo.php?script=sci_arttex\&pid=S0102-79722003000200020> [2004 Mai 01].

- Rezende MA, Lima FGd, Beteli VC, Santos JLF. Habilidades de linguagem e pessoalsocial de crianças de 0 a 3 anso de idade cuidadas em creches. Rev.Bras.Cresc. Desenv. Hum. 2003; 13 (1): 40-52.

- Ribeiro ERRO, Barbieri MA, Bettiol H, Silva AAM. Comparação entre duas coortes de mães adolescentes do Sudestes do Brasil. Rev.Saúde Pública. 2000; 34(2). Disponível em <VRL: http://www.scielo.br/scielo.php?script=sci> [acesso 2002 jul 23]. 
- Rosa MLG, Hortale VA. Óbitos perinatais evitáveis e estrutura de atendimento obstétrico na rede pública: estudo de caso de um município da região metropolitana do Rio de janeiro. Cad. Saúde Pública. 2000; 16(3):773-783.

- Rugolo, LMSS. Follow-up de recém-nascido de muito baixo peso.In: Costa, HPFC; Marba, ST. O recém-nascido de muito baixo peso. São Paulo. Rio de Janeiro. Belo Horizonte. Ribeirão Preto: Atheneu; 2003. P.469-77.

- Saigal S. Global outcome of high- risk infants at school age. In: Baun JD. Birth risks. New York: Raven Press-Nestlé Nutrition workshop series; 1993.v.31.

Santos MC, Matheus M, Sala M. Aspectos neonatais da rotura prematura das membranas. F. Méd(BR). 1986; 92(6): 371-375.

- Silva JLP. Prematuridade: aspectos obstétricos. In: Neme B. Obstetrícia básica. São Paulo: Sarvier; 1995. (59)-372.

- Silva SSC, Le Pendu Y, Pontes, FA Dubois, M. Sensibilidade materna durante o banho. Psic:teor. E pesq. 2002 ;18(3).p.345-352 -ISSN 0102- 372

- Silva, AAM et al. Infant mortality and low birth weight in cities of Northeastern and Southeastern Brazil. Rev.Saúde Pública. 2003; 37 (6): 693-8.

- Siqueira AAF. Indicadores de risco de peso inadequado ao nascer. São Paulo: 1981. [Tese de Livre- Docência - Faculdade de Saúde Pública da USP].

- Siqueira AAF. O nascimento biológico da criança. Rev. Bras. Cresc. Des. Hum. 1991;1(1): 44-53.

- Souza MLR, Tanaka ACD’A, Siqueira AAF, Santana RM. Estudo sobre nascidos vivos em maternidades. 1- Peso ao nascer, sexo, tipos de nascimento e filiação previdenciária das mães. Rev. S. Públ. 1988; 22(4): 489- 93. 
- Sterne JAC e Smith GD. Sifting the evidence - what's wrong with the significance tests? BMJ. 2001; 322: 226-231.

- Tananka ACD'A, Siqueira AAF, Bafile PN. Situação de saúde materna e perinatal no estado de São Paulo, Brasil. Rev.S.Públ. 1989; 23(1): 67- 75.

- Van Ijzendoorn MH, Vereijken CMJL, Bakermans-Kranenburg J, Riksen-Walraven M Assessing attachment security with the attachement Q-Sort: Meta-Analytic evidence for the validity of the observer AQS. Child Development. 2004; 175(4): 1-26.

- Victora CG et al. Situação de saúde da criança em área da região sul do Brasil, 1980- 1992: Tendências temporais e distribuição espacial. Rev.Saúde Pública. 1994; 28(6):423-32.

- Victora CG, Gigante DP, Barros AJD, Monteiro CA e Mercedes O. Estimativa de prevalência de déficit de altura/idade a partir da prevalência déficit de peso/idade em crianças brasileiras. Rev. Saúde Pública. 1994; 28(6): 423-32.

- Victora, CG et al. Estudo longitudinal da população materno infantil da região urbana do sul do Brasil, 1993: aspectos metodológicos e resultados preliminares. Rev. Saúde Pública. 1998; 32(4): 321-327.

- Wade, GH. Update on the Denver II. Pediatric Nursing. 1992;18(2): 140-141.

- Waters E. Attachment Q-set (Version 3). Items and Explanations. [on line]. 1987a. Disponível em <http//www.johnbowlby.com> [2004 Mai 01].

- Waters E e Deane K. Defining and assessing individual differences in attachment relationships: Q-Metodology and the organization of behavior in infancy and early childhood. In Bretherton I \& Waters E (Eds.). Monographs of the Society for Research in Child Development.1985; 50(1-2): p.41-65.

- Warters E. The "Goodness" of Attachment Assessment: There Is A "Gold Standad" But It Isn't As Simple As That. [on line]. 2002b. Disponível em 
$<$ http://www.psychology.sunysb.edu/attachment/measures/content/attachment_validity.h tml> [2004 Jul 06].

- Waters E. Assessing Secure Base Behavior and Attachment Securtiy Using the QSort Method. [on line]. 2004c. Disponível em <http://www.psychology.sunysb.edu/attachment/measures/content/aqs_method.htm> [2004 Jul 06]

- Wingerd JMA, Schoen MD, Solomon MD. Growth standards in the first two years of life based on measurements of white and black children in a prepaid health car program. Pediatrics. 1971; 47(5).

- World Health Organization. Physical Status: the use and interpretation of anthropometry. Geneva; 1995.

- World Health Organization. Sub Committee on Nutrition. Low birthweight: report of a meeting in Dhaka, Bangladesh on 14- 17 june 1999. Geneva: Podja J. and Kelley L. Nutrition Policy paper; 2000.

- Zambonato AMK, Horta BL, Tomasi E. Fatores de risco pra nascimento de crianças pequenas para idade gestacional. Rev.Saúde Pública. 2004; 38(1):24-29.

- Zimberoff DMA e Hartman DMSW Attachment, detachment, nonattachment: achieving syntesis. Section1. Attachment theory. Jornal of heart-centered therapies, 2002; 5(1): 3-94.http:// (05/07/2004).

- As referências foram organizadas de acordo com a padronização da Faculdade de Saúde Pública da Universidade de São Paulo, cujo formato é o proposto pelo Comitê Internacional de Revistas Médicas (conhecido como Grupo de Vancouver): Universidade de São Paulo. Faculdade de Saúde Pública. Guia de Apresentação de Teses. São Paulo: A Biblioteca, 1998. 
ANEXOS 
GRAMS

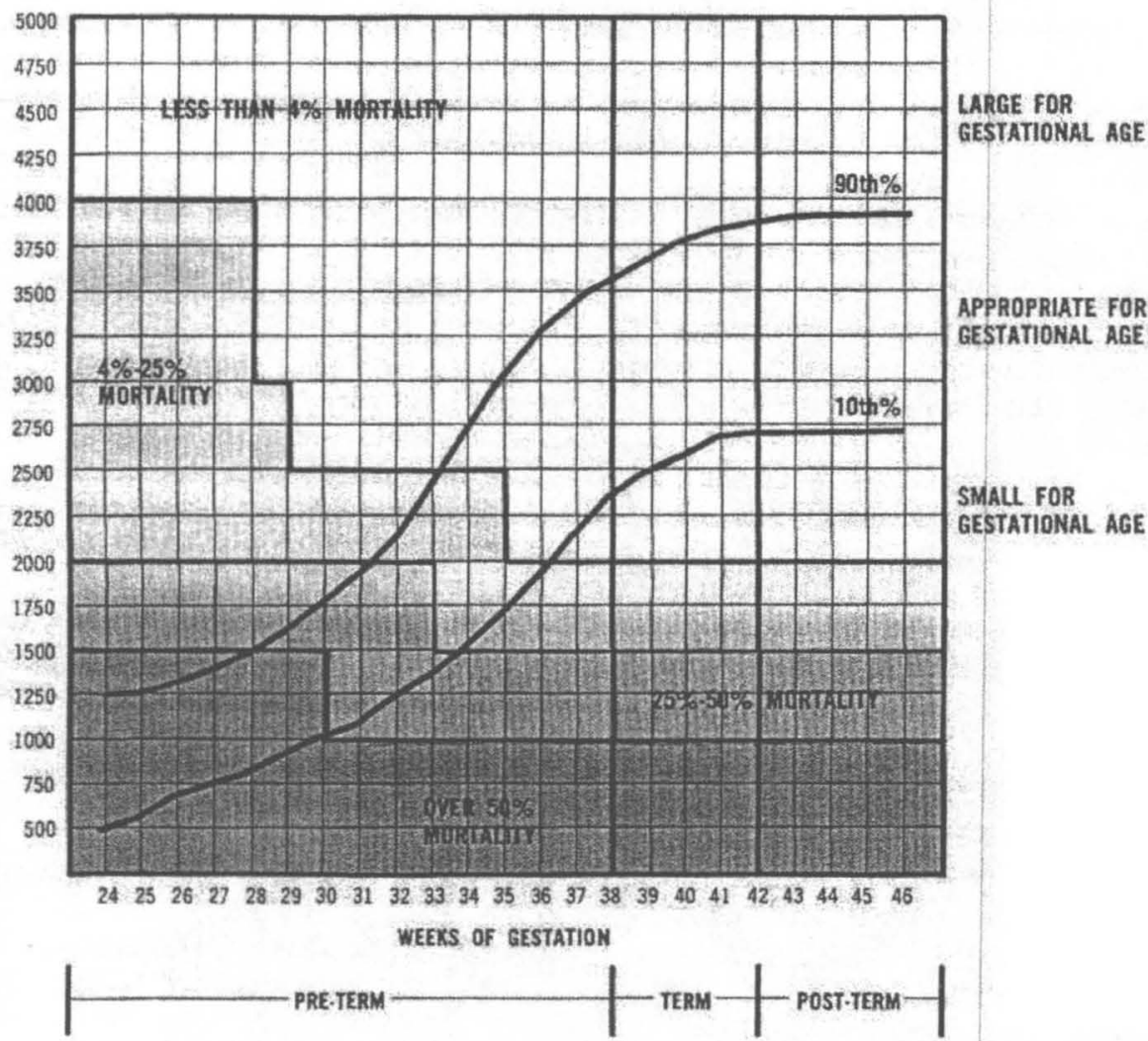

Figure 2. A classification of newborn infants by birth weight, gestational age and intrauterine growth. (From Battaglia, F. C., and Lubchenco, L. O.: A practical classification of newborn infants by weight and gestational age. J. Pediat., $71: 159,1967$, reproduced with permission.? 


\section{Relação de Nascidos Vivos $\times$ Região}

ANDREIA SILVA OLIVEIRA

$21 \quad 1 \quad 4 \quad$ AV. ITAPARK

JD. ITAPARK $\quad 09300000$

DNV: 07367492 Cod Estab. 0017876 HOSP DE CLINICAS DR. RADAMES NARDIN

VALÉRIA APARECIDA MIZOTO

\section{$30 \quad 5 \quad 4 \quad$ R. ANCHIETA}

DNV: 08702605

Cod. Estab. 0017876

HOSP. DE CLINICAS DR. RADAMES NARDIN

CIRLENE FELIPE SILVA

DNV: 08702622

Cod. Estab. 0017876

HOSP. DE CLINICAS DR. RADAMES NARDINI

$32 \quad 2 \quad 1$ R. CARLOS GOMES

EUNICE CAMPOS DE OLIVEIRA PEREIRA

HOSP. DE CLINICAS DR. RADAMES NARDINI

DNV: 08702675

Cod. Estab. 001787

JOSILDA LUIZ DA SILVA

3513 R. RICARDO GONCALVES

DNV: 08734046

Cod. Estab. 0017876 HOSP. DE CLINICAS DR. RADAMES NARDINI

MARTA SOARES MARTINS

$\begin{array}{llll}30 & 5 & 3 & \text { AV. ITAPARK }\end{array}$

DNV: 08736048

Cod. Estab. 0017868

SANTA CASA DE MAUÁ
Data Nasc. 22072001

15

SEXO: $M$

PESO: 2300

VL. BOCAINA 09310510

Data Nasc. 0112200

SEXO: M

PESO: 1880

PQ. DAS AMERICAS 09311110

Data Nasc. 0412200 SEXO: $F$

PESO: 2420

VL. AUGUSTA 09300000

Data Nasc. 1312200

SEXO: $\mathrm{F}$

PESO: 2400

221

SANTA LIDIA $\quad 09300000$

Data Nasc. 14052001

SEXO: $\mathrm{F}$

PESO: 1620

3049

JD. ITAPARK 09350000

Data Nasc. 17082001

SEXO: $M$

PESO: 2430 
AGENDAMENTO POR UNIDADES - 2004

\begin{tabular}{|c|c|c|c|c|c|}
\hline Segunda & Terça & quarta & quinta & Sexta & sábado \\
\hline $25 / 10$ & $26 / 10$ & $27 / 10$ & $28 / 10$ & $29 / 10$ & $23 *$ \\
\hline - & 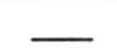 & $3 / 11$ & $4 / 11$ & $5 / 11$ & $6 / 11$ \\
\hline $8 / 11$ & $9 / 11$ & $10 / 11$ & $11 / 11$ & $12 / 11$ & $13 / 11$ \\
\hline - & $16 / 11$ & $17 / 11$ & $18 / 11$ & $19 / 11$ & $20 / 11$ \\
\hline $22 / 11$ & $23 / 11$ & $24 / 11$ & $25 / 11$ & $26 / 11$ & $27 / 11$ \\
\hline $29 / 11$ & $30 / 11$ & $1 / 12$ & $2 / 12$ & $3 / 12$ & $4 / 12$ \\
\hline $6 / 12$ & $7 / 12$ & $8 / 12$ & $9 / 12$ & $10 / 12$ & $11 / 12$ \\
\hline $13 / 12$ & $14 / 12$ & $15 / 12$ & $16 / 12$ & $17 / 12$ & $18 / 12$ \\
\hline
\end{tabular}


ANEXO 4

UBS - REGIÃO DE SAÚDE

\begin{tabular}{|c|c|c|c|}
\hline REGIÃO 1 & Coordenador/ & endereço/ fone & observaçōes \\
\hline \multicolumn{4}{|l|}{ CARLINA } \\
\hline \multicolumn{4}{|l|}{ GUAPITUBA } \\
\hline \multicolumn{4}{|l|}{ PARQUE S. VICENTE } \\
\hline \multicolumn{4}{|l|}{ PRIMAVERA } \\
\hline \multicolumn{4}{|l|}{ VILA ASSIS } \\
\hline \multicolumn{4}{|l|}{ REGIAO 2} \\
\hline \multicolumn{4}{|l|}{ CAPUAVA } \\
\hline \multicolumn{4}{|l|}{ MAGINE } \\
\hline \multirow{2}{*}{\multicolumn{4}{|c|}{$\begin{array}{l}\text { ORATÓRIO } \\
\text { PARANAVÁ́ }\end{array}$}} \\
\hline & & & \\
\hline \multicolumn{4}{|l|}{ SÔNIA MARIA } \\
\hline \multicolumn{4}{|l|}{ REGIÃO 3} \\
\hline \multicolumn{4}{|l|}{ ZAÍRA 1} \\
\hline \multicolumn{4}{|l|}{ ZAÍRA 2} \\
\hline \multicolumn{4}{|l|}{ REGIAO 4} \\
\hline \multicolumn{4}{|l|}{ FLÓRIDA } \\
\hline \multicolumn{4}{|l|}{ ITAPARK } \\
\hline \multirow{2}{*}{\multicolumn{4}{|c|}{$\begin{array}{l}\text { PARQ. das AMÉRICAS } \\
\text { CANTA ÍnIA }\end{array}$}} \\
\hline & & & \\
\hline \multicolumn{4}{|l|}{ REGIÃO 5} \\
\hline \multicolumn{4}{|l|}{ FEITAL } \\
\hline \multicolumn{4}{|l|}{ JARDIM MAUÁ } \\
\hline \multicolumn{4}{|l|}{ SANTISTA } \\
\hline SÃO JOÃO & & & \\
\hline
\end{tabular}


ANEXO 5

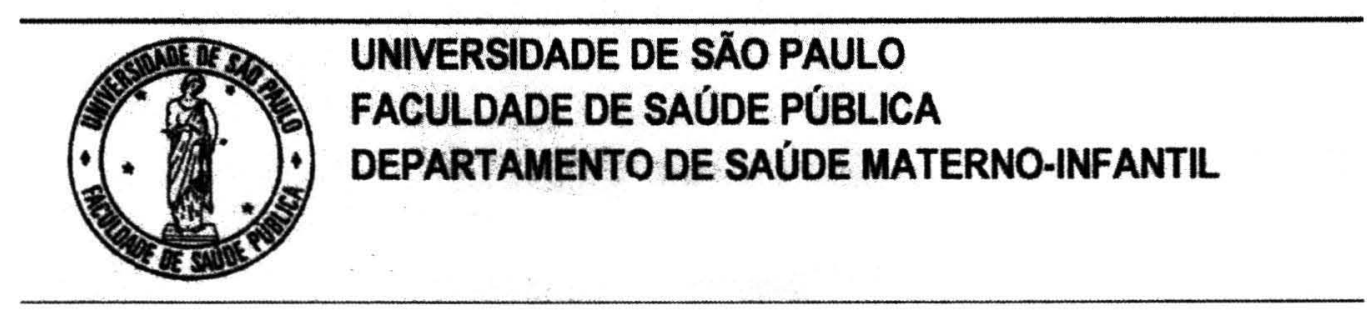

Santo André, outubro de 2004.

Prezada mamãe

Como vai?

Estamos solicitando seu comparecimento à nossa unidade, conforme o dia e horário, datados no lembrete em anexo. A razão é para que possamos avaliar seu filho, se ele está crescendo e se desenvolvendo bem após os (ou quase) seus três anos de vida. Como sabe, ele nasceu com um peso baixo e é muito importante saber como ele está agora para prevenirmos possíveis agravos.

$A$ avaliação se constituirá em medir, pesar e aplicar um teste de desenvolvimento através de uma brincadeira. Só isto!

O seu comparecimento com a criança será muito importante!

Até lá!

\section{Rosangela Filipini}

Secretaria da Saúde de Mauá

Faculdade de Medicina da Fundação do ABC

Faculdade de Saúde Pública da USP 


\section{Relatos de caso}

Conforme descrito no capítulo que trata da metodologia, duas crianças que pertenceram à amostra foram excluídas por apresentarem à entrevista problemas de saúde de origem neurológica. Em razão disso, a inclusão deles levaria a possíveis vieses na interpretação dos dados. A descrição destes casos são apresentados a seguir.

\section{$1^{\circ}$ caso : C.M.}

Menino de 3,4 meses de idade, nasceu com 1.850 gramas, pré- termo, parto vaginal e gravidez única. Apgar de 1' e 5' minuto com notas 7 e 8 . Segundo a mãe, apesar de ter nascido pequeno não apresentou complicações ao nascer e teve alta hospitalar.

A mãe por ocasião do parto era solteira, 15 anos, e fez cerca de 3 a 4 consultas de pré-natal. Com ensino fundamental incompleto e sem filhos.

À entrevista a mãe referiu que não recebeu orientações sobre como cuidar do bebê e, portanto, cuidou a seu modo com a ajuda da avó do bebê. Oferecia-lhe seio materno, mas o mesmo não tinha sucção suficiente e passou a oferecer-lhe leite com conta-gotas. Com 15 dias de vida o bebê aspirou o leite e ficou cianótico, quando, então, a mãe mesma o aspirou. Ficou hospitalizado em UTI e lá apresentou parada cárdiorespiratória evoluindo de pneumonia para sépsis. Segundo a mãe ele já foi internado mais de seis vezes, na maior parte por problemas respiratórios.

A criança apresenta déficit neurológico severo, segundo a mãe é paralisia cerebral, já tentou consultas em associações para deficientes mas não consegue vagas. 
Ao teste de Denver II ele correspondeu a um a criança em torno de 5 meses de idade. Ele apenas firma a cabeça, não vocaliza e apresenta hipotonia muscular.

Situação familiar atual -Atualmente a mãe vive da indenização da criança que, segundo ela, ele está aposentado por invalidez. Continua solteira e na família vivem ela, filho, a avó e uma prima adolescente. Todos estão desempregados.

Á entrevista a mãe parecia uma menina, com vários piercings no rosto e disse que parou de estudar para cuidar da criança, pois a avó não quis assumir o cuidado sozinha.

\section{$2^{\circ}$ caso: L.M.L.F.}

Menino de 3, 3 meses de idade, nasceu com 2.450 gramas, a termo, parto vaginal e gravidez única. Apgar de $1^{\circ}$ e $5^{\circ}$ minuto com notas 8 e 9 . Não apresentou complicações ao nascer e teve alta.

A mãe por ocasião do parto estava casada e com 39 anos. Com apenas 3 anos de escolaridade e não fez pré- natal.

À entrevista a mãe pareceu extremamente confusa, sugerindo de apresentar algum distúrbio de comportamento. Atrapalhada ao dar informações. Segundo seu relato referiu que veio perceber que seu bebê começou a apresentar problemas somente com 1 ano de vida pois ele não crescia e não engordava, mas disse que desde pequeno ele era muito quieto(?) e que caiu muito da cama pois se agitava(?) demais. Vale destacar que não tinha berço em casa. Questionada sobre o leite materno afirmou com convicção que nunca teve leite, portanto nunca tentou. Levou a criança a uma consulta com um ano de vida e, provavelmente, se detectou algo, porque foram pedidos exames. Afirmou que 
teve medo de levá-lo novamente, pois o exame dizia uns nomes estranhos e nunca retornou à consulta.

Desde o nascimento ela apenas o alimenta com mamadeira, nunca o alimentou com outros alimentos, pois disse que ele não consegue engolir, ou eu tento tampando o nariz para ele engolir, mas ele não consegue. Durante a entrevista dava continuamente tapinhas no rosto do menino.

A criança impressionou e comoveu os examinadores. Ela apresentava desnutrição severa constatada apenas ao exame físico e confirmada pela curva de crescimento, com peso de $73 \mathrm{~kg}$ e $76 \mathrm{~cm}$. Seu aspecto era de uma criança marasmática.

Ao teste de Denver apresentou conduta para um bebê no máximo com um mês de vida. Provavelmente com déficit neurológico grave, não vocaliza ou exprime reações para interagir.

Situação familiar atual - A mãe mantém-se casada e com 9 filhos vivos e um morto e teve mais um bebê após esta criança. Seu marido ficou desempregado por 4 anos, porém trabalhando há 2 meses e com história de terem sido catadores de lixo. Recebem ajuda de entidades e visita da equipe de saúde e que, segundo o serviço, a família tem muitos problemas e têm grandes dificuldades ao convencer a família a procurar assistência médica.

Ambos os casos foram discutidos com a equipe de saúde e solicitado encaminhamento. 


\section{Termo de Consentimento Livre e Esclarecido}

Fui informado (a) a respeito da presente pesquisa intitulada" Evolução de crianças nascidas com peso inferior a $2500 \mathrm{~g}$ na cidade de Mauá", sob a responsabilidade de Rosangela Filipini, aluna do curso de doutorado da Faculdade de Saúde Pública da Universidade de São Paulo.

O estudo tem como objetivo verificar se os bebês que nasceram de baixo peso ou "muito magros" estão crescendo e se desenvolvendo bem.

Caso eu aceite participar desta pesquisa, serei entrevistado(a) mediante um questionário, em que responderei questões sobre a minha vida, de meu filho e família. Meu filho será pesado e medido, como também será realizado um teste para ver o seu desenvolvimento. No teste o meu filho vai brincar com o entrevistador, ele vai observá-lo e registrar o resultado do teste.

O meu nome e do meu filho não serão jamais divulgados quando forem apresentados os resultados da pesquisa. Não receberei qualquer pagamento por participar deste estudo. Não sofrerei qualquer prejuízo ou punição caso eu desista ou não queira responder algumas perguntas.

Caso seja identificado algum problema de crescimento e desenvolvimento no meu filho, o pesquisador fará o encaminhamento na rede básica ou convênio onde ele for matriculado.

Se eu estiver de acordo em participar, será pedido que eu assine, junto com o pesquisador, este Termo de Consentimento Livre e Esclarecido. Caso eu prefira não assinar, minha decisão será respeitada, e isto não impedirá que eu participe da pesquisa.

Após a leitura conjunta, minha e do pesquisador, deste Termo de Consentimento, decidi participar, de forma livre e esclarecida.

Mauá, de 200.

Assinatura do participante:

Assinatura do pesquisador:

Pesquisador principal: ROSANGELA FILIPINI

FONE: 49935435.

e-mail: rofilipini@itelefonica.com.br 


\section{FORMULÁRIO}

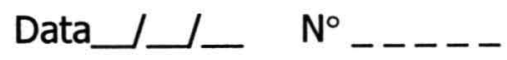

\section{IDENTIFICAÇÃO DA CRIANÇA}

Nome da criança
Sexo
(1) $\mathrm{M}$
(2) $\mathrm{F}$

Data de nascimento

Idade atual:

- I-_I-

Dados secundários da Declaração de nascidos vivos (DNV)

1- $\mathrm{N}^{\circ} \mathrm{DNV}$

2- Nome da mãe

3- Idade por ocasião do parto __ _anos

4- Estado civil mãe: solteira (1); casada (2); viúva(3); sep.judic./divorc (4); ignorado(9)

5- Escolaridade mãe ( em anos de estudo compl/incompl):

$1=$ nenhuma; $2=\operatorname{de~} 1$ a $3 ; 3=\operatorname{de~} 4$ a $7 ; 4=\operatorname{de~} 8$ a $11 ; 5=12$ e mais; $9=$ ignorado

6- Número de filhos vivos em gestações anteriores ( $99=$ ignor.) :

7- Número de filhos nascidos mortos em gestações anteriores ( $99=$ ignor.): _

8- Duração da gestação (semanas):

\begin{tabular}{|c|c|c|}
\hline Pré- termo & Termo & \begin{tabular}{|l|}
$\begin{array}{l}\text { Pós- } \\
\text { termo }\end{array}$ \\
\end{tabular} \\
\hline $1-<22$ sem. & $\begin{array}{|lll|}5- & 37 & a \\
41 & & \\
\end{array}$ & $\begin{array}{l}6-42 \quad \mathrm{e} \\
\text { mais }\end{array}$ \\
\hline $\begin{array}{l}2-22 \text { a } 27 \\
\text { sem. }\end{array}$ & & \\
\hline $\begin{array}{l}\text { 3- } 28 \text { a } 31 \\
\text { sem }\end{array}$ & & \\
\hline $4-32$ a 36 & & \begin{tabular}{|l|}
$9-$ \\
ignorado
\end{tabular} \\
\hline
\end{tabular}

9- Tipo de gravidez $1=$ única; $2=$ dupla; $3=$ tripla ou mais; $9=$ ignorado

10- Tipo de parto: $1=$ vaginal; $2=$ cesáreo; $9=$ ignorado

11- Número de consultas de pré- natal ( $99=$ ignorado)

12- Índice de Apgar do $1^{\circ}$ minuto

13- Índice de Apgar do $5^{\circ}$ minuto

14- Peso ao nascer ( em gramas)

15- Detectada alguma malformação congênita e/ou anomalia cromossômica?: $1=$ sim; 2 = não; 9 = ignorado

16- Código da anomalia (CID10) : 


\section{ENTREVISTA}

1. Situação conjugal atual da mãe:

\section{Mãe}
(1) solteira
(2) casada/ amasiada
separada (3)
(4) viúva

2. Escolaridade

(1) Analfabeto (2) Ensino Fundamental completo/ Incompleto (3) Ensino médio completo/ Incompleto (4) Ensino superior C/I Estuda atualmente? ( ) sim () não

3. No mês passado, qual a renda familiar mensal? $\mathrm{R} \$$

4. Ocupação da mãe

(1) com remuneração no lar (2) remuneração fora do lar (3) estuda e com ocupação remunerada

(4) estuda (5) desempregada

5. tipo de família ( ) nuclear ( ) quebrada ou não tradicional

\section{Antecedentes gestacionais}

6. Número de filhos: vivos __ mortos _-

$\begin{array}{llll}\text { 7. Fumou durante a gravidez desta criança? (1) sim } & \text { (2) não }\end{array}$

$\begin{array}{lll}7 . & \text { Etilista? (1) sim não }\end{array}$

8. Outras drogas? (1) sim (2) não

9. Número de consultas pré- natal _-

10. 17. Tipo de gravidez: (1) única (2) múltipla (9) ign.

11. Problemas de saúde presentes na gestação: (1) sim (2) não. O quê?

\section{CRIANÇA}

12. Tipo de parto: (1) normal (2) cesariana (3) outro

13. Peso ao nascer,$---\mathrm{g}$

14. Comprimento: _-,__cm

15. Idade gestacional (1) a termo (2) pré- temo (3) pós-termo (9) ignorado

16. Apgar $1^{\circ}{ }_{-} \quad$ e $5^{\circ}$ minuto__

17. Anomalia congênita? (1) sim (2) não Complicações neonatais? (1) sim (2) não Qual (ais)

18. A criança participou de algum programa de Follow- up? (1) sim (2) não

Onde? 


\section{Alimentação}

19. Leite materno exclusivo (1) sim (2) não _- (meses)

20. Leite materno misto (1) sim (2) não _- (meses)

21. Sem leite materno (1) sim (2) não

22. Introdução de novos alimentos ( papa salgada; ovo; carne; verduras e legumes; frutas)

23. Freqüenta escola/creche? (1) sim (2) não

24. Tem convênio médico? Sim (1) não (2_)

24. Hospitalização? (1) sim (2) não

\begin{tabular}{|c|c|c|}
\hline Data & Diagnóstico & $\mathbf{N}^{\mathbf{0}}$ dias \\
\hline & & \\
\hline & & \\
\hline
\end{tabular}

25. Descrever as atividades de vida diária da criança (dia alimentar, higiene, controle esfincteriano, sono/ repouso, lazer)

Utilizar o verso da folha para a descrição.

EXAME ANTROPOMÉTRICO:

26. Peso atual: __,_- g

27. Estatura atual : _-_,_ $\mathrm{cm}$

\section{AVALIAÇÃO DO DESENVOLVIMENTO NEUROPSICOMOTOR}

28. Resultado do Teste de triagem de Desenvolvimento de Denver II (DDSTII):

(1) Normal (2) Suspeito (3) Intestável

\section{AVALIAÇÃO DO COMPORTAMENTO DE APEGO SEGURO}

29. Valor de comportamento de apego atingido pela criança de acordo com avaliação do Attachment Q-set - versão 3.0 :

Entrevistador: 
ANEXO 9

\section{LISTA DAS VARIÁVEIS OBTIDAS DA DECLARAÇÃO DE NASCIDOS VIVOS E SUAS DESCRIÇÕES}

\begin{tabular}{|l|l|}
\hline \multicolumn{1}{|c|}{ variável } & \multicolumn{1}{c|}{ Descrição da variável } \\
\hline NUMERODN & Número da declaração de nascido vivo \\
\hline CODCART & Código do cartório \\
\hline NUMERGCART & Número do registro no cartório \\
\hline DTREGCART & Data de entrega no cartório \\
\hline CODMUNCART & Código do município do cartório \\
\hline LOCNASC & $\begin{array}{l}\text { Local de ocorrência do nascimento: } 1=\text { hospital; } 2= \\
\text { outros estab. de saúde; } 3=\text { domicílio; } 4=\text { outros; } 9= \\
\text { ignorado }\end{array}$ \\
\hline CODESTAB & Código do estabelecimento \\
\hline ENDNASC & Endereço de ocorrência do nascimento \\
\hline CODENDNASC & Código do endereço de ocorrência do nascimento \\
\hline NUMENDNASC & Número do endereço de ocorrência do nascimento \\
\hline COMPLNASC & $\begin{array}{l}\text { Complemento do endereço de ocorrência do } \\
\text { nascimento }\end{array}$ \\
\hline CEPNASC & CEP do endereço de ocorrência do nascimento \\
\hline BAINASC & Bairro do endereço de ocorrência do nascimento \\
\hline CODBAINASC & Código do município de ocorrência do nascimento \\
\hline DOCMUNNASC & ???? \\
\hline NOMEMAE & Nome da mãe \\
\hline NUMSUSMAE & Número do SUS da mãe \\
\hline IDADEMAE & Idade da mãe (em anos) \\
\hline CONFIDADE & Confirmação da idade \\
\hline ESTCIVMAE & $\begin{array}{l}\text { Estado civil: } 1=\text { solteira; } 2=\text { casada; 3= viúva; 4= sep. } \\
\text { Judic./divorc.; 9= ignorado }\end{array}$ \\
\hline ESCMAE & $\begin{array}{l}\text { Escolaridade ( em anos de estudo compl/incompl): } \\
1=\text { nenhuma; } 2=\text { de } 1 \text { a 3; 3= de 4 a 7; 4= de 8 a 11; } \\
5=12 \text { e mais; 9= ignorado }\end{array}$ \\
\hline CODOCUPMAE & $\begin{array}{l}\text { Ocupação habitual e ramo de atividade ( código) ainda } \\
\text { vou identificar estes códigos }\end{array}$ \\
\hline QTDFILVIVO & $\begin{array}{l}\text { Número de filhos vivos em gestações anteriores ( 99= } \\
\text { ignor.) }\end{array}$ \\
\hline QTDFILMORT & $\begin{array}{l}\text { Número de filhos nascidos mortos em gestações } \\
\text { anteriores (99= ignor.) }\end{array}$ \\
\hline Residência da mãe (logradouro) \\
\hline ENDRES & \\
\hline
\end{tabular}




\begin{tabular}{|l|l|}
\hline CODENDRES & Código do endereço residencial da mãe \\
\hline NUMRES & Número da residência da mãe \\
\hline COMPLRES & Complemento da residência da mãe \\
\hline CEPRES & CEP da residência da mãe \\
\hline BAIRES & Bairro da residência da mãe \\
\hline CODBAIRES & Código do bairro da residência da mãe \\
\hline CODMUNRES & Código do município da residência da mãe \\
\hline GESTACAO & $\begin{array}{l}\text { Duração da gestação ( vou identificar o significado do } \\
\text { dado) }\end{array}$ \\
\hline GRAVIDEZ & $\begin{array}{l}\text { Tipo de gravidez } 1=\text { única; } 2=\text { dupla; } 3=\text { tripla ou } \\
\text { mais; } 9=\text { ignorado }\end{array}$ \\
\hline PARTO & Tipo de parto: $1=$ vaginal; $2=$ cesáreo; $9=$ ignorado \\
\hline CONSULTAS & Número de consultas de pré- natal ( $99=$ ignorado) \\
\hline HORANASC & Hora do nascimento \\
\hline DATANASC & Data do nascimento \\
\hline SEXO & Sexo: M= masculino; $F=$ feminino; I= ignorado \\
\hline APGAR1 & Índice de Apgar do 10 minuto \\
\hline APGAR5 & Índice de Apgar do 50 minuto \\
\hline RACACOR & $\begin{array}{l}\text { Raça/ cor: } 1=\text { branca; } 2=\text { preta; } 3=\text { amarela; } 4= \\
\text { parda; } 5=\text { indígena. }\end{array}$ \\
\hline PESO & Peso ao nascer ( em gramas) \\
\hline CONFPESO & Confirmação do peso \\
\hline IDANOMAL & $\begin{array}{l}\text { Detectada alguma malformação congênita e/ou } \\
\text { anomalia cromossômica?: } 1=\text { sim; } 2=\text { não; } 9= \\
\text { ignorado }\end{array}$ \\
\hline CODANOMAL & Qual? Código= ainda vou identificar estes códigos \\
\hline NUMEROLOTE & Número do lote \\
\hline CRITICA & ???? \\
\hline CODINST & Código da instituição \\
\hline
\end{tabular}




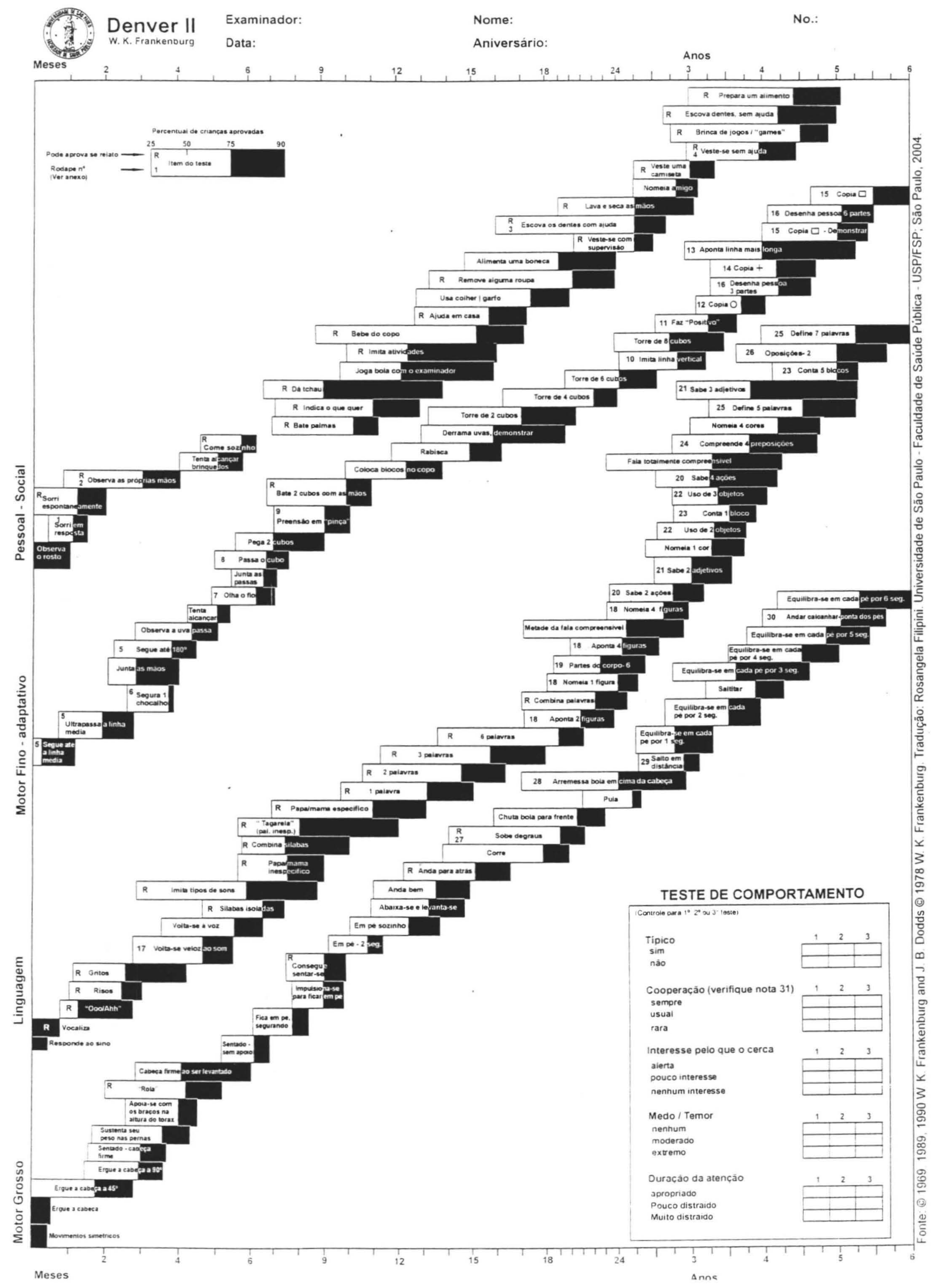


ANEXO 11

Attachment Q-set (Version 3.0)*_. Lista de itens da Classificação de Apego Seguro (AQS) com proposta de 3 categorias

* WATERS,E. Attachment Q-set (Version 3). Items and Explanations, 1987. [ on line] Disponivel na internet :http/l.johnbowlby.com, 2004.

Tradução: FILIPINI, R. Faculdade de Saúde Publica da USP- Departamento de

Saúde materno infantil. São Paulo, 2004.

Obs. Os itens devem ser aplicados na criança.

\begin{tabular}{|c|c|c|c|}
\hline \multirow{3}{*}{ ITENS } & \multicolumn{3}{|c|}{ Observado } \\
\hline & $\begin{array}{l}\text { Maior parte } \\
\text { das vezes }\end{array}$ & $\begin{array}{l}\text { Muito } \\
\text { pouco }\end{array}$ & $\begin{array}{l}\text { Nunca } \\
\text { ou raro }\end{array}$ \\
\hline & 2 & 1 & $\mathbf{0}$ \\
\hline $\begin{array}{l}\text { 1.(1). Criança realmente compartilha coisas com a mãe ou } \\
\text { lhe dá o que segura caso ela os peça. }\end{array}$ & & & \\
\hline $\begin{array}{l}\text { 2.(9). E despreocupada/alegre e brincalhona a maior parte } \\
\text { do tempo. }\end{array}$ & & & \\
\hline $\begin{array}{l}\text { 3.(11). Com freqüência a criança abraça e se aconchega à } \\
\text { mãe sem que ela peça ou o convide para fazê-lo. }\end{array}$ & & & \\
\hline $\begin{array}{l}\text { 4.(14). Quando encontra alguma coisa nova para brincar, } \\
\text { ele carrega sua mãe ou the mostra. }\end{array}$ & & & \\
\hline $\begin{array}{l}\text { 5.(15).Se disposta a falar com uma nova pessoa, mostra- } \\
\text { Ihe brinquedos ou o que ele quer fazer, se a mãe lhe pedir. }\end{array}$ & & & \\
\hline $\begin{array}{l}\text { 6.(18). Segue as orientações da mãe prontamente, quando } \\
\text { elas são claramente sugeridas e não ordenadas. }\end{array}$ & & & \\
\hline $\begin{array}{l}\text { 7.(19). Quando a mãe fala para a criança lhe trazer ou dar } \\
\text { alguma coisa, ela obedece. }\end{array}$ & & & \\
\hline $\begin{array}{l}\text { 8.(21). Mantém-se ligado na localização da mãe quando ela } \\
\text { brinca pela casa. }\end{array}$ & & & \\
\hline $\begin{array}{l}\text { 9.(22). Criança atua como pais afetuosos através de } \\
\text { bonecos, animais ou bebês. }\end{array}$ & & & \\
\hline 10.(28). Adora relaxar no colo da mãe. & & & \\
\hline $\begin{array}{l}\text { 11.(32). Quando a mãe diz "não"ou o pune, criança para de } \\
\text { comportar-se mal (um mínimo de tempo). Não tem que falar } \\
2 \text { vezes. }\end{array}$ & & & \\
\hline $\begin{array}{l}\text { 12.(36). A criança mostra claramente um padrão de } \\
\text { comportamento usando a mãe como base para explorar o } \\
\text { ambiente. Sai para brincar, retorna ou brinca próxima a ela; } \\
\text { sai para brincar novamente, etc. }\end{array}$ & & & \\
\hline $\begin{array}{l}\text { 13.(40). Examina novos objetos ou brinquedos com grandes } \\
\text { detalhes. Tenta usá-los de diferentes maneiras ou } \\
\text { desmontá-los. }\end{array}$ & & & \\
\hline 14.(41). Quando a mãe diz para segui-la, criança o faz. & & & \\
\hline 15.(42). Reconhece quando a mãe está transtornada. Fica & & & \\
\hline
\end{tabular}




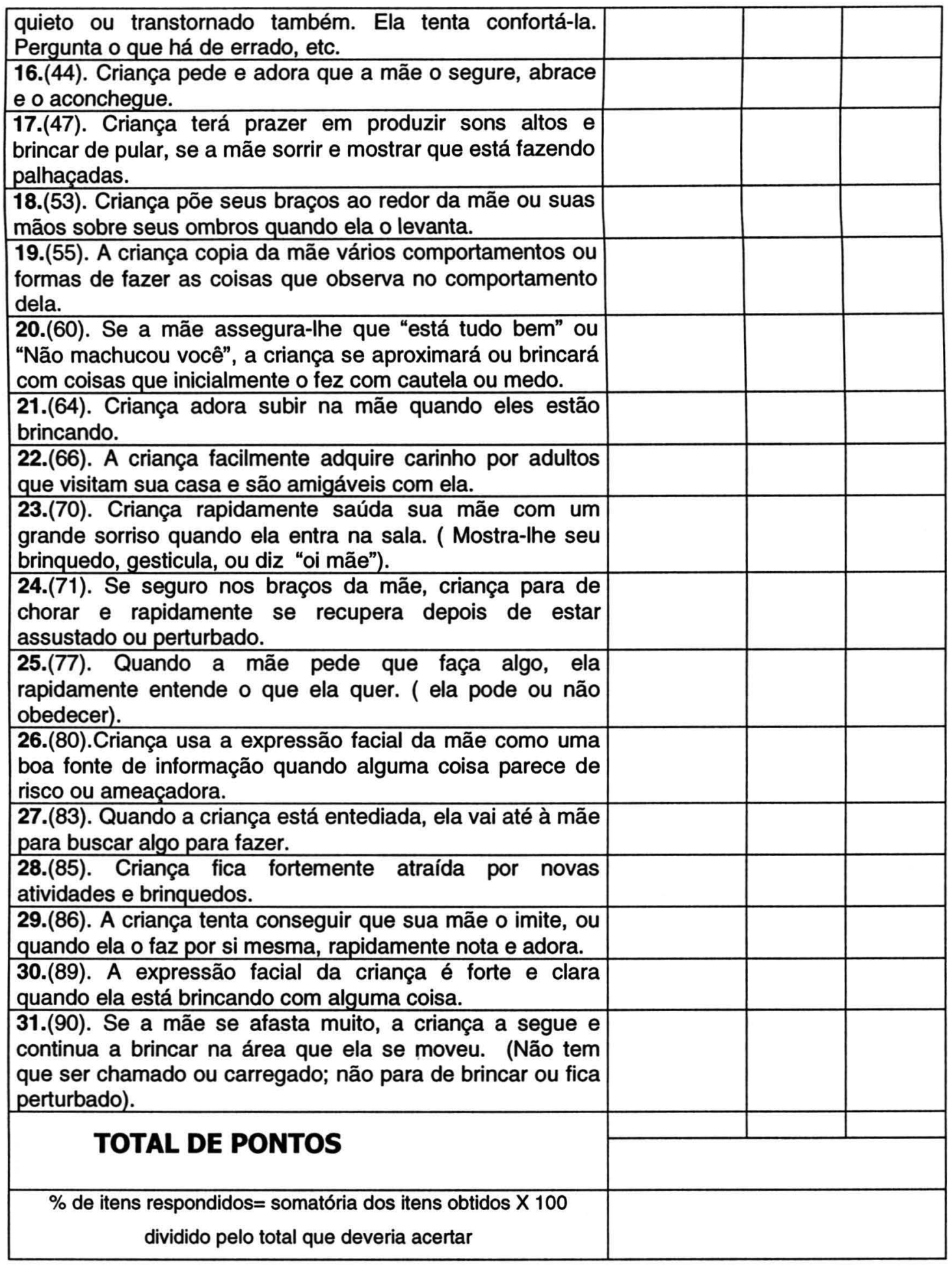

Observações:

Data:

Observador: 


\section{Lista de itens da Classificação de Apego Seguro (AQS) -Versão3.0*}

WATERS,E. Attachment Q-set (Version 3). Items and Explanations, 1987. [ on line] Disponivel na internet :http//.johnbowlby.com, 2004. Tradução: FILIPINI, R. Faculdade de Saúde Publica da USP- Departamento de Saúde materno infantil. São Paulo, 2004.

\section{ITENS}

1. Criança realmente compartilha com a mãe ou lhe dá coisas que segura caso os peça.

2.Quando retorna à mãe após brincar, às vezes fica "caprichoso" sem razão específica.

3. Quando doente ou irritado aceita ser confortado por outros além da mãe.

4. É cuidadosa e gentil com brinquedos e animais domésticos.

5. Mais interesse nas pessoas que em coisas.

6. Quando está próximo da mãe e vê algo para brincar, protesta ou tenta arrastar a mãe àquele objeto.

7. Ri ou sorri facilmente com várias pessoas diferentes.

8.Quando chora, chora fortemente.

9. É despreocupada/alegre e brincalhona a maior parte do tempo.

10.Com freqüência chora ou resiste quando a mãe o leva para uma soneca ou para dormir.

11. Com freqüência a c. abraça e se aconchega à mãe sem que ela peça ou o convide para fazê-lo.

12. Rapidamente se acostuma com pessoas ou coisas que inicialmente o deixavam tímido ou assustado.

13. Quando está transtornada por sua mãe sair, ele continua a chorar ou bravo depois que ela já se foi.

14. Quando encontra alguma coisa nova para brincar, ele carrega sua mãe ou lhe mostra.

15.Se disposta a falar para a nova pessoa, mostra-lhe brinquedos ou o que ele quer fazer, se a mãe lhe pedir.

16. Preferem brinquedos modelos de seres vivos.

17. Rapidamente perde interesse no novo adulto se eles fizerem alguma coisa eu o contrarie.

18. Segue as orientações da mãe prontamente, quando elas são claramente sugeridas e não ordenadas.

19. Quando a mãe fala para a cr. trazer ou lhe dar alguma coisa, ela obedece.

20. Ignora a maioria das "batidas", quedas ou sustos.

21. Mantém-se ligado na localização da mãe quando ela brinca pela casa.

22. Criança atua como pais afetuosos através de bonecos, animais ou bebês.

23. Quando a mãe está com outros membros da família ou está lhes dando afeto, a cr. tenta ganhar o afeto para ele mesmo.

24. Quando a mãe fala firmemente ou eleva suA voz, a criança fica transtornada, sentida ou envergonhada pela ofensa da mãe.

25.É fácil para a mãe perder contato quando ela está brincando fora de sua vista.

26. Chora quando a mãe o deixa em casa com babá, pai ou avós.

27. Ri quando a mãe o caçoa ou provoca.

28. Adora relaxar no colo da mãe.

29.Às vezes está tão atento por alguma coisa que ele parece não ouvir quando uma pessoa fala com ele.

30. Facilmente se enfurece com brinquedos (se frustrado).

31. Quer ser o centro da atenção. Se a mãe está ocupada ou falando com alguém, ele interrompe. 
32. Quando a mãe diz "não"ou o pune, criança para de comportar-se mal (um mínimo de tempo). Não tem que falar 2 vezes.

33. Algumas vezes sinaliza à mãe que quer ser solto, e então fica perturbado ou quer ser pego novamente.

34. Quando a cr. fica transtornada porque sua mão o deixa, senta onde está e chora. Não vai depois com ela.

35. Cr. está independente da mãe. Prefere brincar sozinho; afasta-se facilmente da mãe quando ele quer brincar.

36. Cr. mostra claramente um padrão de comportamento usando a mãe como base para explorar o ambiente. Sai para brincar, retorna ou brinca próxima a ela; sai para brincar novamente, etc.

37. Cr. sempre ativa. Sempre em movimento. Prefere jogos ativos aos calmos.

38. Cr. é exigente e impaciente com a mãe. Protesta e persiste a menos que a mãe faça o que ele quer imediatamente.

39. Freqüentemente fica sério e "profissional" quando brinca longe da mãe ou só com seus brinquedos.

40.Examina novos objetos ou brinquedos com grandes detalhes. Tenta usa-los de diferentes maneiras ou desmontá-los.

41. Quando a mãe diz para segui-la, criança o faz.

42. Reconhece quando a mãe está transtornada. Fica quieto ou transtornado também. Tenta confortá-la. Pergunta o que há de errado, etc.

43. A cr. fica cercando a mãe ou retorna a ela mais vezes do que requer, simplesmente para ter contato.

44. Cr. pede e adora que a mãe o segure, abrace e o aconchegue.

45. Cr. adora dançar e cantar com música.

46. Cr. anda e corre sem bater, cair ou tropeçar.

47. Cr. terá prazer em produzir sons altos e brincar de pular, se a mãe sorrir e mostrar que está fazendo palhaçadas.

48. Facilmente deixa que novos adultos segurem ou compartilhem das coisas que ele tem, se eles pedirem.

49. Corre para a mãe com um sorriso tímido quando novas pessoas visitam sua casa.

50. A reação inicial da cr. quando há visitas é ignorá-las ou evita-las, até que ela eventualmente se interaja.

51. Cr. adora "escalar" visitas quando brincam com ela.

52. Cr. tem dificuldades ao manipular ou montar pequenos objetos.

53. Cr. põe seus braços ao redor da mãe ou suas mãos sobre seus ombros quando ela o levanta.

54. Atua como se esperasse a mãe interferir em suas atividades quando ela simplesmente está tentando ajuda-lo em alguma coisa.

55. A cr. copia da mãe vários comportamentos ou formas de fazer as coisas que observa no comportamento dela.

56. Cr. se torna tímido ou perde interesse quando um atividade pode parecer difícil.

57. Cr. não tem medo de nada.

58. Cr. usualmente ignora adultos que visitam sua casa. Procura suas próprias atividades mais interessantes.

59. Quando termina com uma atividade ou brinquedo, ele geralmente encontra algo mais a fazer sem retornar para a mãe entre estas atividades.

60. Se a mãe assegura-Ihe que "está tudo bem" ou "Não machucou você", a cr. se aproximará ou brincará com coisas que inicialmente o fez com cautela ou medo.

61. Joga bruscamente com a mãe. Bate, arranha ou morde durante a brincadeira. ( não necessariamente significa querer machucar a mãe).

62. Quando a cr. está de bom humor é provável que fique assim o dia todo.

63. Antes de tentar fazer alguma coisa sozinho, tenta conseguir que alguém o ajude.

64. Cr. adora subir na mãe quando eles estão brincando. 
65. Cr. se aborrece facilmente quando a mãe o faz mudar de uma atividade para outra.

66. A cr. facilmente adquire carinho por adultos que visitam sua casa e são amigáveis com ela.

67. Quando a família tem visitas, cr. quer que eles prestem bastante atenção nele.

68. na média, cr. é um tipo de pessoa mais ativo do que a mãe.

69. Raramente pede ajuda à mãe.

70. Cr. rapidamente saúda sua mãe com um grande sorriso quando ela entra na sala. ( Mostra seu brinquedo, gesticula, ou diz ("oi mãe").

71. Se seguro nos braços da mãe, cr. para de chorar e rapidamente se recupera depois de estar assustado ou perturbado.

72. Se a visita ri ou aprova alguma coisa que a cr. fez, ela repete novamente e novamente.

73. $\mathrm{Cr}$. tem um brinquedo suave ou segura um cobertor que ele o carrega, leva para a cama, ou o segura quando perturbado. ( não inclui mamadeira ou chupeta se a cr. tem menos de 2 anos).

74. Quando a mãe não faz o que a cr. quer, imediatamente ela comporta-se como se a mãe não fosse fazer. (protesta, fica furioso, anda e se põe a fazer outras coisas, etc).

75. Em casa, cr. fica transtornada ou chora quando a mãe sai do quarto que estavam. ( pode ou não segui-la).

76. Quando lhe dão uma escolha, cr. prefere brincar com brinquedos do que com adultos.

77. Quando a mãe pede que faça algo, ela rapidamente entende o que ela quer. ( pode ou não obedecer).

78. Cr. adora ser abraçado ou segurado por outros que não seus pais ou avós.

79. A cr. fica brava com a sua mãe facilmente.

80. Cr. usa a expressão facial da mãe como uma boa fonte de informação quando alguma coisa parece de risco ou ameaçadora.

$81 \mathrm{Cr}$. chora como um modo de obter da mãe o que ele quer.

82.Cr. gasta a maior parte do tempo ao brincar somente com poucos brinquedos ou atividades favoritas.

83.Quando a cr. está entediada, ela vai até à mãe para buscar algo a fazer.

84. Cr. faz o mínimo esforço para ficar limpa e arrumada em casa.

85. Cr. fica fortemente atraída por novas atividades e brinquedos.

86. Cr. tenta conseguir que sua mãe o imite, ou quando ela o faz por si mesma, rapidamente nota e adora.

87. Se a mãe ri ou aprova alguma coisa que a cr. faz, ela repete novamente e novamente.

88. Quando alguma coisa desagrada a cr., ela para aonde está e chora.

89. A expressão facial da cr. é forte e clara quando está brincando com alguma coisa.

90. Se a mãe se afasta muito, a cr. a segue e continua a brincar na área que ela se moveu. (Não tem que ser chamado ou carregado; não para de brincar ou fica perturbado.) 


\section{ANEXO 13}

PASSOS DA MODELAGEM DE RISCO RELATIVO DE DENVER II.

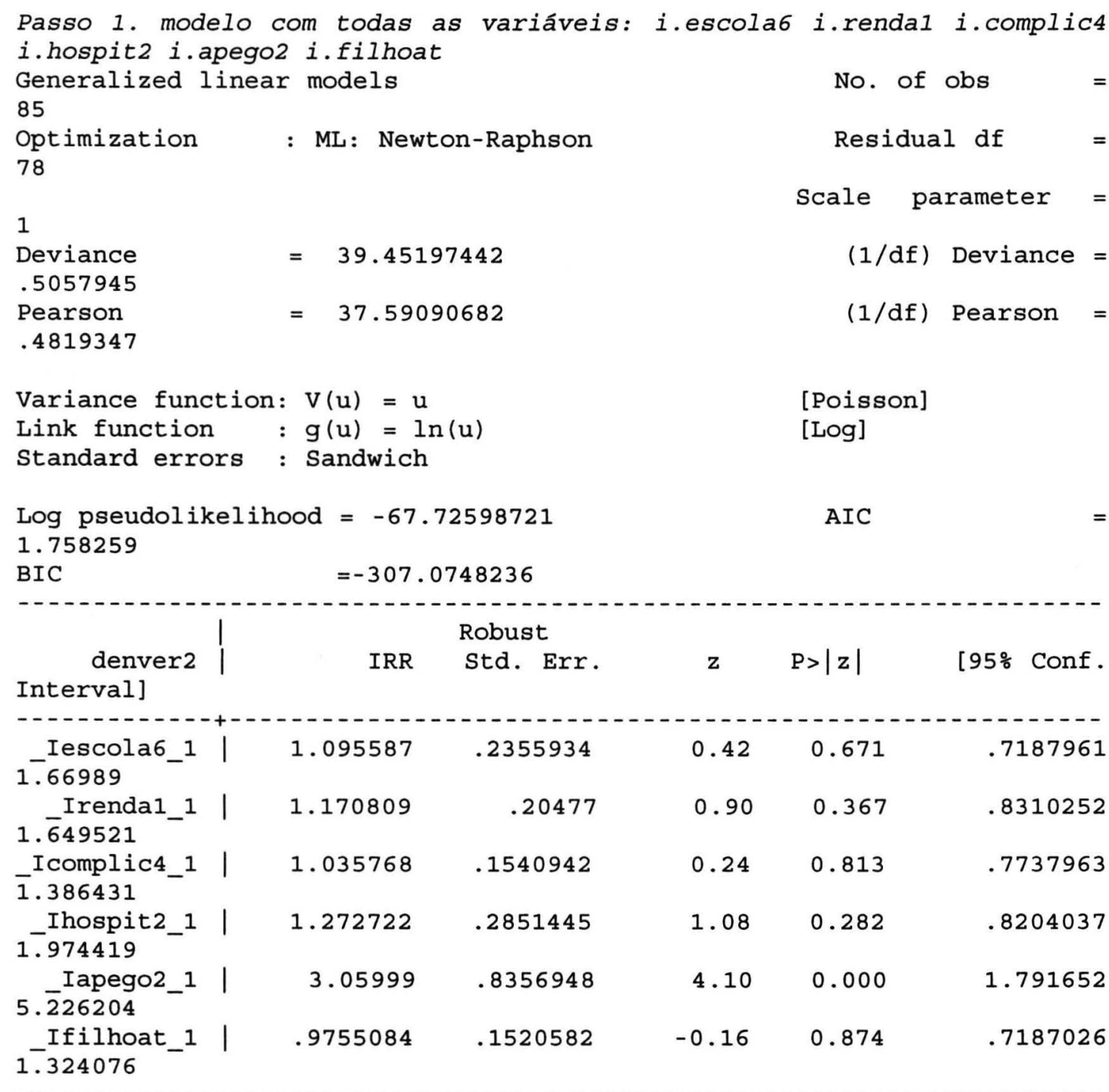

modelo retirando-se filhoat Generalized linear models 85

Optimization : ML: Newton-Raphson

79

1

Deviance

$=\quad 39.4573128$

.4994597

Pearson

$=\quad 37.63610112$

No. of obs

Residual df

.4764063

Variance function: $\mathrm{v}(\mathrm{u})=\mathrm{u}$

[Poisson] 


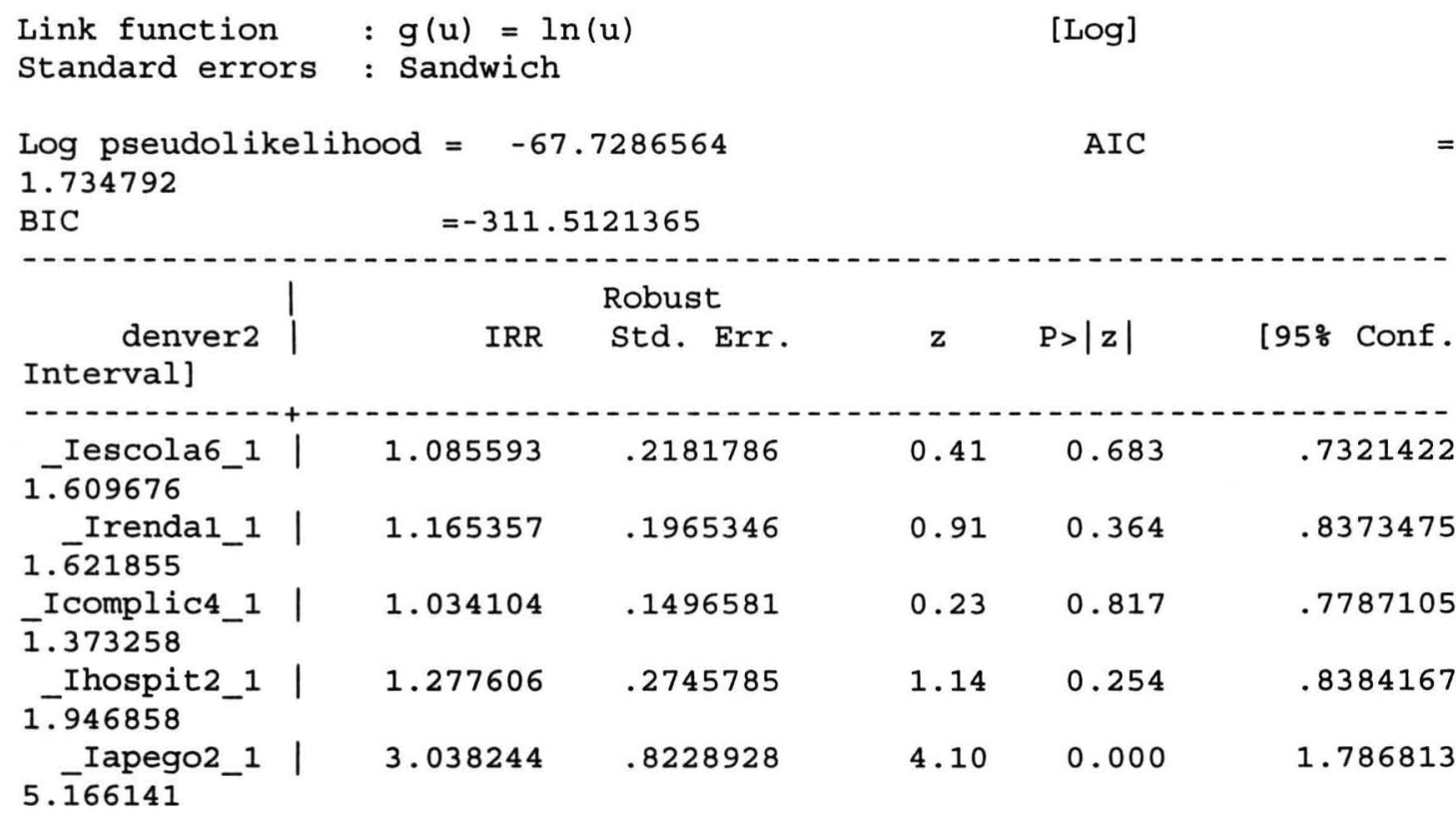

modelo retirando-se complic4

Generalized linear models

86

Optimization : ML: Newton-Raphson

81

1

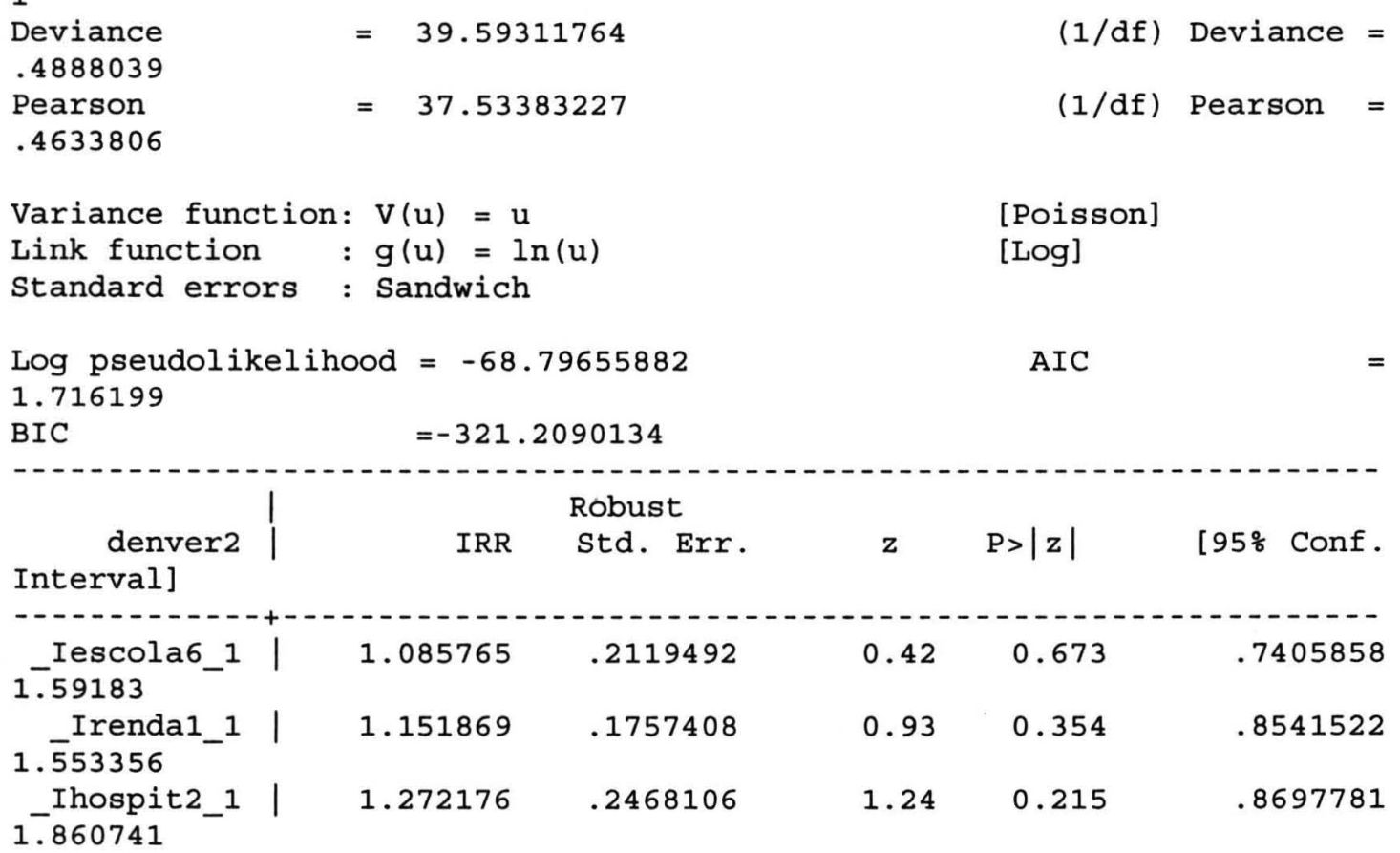

No. of obs =

Residual df = Scale parameter =

$(1 /$ df $)$ Deviance $=$

(1/df) Pearson =

[Poisson]

[Log]

AIC 


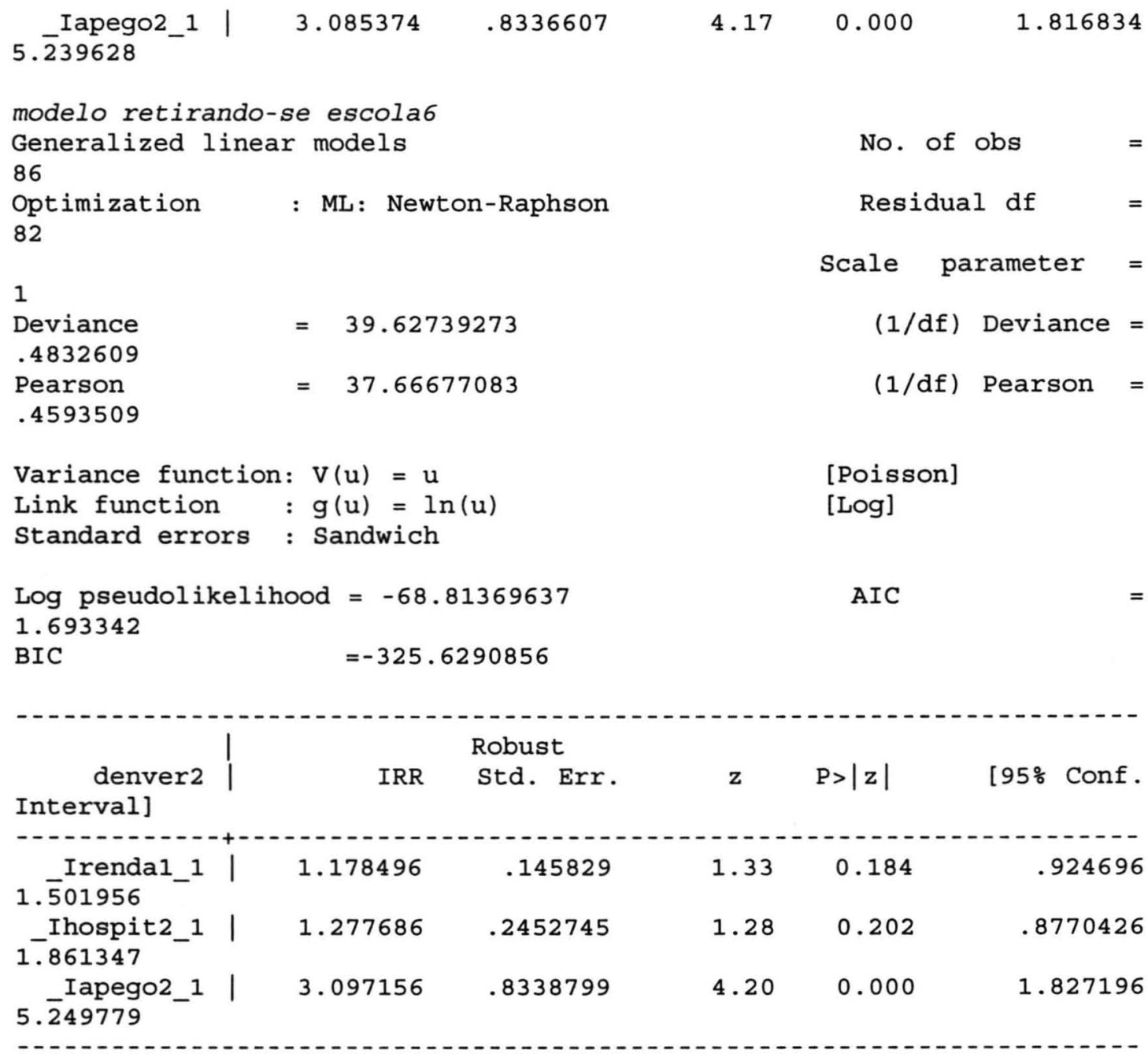

modelo retirando-se hospitalização

Generalized linear models

86

Optimization : ML: Newton-Raphson

82

No. of obs=

1

Deviance

.4832609

$=39.62739273$

Pearson

$=\quad 37.66677083$

Residual df Scale parameter = .4593509

Variance function: $\mathrm{v}(\mathrm{u})=\mathrm{u}$

Link function : $g(u)=\ln (u)$

standard errors : Sandwich

(1/df) Deviance =

(1/df) Pearson =

Log pseudolikelihood $=-68.81369637$

1.693342

[Poisson]

[Log]

AIC 


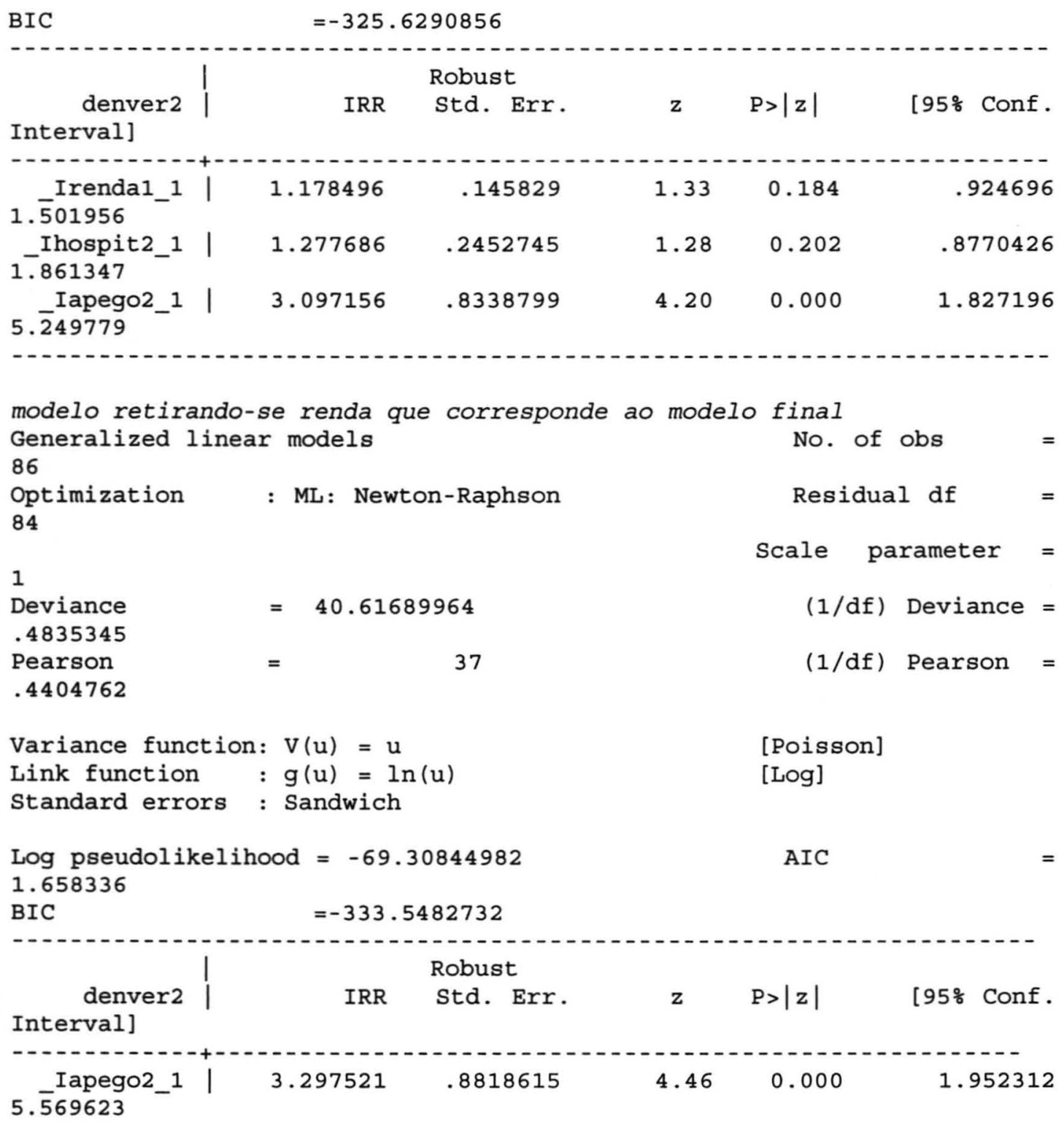

Passo 1. modelo com todas as variáveis: i.escola6 i.rendal i.complic4 i.hospit2 i.apego2 i.filhoat

\begin{tabular}{lccclll}
\hline \multicolumn{1}{c}{ variáveis } & RR & $\begin{array}{c}\text { erro } \\
\text { padrão }\end{array}$ & z & p & \multicolumn{2}{c}{ IC95\% } \\
\hline _lescolaridade6_1 & 1.10 & 0.24 & 0.42 & 0.671 & 0.72 & 1.67 \\
_Irenda1_1 & 1.17 & 0.20 & 0.90 & 0.367 & 0.83 & 1.65 \\
_Icomplic. neo4_1 & 1.04 & 0.15 & 0.24 & 0.813 & 0.77 & 1.39 \\
_Ihospitalização2_1 & 1.27 & 0.29 & 1.08 & 0.282 & 0.82 & 1.97 \\
_lapego2_1 & 3.06 & 0.84 & 4.10 & 0,000 & 1.79 & 5.23 \\
_Ifilhoatual_1 & 0.98 & 0.15 & -0.16 & 0.874 & 0.72 & 1.32 \\
\hline
\end{tabular}


Passo 2. modelo retirando-se filhoatual

\begin{tabular}{lrrrrrrr}
\hline variáveis & RR & $\begin{array}{c}\text { erro } \\
\text { padrão }\end{array}$ & z & p & \multicolumn{2}{c}{ IC95\% } \\
\hline _lescola6_1 & 1,09 & 0,22 & 0,41 & 0,683 & 0,73 & 1,61 \\
_Irenda1_1 & 1,17 & 0,20 & 0,91 & 0,364 & 0,84 & 1,62 \\
_Icomplic4_1 & 1,03 & 0,15 & 0,23 & 0,817 & 0,78 & 1,37 \\
_Ihospit2_1 & 1,28 & 0,27 & 1,14 & 0,254 & 0,84 & 1,95 \\
_lapego2_1 & 3,04 & 0,82 & 4,10 & 0,000 & 1,79 & 5,17
\end{tabular}

Passo 3. modelo retirando-se complicações neonatais

\begin{tabular}{lrrrlll}
\hline variáveis & RR & $\begin{array}{c}\text { erro } \\
\text { padrão }\end{array}$ & \multicolumn{2}{l}{ z } & p & \multicolumn{2}{c}{ IC95\% } \\
\hline _lescola6_1 & 1,09 & 0,21 & 0,42 & 0,673 & 0,74 & 1,59 \\
_Irenda1_1 & 1,15 & 0,18 & 0,93 & 0,354 & 0,85 & 1,55 \\
_lhospit2_1 & 1,27 & 0,25 & 1,24 & 0,215 & 0,87 & 1,86 \\
_lapego2_1 & 3,09 & 0,83 & 4,17 & 0,000 & 1,82 & 5,24
\end{tabular}

Passo 4. modelo retirando-se escolaridade atual

\begin{tabular}{lrrrllll}
\hline variáveis & RR & $\begin{array}{c}\text { erro } \\
\text { padrão }\end{array}$ & \multicolumn{1}{l}{ z } & p & \multicolumn{2}{l}{ IC95\% } & \\
\hline _Irenda1_1 & 1,18 & 0,15 & 1,33 & 0,184 & 0,92 & 1,50 \\
_Ihospit2_1 & 1,28 & 0,25 & 1,28 & 0,202 & 0,88 & 1,86 \\
_lapego2_1 & 3,10 & 0,83 & 4,20 & 0,000 & 1,83 & 5,25
\end{tabular}

Passo 5. modelo retirando-se hospitalização

\begin{tabular}{ccccccc}
\hline variáveis & RR & $\begin{array}{c}\text { erro } \\
\text { padrão }\end{array}$ & \multicolumn{2}{l}{ z } & p & \multicolumn{2}{c}{ IC95\% } & \\
\hline Irenda1_1 & 1,23 & 0,17 & 1,55 & 0,120 & 0,95 & 1,61 \\
_lapego2_1 & 3,24 & 0,87 & 4,38 & 0,000 & 1,91 & 5,47
\end{tabular}

Passo 6. Modelo final. modelo retirando-se renda

\begin{tabular}{crrrllll}
\hline variáveis & RR & $\begin{array}{c}\text { erro } \\
\text { padrão }\end{array}$ & z & p & \multicolumn{2}{c}{ IC95\% } & \\
\hline lapego2_1 & 3,30 & 0,88 & 4,46 & 0,000 & 1,95 & 5,57
\end{tabular}




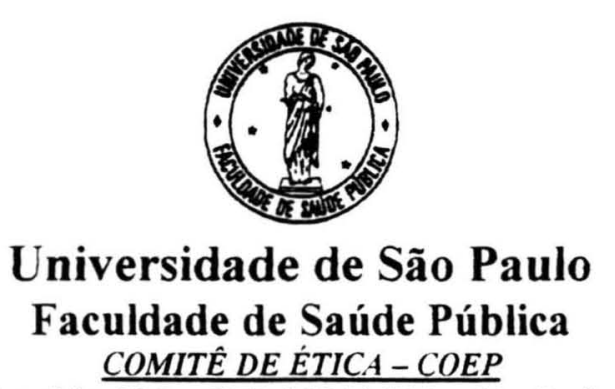

Av. Dr. Amaldo, 715 - CEP 01246-904 - São Paulo - Brasil

Telefones: (55-11) 3066- 7734 - fone/fax (55-11) 3064 -7314 - e-mail: mdgracas@ausp.br

\section{Of.COEP/245/02}

11 e setembro de 2002

Pelo presente, informo que o Comitê de Ética em Pesquisa da Faculdade de Saúde Pública da Universidade de São Paulo-COEP, analisou e aprovou, em sua $7^{\mathrm{a}} . / 02$, realizada em 10.09 .02 , de acordo com os requisitos da Resolução CNS/196/96, o Protocolo de Pesquisa n. ${ }^{\circ} 850$, intitulado: "EVOLUÇÃO DE CRIANÇAS NASCIDAS COM PESO INFERIOR A 2000G NO HOSPITAL MUNICIPAL DE SÃO BERNARDO DO CAMPO", apresentado pela pesquisadora Rosangela Filipini.

Atenciosamente,

Paulo Antonio de Carvatho Fortes

Professor Associado

Coordenador do Comitê de Ética em Pesquisa da FSP-COEP 
ANEXO 15

TABELA F - Distribuição de crianças nascidas em 2001 com baixo peso ao nascer. Mauá, 2004.

\begin{tabular}{|c|c|c|c|}
\hline PESO AO NASCER ( em gramas) & $\mathbf{N}$ & $\%$ & \% Acumulada \\
\hline 1.100 & 1 & 1,2 & 1,2 \\
\hline 1.450 & 1 & 1,2 & 2,3 \\
\hline 1.620 & 1 & 1,2 & 3,5 \\
\hline 1.630 & 1 & 1,2 & 4,7 \\
\hline 1.770 & 1 & 1,2 & 5,8 \\
\hline 1.820 & 1 & 1,2 & 7,0 \\
\hline 1.840 & 1 & 1,2 & 8,1 \\
\hline 1.850 & 2 & 2,3 & 10,5 \\
\hline 1.880 & 1 & 1,2 & 11,6 \\
\hline 1.900 & 1 & 1,2 & 12,8 \\
\hline 2.000 & 1 & 1,2 & 14,0 \\
\hline 2.010 & 1 & 1,2 & 15,1 \\
\hline 2.020 & 2 & 2,3 & 17,4 \\
\hline 2.050 & 2 & 2,3 & 19,5 \\
\hline 2.070 & 2 & 2,3 & 22,1 \\
\hline 2.080 & 1 & 1,2 & 23,3 \\
\hline 2.100 & 4 & 4,7 & 27,9 \\
\hline 2.120 & 3 & 3,5 & 31,4 \\
\hline 2.150 & 2 & 2,3 & 33,7 \\
\hline 2.155 & 1 & 1,2 & 34,9 \\
\hline 2.170 & 1 & 1,2 & 36,0 \\
\hline 2.180 & 1 & 1,2 & 37,2 \\
\hline 2.200 & 2 & 2,3 & 39,5 \\
\hline 2.220 & 1 & 1,2 & 40,7 \\
\hline 2.250 & 5 & 5,8 & 46,5 \\
\hline 2.260 & 1 & 1,2 & 47,7 \\
\hline 2.265 & 1 & 1,2 & 48,8 \\
\hline 2.270 & 1 & 1,2 & 50,0 \\
\hline 2.290 & 1 & 1,2 & 51,2 \\
\hline 2.300 & 1 & 1,2 & 52.3 \\
\hline 2.320 & 1 & 1,2 & 53,5 \\
\hline 2.330 & 2 & 2,3 & 55,8 \\
\hline 2.340 & 1 & 1,2 & 57,0 \\
\hline 2.350 & 2 & 2,3 & 59,3 \\
\hline 2.360 & 1 & 1,2 & 60,5 \\
\hline 2.370 & 1 & 1,2 & 61,6 \\
\hline 2.380 & 2 & 2,3 & 64,0 \\
\hline 2.390 & 2 & 2,3 & 66,3 \\
\hline 2.400 & 2 & 2,3 & 68,6 \\
\hline 2.404 & 1 & 1,2 & 69,8 \\
\hline 2.420 & 4 & 4,7 & 74,4 \\
\hline 2.430 & 4 & 4,7 & 79,1 \\
\hline 2.440 & 3 & 3,5 & 82,6 \\
\hline 2.445 & 1 & 1,2 & 83,7 \\
\hline 2.450 & 2 & 2,3 & 86,0 \\
\hline 2.470 & 5 & 5,8 & 91,9 \\
\hline 2.480 & 3 & 3,5 & 95,3 \\
\hline 2.490 & 4 & 4,7 & 100,0 \\
\hline TOTAL & 86 & 100,0 & \\
\hline
\end{tabular}

Fonte: Declaração de Nascidos Vivos ( SIM/SINASC- Secretária Municipal da Saúde de Mauá; 2004) 